\title{
International Sport Coaching Journal
}

Volume $8 \cdot$ Supplement 1 - November 2021

\section{International Council for Coaching Excellence (ICCE) 13th Global Coach Conference}

\author{
Virtual \& In-person Conference
}

November 17-21, 2021

Lisbon, Portugal

\section{Contents}

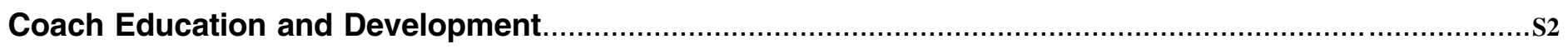

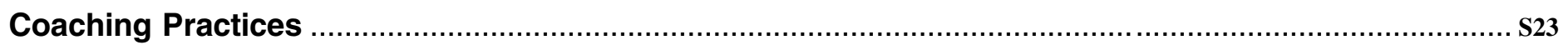

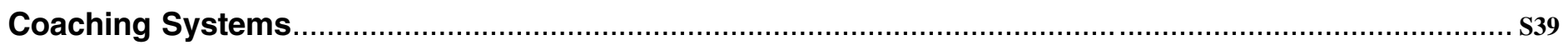

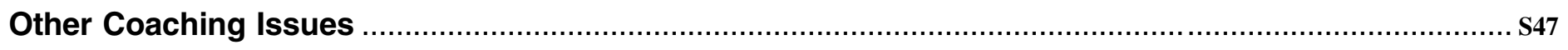

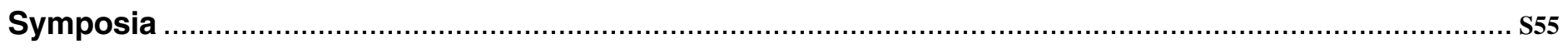

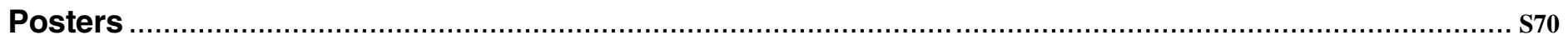

Supplement created and edited by: Bettina Callary, Catalina Belalcazar, \& Joseph Gurgis Cape Breton University, Canada 


\section{Coach Education and Development}

(in alphabetical order by first author's last name) 
B

Synthesis of the Self-Regulation of Sport Practice Survey and Its Potential for Coaching: A Case Study

Bain, Lisa ${ }^{1}$; Wilson, Stuart G. ${ }^{1}$; Boivin, Jason ${ }^{1}$; Siekańska, Małgorzata ${ }^{2}$; Hoar, Sharleen ${ }^{3}$; Baker, Joe ${ }^{4}$; \& Young, Bradley W. ${ }^{1}$

${ }^{1}$ University of Ottawa, Ottawa, Canada; ${ }^{2}$ University of Physical Education in Krakow, Poland; ${ }^{3}$ Canadian Sport Institute Pacific, Victoria, Canada; ${ }^{4}$ York University, Toronto, Canada

Self-regulated learning (SRL) how an athlete self-controls thoughts, motivations, and goal-oriented behaviours helps optimize practice quality (McCardle et al., 2017). Emerging conceptualizations of coaching for skill acquisition within the Co-regulatory Coaching Interface Model (CCIM; Bain \& Young, 2019) demonstrate that an athlete's SRL competencies are an outcome of effective coaching in dyadic sports. Wilson et al. (2021) validated the Self-Regulation of Sport Practice (SRSP) survey to reliably assess SRL engagement during practice. The presentation aims to further the narrative on self-regulated sport practice and athlete agency in terms of new perspectives for coaching. We explore how coaches could use the SRSP survey in their practices and share findings from an extensive semi-structured interview with an experienced university male swimming coach. Our questions addressed his understanding of SRL and its subprocesses, whether the SRSP survey could be used to engage with his athletes, and the conditions in which it could be implemented. The coach demonstrated a sophisticated understanding of SRL and described understanding/improving such athlete competencies as key coaching values, crucial for improving athlete performance. He provided insights on using the SRSP to guide conversations and interventions related to learning and practice skills. Moreover, the coach considered the SRSP for athletes at multiple skill levels, ages, and stages of self-regulatory development. We discuss the prospect of the SRSP as a discussion tool for coaches, locate such discussion within the co-regulatory interface of the CCIM, and point out the novelty of this tact with respect to prevailing dialogue in coaching.

\section{References}

Bain, L., \& Young, B. W. (2019). A naturalistic case study of co-regulatory scaffolding with a mature coach-athlete dyad in figure skating. Journal of Exercise, Movement, and Sport, 51(1), 76.

McCardle, L., Young, B. W., \& Baker, J. (2017). Self-regulated learning in sport training contexts: Current status, challenges, and future opportunities. International Review of Sport and Exercise Psychology, 12(1), 112138. https://doi.org/10.1080/1750984X.2017.1381141

Wilson, S. G., Young, B. W., Hoar, S., \& Baker, J. (2021). Further evidence for the validity of a survey for self-regulated learning in sport practice. Psychology of Sport and Exercise, 56. https://doi.org/10.1016/j .psychsport.2021.101975

\section{Presenter Biography}

Lisa Bain is a PhD student in the School of Human Kinetics at the University of Ottawa under the supervision of Dr. Bradley Young. Her research is in sport psychology, with an interest in how coach-athlete interactions in practice relate to an athlete's ability to self-regulate their learning.
Exploring Anti-Doping and Integrity Coach Education in the System of English Football

Barnes, Luke ${ }^{1}$; Patterson, Laurie ${ }^{1}$; \& Backhouse, Susan ${ }^{1}$

${ }^{1}$ Carnegie School of Sport, Leeds Beckett University, UK

Coaches' have responsibilities under the World Anti-Doping Code (WADA, 2021). However, limited research has investigated anti-doping education within coach development contexts. The study explored coaches' and coach developers' experiences of anti-doping, integrity and overall coach development activities within English football. Implementation of coach development initiatives were explored across levels of the coach development system, namely, individual, interpersonal, and organisational levels (Bronfenbrenner, 1977). Adopting a qualitative research design, semi-structured interviews were conducted with a purposive sample of 21 coaches/managers $(n=9)$ and coach developers $(n=12)$, aged between 26 and 60 years (Mage $=41, \mathrm{SD}=9.8$ ). Reflexive thematic analysis was conducted (Braun \& Clarke, 2020) and five themes were generated to capture coach development experiences across individual, interpersonal, and organisational levels. Clear differences in implementation existed across general coach development activities and learning activities targeting integrity and anti-doping. Anti-doping coach development activities are limited to knowledge acquisition, focused on coach compliance. Yet other areas of coach development have evolved over time. Integrity-related coach development has begun to adopt personal values-informed learning to enhance coach development, whilst general coach development has increasingly aimed to create holistic and coach-led learning environments. Coach anti-doping is currently only addressed as an individual, compliance-based topic, which is unlikely to impact upon actual coaching practices. To initiate coach anti-doping behaviours, future anti-doping coach education should target the wider coach development system (i.e., interpersonal and organisational levels), for example, through integrating anti-doping into holistic coach development activities.

\section{References}

Braun, V., \& Clarke, V. (2021). One size fits all: What counts as quality practice in (reflexive) thematic analysis. Qualitative Research in Psychology, 18(3), 328-352. https://doi.org/10.1080/14780887.2020.1769238

Bronfenbrenner, U. (1977). Toward an experimental ecology of human development. American Psychologist, 32, 513-532.

World Anti-Doping Agency. 2021, January 1). World Anti-Doping Code. World Anti-Doping Agency play true. https://www.wada-ama.org/en/ resources/the-code/world-anti-doping-code

\section{Presenter Biography}

Luke Barnes is an accredited Sport and Exercise Psychologist currently undertaking his $\mathrm{PhD}$ within the Carnegie School of Sport at Leeds Beckett University, UK. His research investigates how anti-doping education features in broader coach development activities, with a focus on the specific system of English football.

Exploring the Implementation of Anti-Doping Policy in English Football Through Coach Development

Barnes, Luke ${ }^{1}$; Patterson, Laurie ${ }^{1}$; \& Backhouse, Susan ${ }^{1}$

${ }^{1}$ Carnegie School of Sport, Leeds Beckett University, UK 
A dearth of research has investigated anti-doping education within specific coach development contexts, despite the World Anti-Doping Code (WADA, 2019) identifying coaches as key anti-doping stakeholders. This study explored coaches' and coach developers' experiences of anti-doping, integrity, and overall coach development activities within the English Football system. Consideration was given to how development activities corresponded to the Behaviour Change Wheel (BCW; Michie et al., 2011), including how activities were perceived to target coaches' Capability (physical or psychological capacity to act), Opportunity (features of the social or physical environment) and Motivation (reflective or automatic processes), which impact subsequent behaviours (COM-B; Michie et al., 2011). Adopting a qualitative research design, semi-structured interviews were conducted with a purposive sample of 21 coaches/managers $(n=9)$ and coach developers $(n=12)$, aged between 26 and 60 years $($ Mage $=41, S D=9.8)$. Clear differences in practise existed across the system, depending on the focus of activities. General coach development has evolved to focus on enhancing coach COM-B through creating holistic and needs-led learning environments. Integrity-related coach development adopted some of these features, including values-informed learning to enhance COM-B. However, anti-doping coach development activities only targeted through compliance-driven education, which focused on knowledge acquisition alone. A shift is needed in coach development activities to ensure that anti-doping is no longer addressed as a negative, awareness-raising exercise. In particular, anti-doping must be integrated into holistic coach development activities, with an emphasis on enablement and coach-led guidelines, promoting COM-B.

\section{References}

Michie, S., van Stralen, M. M., \& West, R. (2011). The behaviour change wheel: A new method for characterising and designing behaviour change interventions. Implementation Science, 6, 42-53.

World Anti-Doping Agency. 2019). 2021 Code Review. World AntiDoping Agency play true. https://www.wada-ama.org/en/what-we-do/ the-code/2021-code-review

\section{Presenter Biography}

Luke Barnes is an accredited Sport and Exercise Psychologist currently undertaking his $\mathrm{PhD}$ within the Carnegie School of Sport at Leeds Beckett University, UK. His research investigates how anti-doping education features in broader coach development activities, with a focus on the specific system of English football. From this work, Luke recently published a narrative synthesis of coach anti-doping research and plans to present work from an interview study capturing coach and coach developer perspectives toward anti-doping education within coach development.

\section{A Professional Development Program for Masters Coaches in Colombia}

Belalcazar, Catalina \& Callary, Bettina

\section{Cape Breton University, Sydney, Canada}

Masters athletes (MAs) are adults that engage in competitive leisure sport, train regularly, and are formally registered in clubs. An aging population and continued participation in sport past the typical age of peak performance make MAs a fast-growing sport cohort in many countries (Weir et al., 2010). Masters coaches (MCs) can positively contribute to MAs' sport experiences, but have few resources to help them know how to coach an adult cohort in sport (Callary et al., 2018). A pan-Canadian team of researchers (Callary et al., 2021) created an evidence-based self-assessment tool for Masters coaches, entitled the Adult Oriented Sport Coaching Survey (AOSCS; Rathwell et al., 2020). This presentation will outline the first Participatory Action Research study that has used the AOSCS in professional development workshops for coaches in a Colombian Masters football (soccer) league, which includes 490+ male Masters athletes who are 60-years-old+. Firstly, to determine MCs' learning needs, data was collected from $20 \mathrm{MCs}$ from the 60, 65, and 70+ age categories via interviews and game observations. The data were thematically analyzed to understand what information to provide in a series of research-based individualized workshops to develop their adult-oriented coaching approaches. Using the AOSCS as a guide, coaches identified key themes for their personal development and in this presentation, we outline how coaches applied that knowledge in Masters coaching. In particular, our results indicate that culturally-sensitive and personalized professional development enabled better-structured leadership in the league, creating quality Masters sport experiences and community development.

\section{References}

Callary, B., Rathwell, S., \& Young, B. W. (2018). Coach education and learning sources for coaches of Masters Swim Athletes. International Sport Coaching Journal, 5(1), 47-59. https://doi.org/10.1123/iscj.2017-0056

Callary, B., Young, B. W., \& Rathwell, S. (Ed.) (2021). Coaching Masters Athletes: Advancing research \& practice in adult sport. London: Routledge.

Rathwell, Scott., Young, Bradley W., Callary, Bettina., Motz, Derrik., Hoffmann, Matt D., \& Currie, Chelsea., (2020). The Adult-Oriented Sport Coaching Survey: An Instrument Designed to Assess Coaching Behaviors Tailored to Adult Athletes. Journal of Sport \& Exercise Psychology. Advance online publication. 10.1123/jsep.2020-0031.

Weir, P., J. Baker, \& S. Horton. (2010). The emergence of Masters sport: Participatory trends and historical developments. In J. Baker, S. Horton, \& P. Weir (Eds.), The Masters athlete: Understanding the role of sport and exercise in optimizing aging (pp. 7-14), London: Routledge.

\section{Presenter Biography}

Catalina Belalcazar received her MBA in Community Economic Development at Cape Breton University in Nova Scotia, Canada with Dr. Bettina Callary as her supervisor. She is a scholarship recipient from the Social Sciences and Humanities Research Council of Canada. She received a BA Community Studies from Cape Breton University. Research interests include coaching Masters athletes, and flourishing community development through sport.

\section{'Trenerløftet' - A Structured Mentoring Program for Coaches for Emerging Athletes in Norway}

Bjørkøy, John Anders ${ }^{1}$; Moen, Frode ${ }^{2} ; \&$ Olsen, Maja ${ }^{3}$

${ }^{1}$ Olympiatoppen, The Norwegian Centre for Elite Sports, Oslo, Norway; ${ }^{2}$ Olympiatoppen, The Norwegian Centre for Elite Sports, Trondheim, Norway; Norwegian University of Science and Technology, Trondheim, Norway; ${ }^{3}$ Centre for Elite Sports Research, Norwegian University of Science and Technology, Trondheim, Norway

'Trenerløftet' is a 2-year project that has given structured mentoring to 132 coaches for 1 year: 64 in 2019 and 68 in 2020. The coaches have been from 35 different sports, and they have all been coaches for emerging talented athletes. Each coach was given: at least 10 meetings with their mentor, with most of the meetings taking place in the coaches' practice field; at least 4 meetings/seminars with other coaches who were part of the project; and a scholarship (1000Euros) to use on something of their own interest that would help the coach further improve (e.g., visiting other development 
environments.) The project had 28 mentors throughout the country and they all had to participate at a mentoring program at the Norwegian University of Science and Technology, Department of Pedagogy and Lifelong Learning. The mentors covered all of Norway and have experience from 15 different sports. 'Trenerløftet' aimed to pair mentors and coaches from different sports. There were two research programs closely connected with 'Trenerløftet'; a quantitative study at University of South East of Norway, looking at 1 project management, 2 mentors, 9 coaches and their athletes and a qualitative study at Norwegian University of Science and Technology, collecting data from surveys given to all coaches and their athletes. Both research teams aim was to find out what was working/not working in 'Trenerløftet', pinpointing what was leading to a positive change at coachlevel and what would be beneficial for their athletes.

\section{Presenter Biography}

John Anders Bjørk $\varnothing \mathrm{y}$ is a former professional football player now working as head of coach development at Olympiatoppen, the Norwegian Centre for Elite Sports.

\section{Transforming Coach Education for the 21st Century}

Bjørndal, Christian Thue ${ }^{1}$; Toering, Tynke ${ }^{1} ;$ \& Gjesdal, Siv ${ }^{1}$

${ }^{1}$ Department of Sport and Social Sciences, Norwegian School of Sport Sciences, Oslo, Norway

Participation in sport can positively impact young lives by promoting social development, and also physical and mental health, and well-being (Eime et al., 2013). However, several challenges related to sport participation still exist, such as dropout, health risks related to overtraining, and misconceptions about what evidence-based sport coaching knowledge is (Collins \& Bailey, 2013; DiFiori et al., 2014). The present chapter critically discusses the scientific and cultural premises on which current coach education in sport is based and offers reflections on how this education can be developed and improved. We suggest that current sports science models, characterised by separate siloes of knowledge, may limit holistic approaches to sports coaching (Pol et al., 2020). Additionally, these systems of knowledge are created by power dynamics that are explicitly and implicitly valued in coach education, leading to the production of normative ideas about sports coaching and athlete development (Mills \& Denison, 2018). This limited view may lead to blind spots in coach expertise development and hinder the improvement of coaching and coach education. We conclude by sharing some ideas that may contribute to the transformation of coach education through the design of more transdisciplinary approaches in coaching courses.

\section{References}

Collins, D., \& Bailey, R. (2013). 'Scienciness' and the allure of secondhand strategy in talent identification and development. International Journal of Sport Policy, 5(2), 183-191.

DiFiori, J. P., Benjamin, H. J., Brenner, J. S., Gregory, A., Jayanthi, N., Landry, G. L., \& Luke, A. (2014). Overuse injuries and burnout in youth sports: A position statement from the American Medical Society for Sports Medicine. British Journal of Sports Medicine, 48(4), 287-288.

Eime, R. M., Young, J. A., Harvey, J. T., Charity, M. J., \& Payne, W. R. (2013). A systematic review of the psychological and social benefits of participation in sport for children and adolescents: Informing development of a conceptual model of health through sport. International Journal of Behavioral Nutrition and Physical Activity, 10(1), 98.
Mills, J. P., and Denison, J. (2018). How power moves: A Foucauldian analysis of (in)effective coaching. International Review for the Sociology of Sport, 53(3), 296-312.

Pol, R., Balagué, N., Ric, A., Torrents, C., Kiely, J., \& Hristovski, R. (2020). Training or synergizing? Complex systems principles change the understanding of sport processes. Sports Medicine - Open, 6(1), 28.

\section{Presenter Biography}

Christian Thue Bjørndal, $\mathrm{PhD}$, is an associate professor at the Department of Sport and Social Sciences, Norwegian School of Sport Sciences. Tynke Toering, $\mathrm{PhD}$, is a senior researcher and lecturer at the School of Sports Studies, Hanze University of Applied Sciences, Groningen. Siv Gjesdal, $\mathrm{PhD}$, is an associate professor at the Department of Sport and Social Sciences, Norwegian School of Sport Sciences, Oslo, Norway.

\section{C}

Addressing the Assessment Conundrum: Implementing Formative Approaches Within Coach Education

Chesterfield, Gavin ${ }^{1}$; Cropley, Brendan ${ }^{1}$; Adams, David ${ }^{2}$; \& Darlington, $\mathrm{Carl}^{2}$

${ }^{1}$ University of South Wales, Pontypridd, Wales; ${ }^{2}$ Football Association of Wales Trust, Wales

Researchers and coaches alike have widely reported a range of issues associated with formal approaches to coach education (e.g., Walker et al., 2018). Specifically, it is suggested that formal education programmes do little to prepare coaches for the dynamic demands of coaching practice (Stodter \& Cushion, 2014). Accordingly, the summative approaches used to assess coaches at the end of a formal education programme, as a way of accrediting an individual's ability to operate at a specified level, have been criticised for being de-contextualised and characterised by techno-rational indoctrination (e.g., Cushion \& Nelson, 2013). To address these issues, and fundamentally enhance the learning and development experiences of coaches undertaking a Level 4 (UEFA A Licence) coaching qualification with the Football Association of Wales Trust, we have purposively moved away from the concept of summative assessment and instead implemented a formative assessment-for-learning approach. This is underpinned by a process of active participation by the coach, affording them ownership and accountability over learning, assessment, and targeted mentoring activities that occur in the coach's own practice environment. Implementing this approach has altered our education philosophy from the position of assessment needing to be structured to normalise performance, to one that attempts to: support and augment coaches' individual approaches and philosophies; encourage coaches' holistic development; celebrate coaches' idiosyncrasies; and embrace coaching's inherent complexity. In this presentation, we will reflect-on the lessons learned from implementing this novel approach and discuss the potential impact of formative assessment as a method to facilitate situated coach learning and development.

\section{References}

Cushion, C. J., \& Nelson, L. (2013). Coach education and learning: Developing the field. In P. Potrac, J Gilbert, \& W. Denison (Eds.), Routledge handbook of sports coaching (pp. 359- 374). Routledge.

Stodter, A., \& Cushion, C. J. (2014). Coaches' learning and education: A case study of cultures in conflict. Sports Coaching Review, 3(1), 63-79. https://doi.org/10.1080/21640629.2014.958306

Walker, L. F., Thomas, R., \& Driska, A. P. (2018). Informal and nonformal learning for sport coaches: A systematic review. International 
Journal of Sports Science \& Coaching, 13(5), 694-707. https://doi.org/10 $.1177 / 1747954118791522$

\section{Presenter Biography}

Gavin Chesterfield is a Senior Lecturer in Football Coaching and Development at the University of South Wales. He is also a UEFA Professional Licence (Level 5) football coach, who currently works in the Welsh Premier League. In addition to these roles, Gavin is a Coach Developer and Mentor for the Football Association of Wales Trust, primarily supporting the UEFA Level 4 and 5 coaching qualifications, and has previously coached Wales age group international teams.

The Who, What, and How of Enhancing Coach-Parent Relationships in Youth Sport

Clarke, Nicola ${ }^{1}$; Knight, Camilla ${ }^{2} ; \&$ Cowburn, $\operatorname{Ian}^{1}$

${ }^{1}$ Research Centre for Sport Coaching, Carnegie School of Sport, Leeds Beckett University, Headingley Campus, Leeds, UK; ${ }^{2}$ School of Sport and Exercise Sciences, Swansea University Bay Campus, Swansea, UK

Connections to existing coaching frameworks are limited within sport parenting literature, despite the need to help coaches translate research findings into their practice. In this presentation, we outline how the coach decision making model (Abraham et al., 2010), as supplemented with literature about sport parenting can be adapted to offer a tool for coaches to reflect on current interactions and plan future engagement with parents in youth sport. We suggest that a focus on the who, what, and how of coachparent relationships moves beyond generic advice for what coaches can do to "manage" parents (e.g., Smoll et al., 2011), towards possibilities for creating authentic, productive, and context-sensitive collaborative partnerships. Knowing who the parents are that coaches work with (e.g., their experiences, backgrounds, beliefs, expectations) can help coaches to develop an empathetic understanding of individual parents, from which mutual respect can be fostered. Considering what coaches would prefer their collaborations with parents to look like (e.g., level of trust, respect, openness) and achieve (e.g., maximise positive outcomes for children, establish shared goals, minimise conflict) emphasises promoting desired relational qualities, rather than seeking to manage parent behaviours. Planning how to optimise coach-parent collaborations (e.g., enhance communication, build trust), allows for practical strategies to be adapted to fit the coaching context. Coach-parent collaborations will be positioned in relation to coaches' personal beliefs, experiences, and behaviours, and the social norms, values, and resources of the context to enable coaches to reflect upon how to facilitate partnerships with parents in their specific coaching roles.

\section{References}

Abraham, A., Muir, B., \& Morgan, G. (2010). UK Centre for Coaching Excellence scoping project report: National and international best practice in level 4 coach development. Sports Coach UK. https://eprints .leedsbeckett.ac.uk/id/eprint/601/

Smoll, F. L., Cumming, S. P., \& Smith, R. E. (2011). Enhancing coachparent relationships in youth sports: Increasing harmony and minimizing hassle. International Journal for Sports Science and Coaching, 6(1), 1326. https://doi.org/10.1260/1747-9541.6.1.13

\section{Presenter Biography}

Dr. Nicola Clarke is a Senior Lecturer in Sport Coaching at Leeds Beckett University. Her research interests centre around understanding how the social context influences experiences and relationships in sport, with a focus on coaches, parents, and athletes.
Dr. Ian Cowburn is a Senior Lecturer in Sport Coaching at Leeds Beckett University. His research focuses on talent development and life skill development through sport, with an interest in working with parents and coaches to understand and enhance their roles.

\section{Innovation in Sport Education: The International Tennis Federation Academy}

Crespo, Miguel

International Tennis Federation (London, UK)

The ITF Academy is a key digitalization project of the International Tennis Federation (ITF) as it forms part of the main objectives of its 2020-2024 strategy (ITF, 2021). It is an example of innovation through digitalization applied to education (Crespo et al., 2021). It is an integral element of the "blended learning" methodology already implemented in all ITF certification courses. All the ITF education activities are done through this platform. The platform is directed towards coaches, players, parents, and all interested in increasing their tennis knowledge. Under the challenging circumstances during 2020 the ITF online educational digital platform has provided valuable free of charge resources to all the tennis stakeholders. It has also been used to deliver courses with Olympic Solidarity and the different national associations, webinars, conferences, and online events during these unprecedented times. This platform will be presented as an example of digital innovation applied to the education in the sport ecosystem and the ITF's commitment to develop ideas and implement innovative practices (Crespo \& Jabaloyes, 2020).

\section{References}

Crespo, M., Botella-Carrubó, D., \& Jabaloyes, J. (2021). Innovation in tennis: An overview of research. ITF Coaching and Sport Science Review, 83(29) 28-30, https://doi.org/10.52383/itfcoaching.v29i83.53

Crespo, M., \& Jabaloyes, J. (2020). Something new innovation post COVID-19. A must for tennis. ITF Coaching and Sport Science Review, 81(29), 6-8. https://doi.org/10.52383/itfcoaching.v28i81.31

International Tennis Federation. (2019). Strategy. ITF Tennis. https:// www.itftennis.com/en/growing-the-game/itf-2024-strategy/

\section{Presenter Biography}

Miguel Crespo is the Head of Participation and Education of the Integrity and Development Department at the International Tennis Federation (ITF). He oversees the projects, resources, conferences, courses, and research on these areas. A former player and coach, he holds a Ph.D. in Law and a Ph.D. in Psychology. He is the Treasurer of the International Council for Coaching Excellence (ICCE).

\section{Evaluation of Online Coach Education in Football (England)}

Cushion, Chris; Downham, Lauren; \& Cope, Ed.

\section{Loughborough University}

The use of Technology Enhanced Learning (TEL) in coaching has accelerated in response to the global pandemic (COVID-19). However, there remains a presumption that developmental outcomes such as increased collaboration and communication, knowledge building, resource sharing and learner engagement will "just occur" through the use of technology rather than require pedagogical and instructional strategies. The purpose of this research was to evaluate the delivery and pedagogy of online coach education and continuing professional development (CPD) of 
a Sport Governing Body (SGB). The research design had two phases. In phase one a review of literature was undertaken to identify evidence informed learning principles. In phase two a sample of online coach education and CPD content (900 minutes) delivered by the SGB's online learning platforms was reviewed. This content was mapped against the learning principles organised under headings "structure and organization", "content" and "outcomes". This created a coding rubric that allowed a weighting to be given for the content against each learning principle. Results showed that different types of content hit several contrasting learning principles. For example, coaching session content connected with principles related to the "use of examples" and "amount of subject matter". Learning principles related to "building learning capacity", fostering "learner activity" and a "collaborative environment" were less common. The findings recommend an educational strategy considering an "optimal mix" of learning principles linked to content purpose and outcomes. This research provided a resource that supported the SGB's approach to online learning from a "blanket cover everything" to more variable and focused solutions.

\section{Presenter Biography}

Dr Lauren Downham is a Research Associate at Loughborough University and Market Research Manager at UK Coaching. In these roles, Lauren works closely with Sport Governing Bodies investigating contemporary coaching issues to produce evidence-based implications to support coaching and coach development. Lauren has ten years of coaching experience in both participatory and youth performance contexts.

\section{D}

\section{"Who Am I to Tell Them How to Coach": Critical Analysis of the Work and Learning of Coach Developers}

Davidson, James ${ }^{1} \&$ Townsend, Robert ${ }^{1}$

${ }^{1}$ University of Waikato

This presentation gives an overview on recent research undertaken in New Zealand on the learning and development of sports coach developers. Specifically, I focus attention on how coach developers understand and perform their roles. Drawing on multiple semi-structured interviews, observations and reflexive insights, the research highlights the idiosyncratic, complex, nature of coach developers' learning and development. Specifically, the data highlighted a level of ambiguity around their role and competing ideologies in how to best facilitate coaches' learning (Stodter \& Cushion, 2019). For example, coach developers often entered the role with deeply held beliefs about learning formed through personal biography and lifetime of learning (Ciampolini et al., 2020). However, the data highlighted the multiple and competing interests and networks of power that influenced their beliefs and practices about effective coach development (Cushion et al., 2019). This tension provided instances of ideological conflict, and a requirement for social, cultural, and contextual literacy within their individual coach development ecosystems (Potrac et al., 2020). Finally, of interest was the ways in which the research interviews provided a learning intervention and an opportunity to reflect on previously unexplored understandings of their roles. This allowed coach developers the opportunity to reflect, build, craft, and even develop their own personal understanding of their roles. This further underlined the differential impact of existing coach developer training programmes and the need for structured reflective conversations in practitioner development (Watt et al., 2021).

\section{References}

Ciampolini, V., Tozetto, A. V., Milan, F. J., Camiré, M., \& Milistetd, M. (2020). Lifelong learning pathway of a coach developer operating in a national sport federation. International Journal of Sports Science \& Coaching, 15(3), 428-438.

Cushion, C. J., Griffiths, M., \& Armour, K. (2019). Professional coach educators in-situ: A social analysis of practice. Sport, Education and Society, 24(5), 533-546.

Potrac, P., Nichola, A. J., \& Hall, E. T. (2020). Critically understanding and engaging with the (micro)political dimensions of coaches' work in an advanced undergraduate coaching course. In B. Callary \& B. Gearity (Eds.), Coach education and development in sport. Routledge.

Stodter, A., \& Cushion, C. J. (2019). Layers of learning in coach developers' practice-theories, preparation and delivery. International Sport Coaching Journal, 6(3), 307-316.

Watts, D., Cushion, C., \& Cale, L. (2021). Exploring professional coach educators' journeys and perceptions and understandings of learning. Sport, Education and Society, 1-15. https://doi.org/10.1080/13573322.2021 .1887115

\section{Presenter Biography}

I work in and research coach development in Aotearoa, New Zealand. I currently work as a Regional Coaching Advisor and hold several consultancy roles in High Performance coaching. Having previously been an athlete and coach at the international level, I work with multiple sports as a coach developer, trainer, and programme designer. I have experienced many different aspects of the New Zealand coaching system. The wide array of experiences and insights I have built over my career, inform my research.

\section{Reflective Practice in a High-Performance Coach Education Pro- gramme: An Ethnographic Study}

Downham, Lauren ${ }^{1} \&$ Cushion, Chris ${ }^{1}$

\section{${ }^{1}$ Loughborough University, Loughborough, United Kingdom}

Reflection is established as important in coaching and coach development, however, it remains poorly defined and understood, and these conceptual issues impact how it is practiced. In addition, research has shown that coach education programmes produce limited or temporary changes to coaches' reflective practice. The purpose of this research therefore was to explore how reflection was practiced, understood, and supported in high performance coach education. Data were collected over a two-year period during a high-performance coach education programme delivered by a National Sports Organisation (NSO). The longitudinal research design meant that changes in reflective practice and coach developer support could be traced throughout the programme and captured through several data collection points and methods. Using an ethnographic framework, methods included participant observation of eight three-day coach education workshops spread across the two-year period, and interviews conducted at the start and end of the programme with twenty high-performance coaches and nine coach developers. Analysis identified three themes: "Reflective Practices"; "Types of Reflection"; and "Reflection Methods and Tools". Participants displayed a varied understanding of reflection, drawing on their experiences to inform their reflective practice. For the coaches, reflection had become a slogan for a wide range of activities. The coach education programme impacted reflection by developing in the coaches a greater appreciation of multiple perspectives, but these changes were experienced unevenly. While a target for development by the programme, limited critical reflection was undertaken or developed to challenge existing beliefs and assumptions or informing actions to challenge and change established coaching practice. 


\section{Presenter Biography}

Dr. Lauren Downham is a Research Associate at Loughborough University and a Research Consultant at LMD Research. In these roles, Lauren works closely with National Sport Organisations investigating contemporary coaching issues to produce evidence-based implications to support coach development. Lauren has ten years of coaching experience in both participatory and youth performance contexts. Her research interests include a sociological focus on how reflection is practiced, understood, and supported in high-performance coach education.

\section{Psychosocial Skills of Elite Professional Coaches: A Thematic Analysis} Duarte, Daniel $^{1} \&$ Teques, Pedro ${ }^{1,2}$

${ }^{1}$ N2i, Instituto Politécnico da Maia, Portugal; ${ }^{2}$ CIPER, Faculdade de Motricidade Humana, Universidade de Lisboa, Portugal

Coach leadership skills is a hot topic in sport psychology. However, despite the numerous theoretical perspectives on leadership and the coach-athlete relationship, little is known about the skills needed for a coach to perform in trainings and competitions. Therefore, the purpose of this study is to explore the coach's skills associated with good coach performance. For this purpose, 3 professional trainers between the ages of 46 and 57 years were interviewed. The coaches had between 8 and 19 years of experience with professional football, volleyball, and basketball teams. The results from the thematic analysis revealed that socio-emotional skills (i.e., self-knowledge, communication with athletes, ability to motivate, and positively influence by example) and techniques (i.e., organization and planning, innovating in training, knowledge of the game) are the most relevant to the performance of a professional coach. These exploratory findings show the importance of training psychosocial skills in coaches' clinics, revealing key aspects for development of aspiring young coaches.

\section{Presenter Biography}

Daniel Duarte has a Ph.D. in Sport Sciences and is the Director of the Social Sciences, Sports and Education School of the Polytechnique Institute of Maia. He has more than 15 years of experience in training and educating children, adolescent, and adults. He has publications in impact journals.

\section{$\mathbf{F}$}

\section{A Contextualized Knowledge to Action Model for Sport}

Ferreira, Marta ${ }^{1}$; Santos, Fernando ${ }^{1,2,3} ; \&$ Holt, Nicholas ${ }^{4}$

${ }^{1}$ Higher School of Education, Polytechnic Institute of Porto, Portugal; ${ }^{2}$ Higher School of Education, Polytechnic Institute of Viana do Castelo, Portugal; ${ }^{3}$ inED, Center for Research and Innovation in Education; ${ }^{4}$ Faculty of Kinesiology, Sport, and Recreation, University of Alberta, Canada

The purpose of this study was to examine coaches' and researchers' perceptions of factors that influence the knowledge translation process in sport. Researchers $(n=25)$ and coaches $(n=36)$ from Portugal and Brazil were involved in focus group interviews. A thematic analysis was carried out. Data were organized around the concepts of knowledge creation, knowledge dissemination and knowledge integration. More specifically, findings showed that (a) researcher-coach partnerships could facilitate knowledge creation that can drive knowledge integration more effectively; (b) barriers to knowledge creation and dissemination included funding, publication climate, recognition, research focus, and time; (c) sources of knowledge included peers, seminars, media, research papers, and books, (d) strategies of dissemination included social networks, discussion forums, accessible language, concrete examples, and reflection; and (e) knowledge integration outcomes associated to the extent to which coaches are able or not to effectively apply knowledge created and disseminated by researchers. It appears that knowledge creation, dissemination, and integration are viewed as separate and disconnected concepts. In Portuguese and Brazilian contexts, initiatives to facilitate knowledge translation may increase the reach of research and the adoption of evidence-based coaching practices.

\section{Presenter Biography}

Marta Ferreira is an assistant professor and researcher in the School of Higher Education at the Polytechnic Institute of Porto in Porto, Portugal. She is also a Master's student in Physical Education and is a karate and climbing athlete.

\section{H}

\section{Exploring the Learning Experiences and Practice of Community Para Sport Coaches}

Hardwick, Amy Elizabeth ${ }^{1} \&$ Huntley, Tabo ${ }^{1}$

${ }^{1}$ Liverpool John Moores University, Liverpool, United Kingdom

There is a lack of research into disability sport, with a notable absence of studies focusing on coaches; this is despite the growth of research in sport coaching over recent years. Not only this, but there is a dearth of formal coach education available to coaches working within disability sport. Therefore, the purpose of this study was to explore the experiences and development of para sport coaches, identifying how they are currently learning and developing their practice whilst meeting the needs of their athletes. The study included two groups of participants; International Governing Body Administrators $(\mathrm{N}=2)$ and coaches $(\mathrm{Male}=4$, Female $=4)$, recruited through criteria, purposeful sampling. At the time of the study, the coaches were actively working in five different countries across Europe and one in South America, with over 27 combined years of experience coaching para sport. Data were gathered across a period of three months, using a variety of methods (semi-structured interviews, observations of coaching practice, reciprocal interviews and field notes). Data analysis was undertaken using the essence of constructivist grounded theory, allowing themes to be grounded in the data (Charmaz, 2006). Following the iterative analysis process, three categories were identified; Becoming a Coach, Coaching Philosophy, Impairment and Reality of Practice. Influenced by models of disability, the findings revealed that there is a need for coach education to be approached using social-relational model considerations rather than traditional, medical model discourse. In conclusion, more work is needed to explore the complexity of learning, development and practice.

\section{References}

Charmaz, K., 2006. Constructing grounded theory: A practical guide through qualitative analysis. Sage.

\section{Presenter Biography}

Amy is a graduate of Liverpool John Moores University with both a BA and M.Sc in Sport Coaching. She is currently working as the Project Officer on the Erasmus funded ParaCoach Project, whilst also studying for her Ph.D. which is focussing on coach learning, practice, and development within the context of Special Olympics. 
The Role and Impact of Individual Differences on Coach Learning and Coach Developer Practice

Hodgson, Gary ${ }^{1}$; Abraham, Andrew ${ }^{1}$; \& Piggott, David ${ }^{1}$

${ }^{1}$ Leeds Beckett University, Leeds, United Kingdom

Coaches are encouraged to understand more about their athletes to personalise practice. Our argument would be that the same emphasis should exist for coach educators and policy makers to know more about coaches to also personalise practice. Some insight to this problem is offered through the recent research examining coaches' preferences relating to formal, non-formal and informal education approaches (Erickson et al., 2008; Nelson et al., 2006; Mesquita et al., 2010; Cushion et al., 2003). However, this still appears some distance away from attempting to look at how coaches learn on an individual level. This study aimed to explore the characteristics of different coach learners in context through the perspective of elite coach developers and their practice. 14 elite coach educators participated in semi-structured interviews exploring characteristics of different learner types. Characteristics associated with typically good learners include being highly self-regulated, open to experience, thirsty for knowledge, and a willingness to challenge existing knowledge and beliefs. Nine elite coach developers were then interviewed to explore the strategies implemented with a range of coach learners. A range of appropriate strategies were discussed and matched with a range of learner characteristics. While this is the case, strategies discussed were often general, with only a few specific cases elaborated on. From what specific narratives were shared, the concept of trust has been deemed a critical mediator to developing meaningful learning relationships, and facilitating positive shifts in learners' openness to, and conceptions of learning and knowledge.

\section{References}

Cushion, C. J., Armour, K. M., \& Jones, R. L. (2003). Coach education and continual professional development: Experience and learning to coach. Quest, 55(3), 215-230.

Erickson, K., Bruner, M., MacDonald, D., \& Côté, J. (2008). Gaining insight into actual and preferred sources of coaching knowledge. International Journal of Sports Science \& Coaching, 3(4), 527-538.

Mesquita, I., Isidro, S., \& Rosado, A. (2010). Portuguese coaches' perceptions of and preferences for knowledge sources related to their professional background. Journal of Sports Science and Medicine, 9, 480-489.

Nelson, L., Cushion, C., \& Potrac, P. (2006). Formal, nonformal and informal coach eLearning:

A holistic conceptualisation. International Journal of Sports Science \& Coaching, 1(3), 247-259.

\section{Presenter Biography}

Gary Hodgson is a Post-Graduate Research Fellow at Leeds Beckett University. A former academy football coach and Lecturer in Sport Coaching, he currently works with the ICOACHKIDS Global Movement, supporting the vision to create child-centred environments that provide safe developmental experiences that put kids first. He is also in the final stages of his Ph.D., which is in the area of Coach Learning and Development.

Exploring the Effectiveness of a Community of Practice $(\mathrm{CoP})$ on the Development of Volunteer Coaches

Hogan, Irene ${ }^{1}$; Bowles, Richard ${ }^{1}$; \& Kitching, Niamh ${ }^{1}$

${ }^{1}$ Mary Immaculate College, Limerick, Ireland.
Club-based support structures are needed to develop volunteer coaches and Communities of Practice ( $\mathrm{CoP}$ ) encourage such support through participants sharing resources, knowledge, and experiences. A Coaching Community of Practice (CCoP) was established by an experienced coach developer (first author) for male and female coaches within three ladies' football clubs across a playing season. An action research approach was applied to answer this research question - How effective is a season long club-based $\mathrm{CCoP}$ at developing volunteer coaches? Interviews were conducted with the club gatekeepers to establish the structures and desired outcomes from the CCoP. Questionnaires for club coaches were used to determine individual development goals and perceptions of their club coaching structures. The voice of female volunteer coaches was explored through interviews $(n=12)$ to discuss their coaching experiences and expectations of the CCoP. A focus group with a sample of male and female coaches $(n=12)$ was held during and after the CCoP to ascertain the effectiveness of the $\mathrm{CCOP}$ from their perspective. The coach developer kept a journal throughout which included observations and selfreflections. The Value Creation Framework (Wenger et al., 2011) informed the research design and analysis. Preliminary findings suggest that the participants want greater unity in coaching practices to help develop and retain existing coaches and attract new coaches, particularly females. Further results will be available for the ICCE conference. This study makes an original contribution to qualitative understandings of volunteer coaches and should inform coach development practices within a club context.

\section{References}

Wenger, E., Trayner, B., \& De Laat, M. (2011). Promoting and assessing value creation in communities and networks: A conceptual framework. The Netherlands: Ruud de Moor Centrum, 20, 2010-2011.

\section{Presenter Biography}

Irene Hogan is a Lecturer and Ph.D. candidate exploring the experiences and development of volunteer women coaches in the team sport of Ladies Gaelic Football in Ireland. She has 15 years of experience as a coach developer, over 20 years of experience as a volunteer coach, and was also a former player, committee member and referee in ladies' football. Irene's roles give her a unique insight into the experiences of volunteer women coaches.

\section{J}

Providing Augmented Information for Footballers: The Transitional Learning Model for Coaches

Jones, Gérard ${ }^{1}$; Stone, Joseph ${ }^{1}$; Rothwell, Martyn ${ }^{1}$; Rumbold, James ${ }^{1}$; Davids, Keith ${ }^{1}$; \& Otte, Fabian ${ }^{2}$

${ }^{1}$ Sport and Physical Activity Research Centre, Sheffield Hallam University, Sheffield, United Kingdom; ${ }^{2}$ Department of Cognitive and Team/ Racket Sport Research, German Sport University Cologne, Cologne, Germany

Providing augmented information (i.e., feedback and instruction) is considered a dominant coaching behaviour (Raya-Castellano et al., 2020). Augmented information is typically delivered concurrently (i.e., during movement performance) or terminally (i.e., after movements) in the form of error correction (Davids et al., 2008) to prescribe footballers "the solution" with reference to an optimal movement template. An optimal movement solution, prescribed by the coach, may fail to consider the complex, dynamic and nuanced nature that is football, or the need for footballers to develop their own adaptable performance solutions. By 
viewing practice as "search" (Newell, 1991), we reconsider the role of the coach in designing decision-rich environments that use feedback as an informational constraint (Newell \& Ranganathan, 2010) to guide the athlete's attentional search for movement solutions (Correia et al., 2019). The coach's challenge is to create environments that offer footballers choices, whilst using augmented information as a constraint to guide player's decisions on time, space, and their interactions with teammates and opponents. Here, we propose that a model based on delivering feedback transitionally (Newell, 1991), can be used concurrently or terminally, and does not prescribe a solution, but instead helps the footballer develop relevant skills needed to search the performance environment for functional, adaptable solutions. Our Transitional Learning Model (TLM) is based on the following principles: Search, Discover and Exploit to provide challenges, priming the athlete to attune to available affordances in preparation for actions. Our proposed TLM can be evaluated in practice through Action Based research, ethnographic and intervention studies.

\section{References}

Correia, V., Carvalho, J., Araojo, D., Pereira, E., \& Davids, K. (2019). Principles of nonlinear

pedagogy in sport practice. Physical Education and Sport Pedagogy, 24(2),117-132.

Davids, K., Button, C., \& Bennett, S. (2008). Dynamics of skill acquisition: A constraints-led approach. Human Kinetics.

Newell, K. M. (1991). Motor skill acquisition. Annual Review of Psychology, 42(1), 213-237.

Newell, K. M., \& Ranganathan, R. (2010). Instructions as constraints in motor skill acquisition. In I. Renshaw, K. Davids, \& G. J. P. Savelsbergh (Eds.), Motor learning in practice: A constraints-led approach (pp. 1732). Routledge.

Raya-Castellano, P., Reeves, M. J., Littlewood, M., \& McRobert, A. P. (2020). An exploratory investigation of junior-elite football coaches' behaviours during video-based feedback sessions. International Journal of Performance Analysis in Sport, 20(4), 729-746.

\section{Presenter Biography}

Gérard Jones is a Ph.D. student at Sheffield Hallam University investigating how coaches can use feedback to guide the attentional search of footballers to form their own adaptable movement solutions. He recently served as an Elite Coach Educator for the Fédération Royale Marocaine de Football as a FA UEFA 'A' Licensed Coach and CAF Instructor with over 14 years coaching experience working in both the professional and grassroots game around the world.

\section{K}

Mindful Self-Reflection as a Strategy to Enhance Sustainability Among High Performance Swim Coaches

Kenttä, Göran ${ }^{1}$; Hägglund, Karin ${ }^{1}$; Thelwell, Richard ${ }^{2}$; Wagstaff, Christopher $^{2} ; \&$ Bentzen, Marte ${ }^{3}$

${ }^{1}$ GIH The Swedish School of Sport and Health Sciences, Stockholm, Sweden; ${ }^{2}$ School of Sport, Health and Exercise Science, University of Portsmouth, Portsmouth, UK; ${ }^{3}$ Norweigen School of Sport Science, Norway

High performance coaching (HPC) is a demanding profession characterized by job-insecurity, work-home-interference, lack of recovery and a high threshold for help-seeking. Altogether, these challenges may lead to burnout, poor mental health and drop-out. Scholars have recently noted a lack of research that examine coach well-being and self-care strategies (Cropley et al., 2020). The overall purpose with this research is to advance theoretical and applied knowledge of sustainable leadership and mental health among HPCs. More specifically, the goal is to further evaluate a method that is applicable in the high-performance context by refining and implementing a user-friendly method based on a Short-Message-Service (SMS) diary. In total, 18 swim coaches ( 7 women and 11 men) aged 25 to 65 years provided consent to participate in this study. Quantitative data will be used to explore the correlations of daily self-ratings of energy and mood for 8 weeks. Measures of mental health was collected at baseline, end of intervention and at 6-months follow-up. Focus-group-interviews will evaluate the perceived effectiveness of the intervention. Preliminary results will be presented and discussed from an applied perspective. In summary, both qualitative and quantitative findings lend support to the importance of mindful self-reflections to increase self-awareness and support self-care and well-being over time. One coach noted: "It is important to stop and reflect about what is important and supporting sustainable coaching will only become more critical in the future, not only to keep coaches in the profession but also to attract women and men to become high performance coaches."

\section{References}

Cropley, B., Thelwell, R., Mallett, C. J., \& Dieffenbach, K. (2020). Epilogue: A commentary and reflection on sport psychology in the discipline of sports coaching. Journal of Applied Sport Psychology, 32, 121-128.

\section{Presenter Biography}

The majority of Göran's research has focused on elite sports with a stressrecovery perspective. Currently, Göran holds a research position in Stockholm at The Swedish School of Sport and Health Sciences, and a former director of the Coach Education Program at the university. He is also the past president of the Swedish Sport Psychological Association. In addition, Göran holds a position at the Swedish Sport Federation as Head of Discipline in sport psychology and an adjunct professor position at Ottawa University.

\section{Tokyo Olympic Lessons Learned: USRowing's Approach to High Performance Coach Development}

Kiosoglous, Cameron

\section{USRowing/ Drexel University}

The pandemic has redefined the standards of uncertainty in high-performance sport (Samuel et al., 2020). In this presentation, lessons learned from a coach development perspective will be shared as it relates to lessons learned in optimizing athlete experience over the five-year Olympic cycle focusing on the opportunities and challenges of the unprecedented postponement. We will share the issues relating to the ongoing changes that have been managed right up to the very end of preparation for this uniquely challenging Olympic Games. An interpretation of managing athlete and coach welfare during this time will also be covered (Dijkstra et al., 2014). A central theme that has been the focal point of this Olympic preparation is being nimble, ready to pivot at any moment, and that doing more with less resources is one principle that will be a lasting legacy way beyond this Olympic cycle. The purpose of this presentation is to share with our coach developers' lessons learned about people management, crisis preparation, and a constant return to what is essential to perform at the highest level once every "four" years. Innovation is 
a critical aspect of any Olympics and this one will be like no other. Insights will be shared in this presentation into the age-old discussion, should we try something new, or go with what we know?

\section{References}

Dijkstra, H. P., Pollock, N., Chakraverty, R., \& Alonso, J. M. (2014). Managing the health of the elite athlete: a new integrated performance health management and coaching model. British Journal of Sports Medicine, 48(7), 523-531.

Samuel, R. D., Tenenbaum, G., \& Galily, Y. (2020). The 2020 coronavirus pandemic as a change-event in sport performers' careers: Conceptual and applied practice considerations. Frontiers in Psychology, 11.

\section{Presenter Biography}

Cam Kiosoglous is an Assistant Clinical Professor and Sport Coaching Leadership Program Director at Drexel University and for the last five Olympic cycles has supported high performance athletes and coaches. Kiosoglous is currently the Director of National Team Sport Science with USRowing. He also serves as the Chair of Education with the United States Center for Coaching Excellence (USCCE) and has consulted with a variety of organizations in coaching development.

\section{A Community of Practice (CoP) for Coach Developers: Making Meaning During the Pandemic}

Kiosoglous, Cameron ${ }^{1}$; Dieffenbach, Kristen ${ }^{2} ; \&$ Thompson, Melissa ${ }^{3}$

${ }^{1}$ Drexel University/ USRowing; ${ }^{2}$ West Virginia University; ${ }^{3}$ Southern Mississippi University

During the 2020 pandemic, one of the ways communities came together and/or stayed connected was by utilizing the concept of a community of practice (CoP) (Davis \& Irish, 2021). A group of coach developers in the US, through their collaboration and membership with the United States Center for Coaching Excellence (USCCE), met weekly for much of the pandemic to discuss critical issues facing coach education during this unique and challenging time. In this presentation, we will share some of the key aspects of how this group formed, some of the themes discussed by the group, and lessons learned on community management. As with many $\mathrm{CoPs}$, one of the key take-aways for group members was the value of the shared learning that took place during these meetings. One unique experience, regardless of the focus of discussion, was that the last ten minutes of the meetings seemed to be the most valuable time of discussion, where deeper thinking was driving the conversation. A second point of discussion will be the choice to record sessions and the best way to keep track of topics discussed while balancing confidentiality and the respect of privacy during some of the discussions in the group. The purpose of this presentation will be to share the unique challenges in the building of an online community of coach developers during the pandemic while also discussing potential strategies for group management in the future.

\section{References}

Davis, J. S., \& Irish, C. (2021). Lessons from the pivot: Higher education's response to the pandemic. Education Faculty Articles, 11. https://scholar .umw.edu/cgi/viewcontent.cgi?article $=1010 \&$ context=education

\section{Presenter Biography}

Cam Kiosoglous is an Assistant Clinical Professor and Sport Coaching Leadership Program Director at Drexel University and for the last five Olympic cycles has supported high-performance athletes and coaches. Kiosoglous is currently the Director of National Team Sport Science with
USRowing. He also serves as the Chair of Education with the United States Center for Coaching Excellence (USCCE). He has consulted with a variety of organizations in coaching development.

\section{What Does Coaching Libertarian Feminist Football Look Like?}

Korsakas, Paula ${ }^{1}$; Tato, Enriqueta ${ }^{2}$; Aon, Jimena ${ }^{2}$; Lozano, Juliana Ro$\operatorname{man}^{2}$; Bramanti, Maria Belén ${ }^{2}$; Figueroa, María José ${ }^{2} ; \&$ Santino, Mónica ${ }^{2}$

${ }^{1}$ Campinas State University, Campinas, Brazil; ${ }^{2}$ La Nuestra Fotbol Feminista, Buenos Aires, Argentina;

Football is the most prominent sport in South America and women still face challenges to play. To build and keep a safe playing space for women and diversities is what moves La Nuestra Fotbol Feminista (LN), a community-based collective of coaches that, since 2007, have occupied a football field at Villa 31, an informal settlement in Buenos Aires, Argentina. In 2020, seeking answers to the question-title above, a Community of Practice $(\mathrm{CoP})$ was created, and this work shares the learnings generated. 13 virtual $\mathrm{CoP}$ meetings with 7 coaches were facilitated by a Brazilian Coach Developer (CD). Meeting memories, documents produced, and personal reflections were thematically analyzed. Reflections revolved around how to decentralize power and to promote sport development. Repetition and imitation were replaced by creativity and emancipation in task design. The CoP was recognized as a potent social learning space to help coaches "de-automatize coaching", to theorize about their practices and "to put words" to their doings, resulting in a Game Model and a Long-term Development Curriculum that articulates sport and political development. This experience moves the debate forward by challenging the view of sport, and football in particular, as a practice of the traditional hegemonic male world, and by positioning coaching, from a libertarian and feminist perspective, as a political act that proclaims sport as a right and commits to embrace all bodies and identities.

\section{Presenter Biography}

Paula Korsakas is a sport consultant, researcher and lecturer in Sport Psychology and Sport Pedagogy, working in the areas of athlete and coach development. She serves as a Board Member of the Brazilian Rugby Federation and is an activist for the right to play sport and gender equality in sport. Korsakas is an International Coach Developer, NSSU/NCDA/ICCE and a Ph.D. student at the Laboratory of Studies and Research in Sports Pedagogy, Campinas State University, Brazil. She has a Master in Pedagogy of Human Movement and Bachelor in Sport Sciences, São Paulo University, Brazil.

\section{Where Quality Coaching Meets Social Inequalities: Coaches in Sport for Development in Brazil}

Korsakas, Paula ${ }^{1}$; Casline, Larissa Stevanato ${ }^{1}$; \& Galatti, Larissa Rafaela ${ }^{1}$

${ }^{1}$ Campinas State University, Campinas, Brazil

Coaching is a profession in Brazil that mandates a Physical Education (PE) degree to work in any context, including Sport for Development (S4D). Sport for Social Change Network (REMS) stands out as a key player of S4D in the country by gathering 161 institutions, mostly non-governmental organizations (NGOs), that provide free sport activities for underserved populations. To better understand who coaches in this context, 122 practitioners from 10 REMS NGOs founded by former elite athletes were invited to answer an online questionnaire. 54 coaches participated and descriptive statistics were applied. Results showed the majority of coaches are male $(55.5 \%)$, between $30-49$ years $(66.7 \%)$, have 5 years or less of work experience in the sector (57.4\%) and second occupation (98\%), 
mainly as PE teachers (50\%). Regarding their development pathway, most of them practiced the same sport they coach $(71 \%)$, have a degree in Physical Education (87\%) and attended or are attending postgraduate courses $(70 \%)$. In the last year, many also have participated in non-formal courses by their own initiative $(63 \%)$ or offered by the NGOs $(93 \%)$ with emphasis on professional knowledge and, if intrapersonal knowledge were not reported, other social/political knowledge (e.g., social oppressions and decolonial pedagogy) were mentioned. While coaching in S4D presented some similarities to other contexts, it also revealed nuances, such as the high formal education qualification of coaches and the emergence of new knowledge contents, probably, due to the uniqueness of this context where quality sport coaching must embrace the fight for social inequalities.

\section{References}

Côté, J., \& Gilbert, W. (2009). An integrative definition of coaching effectiveness and expertise. International Journal of Sports Science \& Coaching, 4(3), 307-323. https://doi.org/10.1260/174795409789623892

Galatti, L. R., Reverdito, R. S., Korsakas, P., Tozetto, A. V. B., \& Santos, Y. Y. S. (2019). Sport, social programs and coaches in Brazil: Fostering positive youth development. In F. Santos, L. Strachan, P. Pereira, \& D. J. MacDonald (Eds.), Coaching Positive Development: Implications and practices from around the world. (pp. 159-170). Omniserviños.

Korsakas, P., Rizzi, E. G., Tsukamoto, M. H. C., \& Galatti, L. R. (2021). Entre meio e fim: Um caminho para o direito ao esporte. LICERE - Revista Do Programa De Pos-graduañão Interdisciplinar Em Estudos Do Lazer, 24(1), 664-694. https://doi.org/10.35699/2447-6218.2021.29534

\section{Presenter Biography}

Paula Korsakas is a sport consultant, researcher and lecturer in Sport Psychology and Sport Pedagogy, working in the areas of athlete and coach development. She serves as a Board Member of the Brazilian Rugby Federation and is an activist for the right to play sport and gender equality in sport. Korsakas is an International Coach Developer, NSSU/NCDA/ICCE and a Ph.D. student at the Laboratory of Studies and Research in Sports Pedagogy, Campinas State University, Brazil. She has a Master in Pedagogy of Human Movement and Bachelor in Sport Sciences, São Paulo University, Brazil.

\section{Promoting Cultural and Linguistic Equality in Coaching}

Kubischta, Frauke ${ }^{1}$; Tuunainen, Sari $^{1}$; \& Simojoki, Eero ${ }^{1}$

${ }^{1}$ Finnish Coaches Association, Helsinki

The Promoting Cultural and Linguistic Equality in Coaching Initiative (KKY) is an important action executed by the Finnish Coaches Association with financial support by the Ministry of Culture and Education during 2021. Key objectives of the initiative are: expand the cultural and intercultural understanding within sports in Finland; develop mentors for coaches; help coaches and athletes with a foreign background in establishing connections and networks within the Finnish sport system; deepen their comprehension of the Finnish sport system; and increase the recognition of the competencies and skills of these coaches and athletes within Finnish Sports. To achieve these key objectives, the Athlete to Coach (AtoC) education training was organized, which is a mentor education program for coaches with a foreign background to support the development of their peer-coaches. All efforts are realized in English because education and development opportunities in sports have to date only rarely been organized in Finland in languages other than Finnish or Swedish, severely limiting the participation of athletes/coaches with a foreign background. Project results, lessons learned, best practices and implications for the future are shared.

\section{Presenter Biography}

Frauke Kubischta is a graduate of cohort 7 of the NSSU Coach Developer Academy, Tokyo, Japan, and holds a Master's Degree from the HaagaHelia University of Applied Sciences in Sport Coaching, Helsinki, Finland. She is a Coach Developer in the AtoC education training and a project worker at the Finnish Coaches Association for the Promoting Cultural and Linguistic Equality in Coaching Initiative. Her moto is to use challenges as development opportunities.

\section{$\mathbf{L}$}

\section{Safe Sport Practices for Coaching in Singapore}

Latiff, Syahirah; Wang, Shao Ing; \& Chng, Lynnette

\section{Sport Singapore}

SportSG has stepped up its safeguarding interventions in terms of awareness, prevention and incident management over the past three years through the National Sporting Associations (NSA) and the National Registry of Coaches (NROC). As coaches are key drivers in ensuring that sport remains safe and enjoyable place for its participants, this presentation will highlight the coach-specific efforts, feedback from our focus group discussions and upcoming plans. Awareness: Coaches are educated through SportSG-ED online learning platform, workshops, engagement sessions, website, and formal coach education courses on how to deal with different coaching scenarios. Education involves a general awareness module on Safe Sport and a role-specific module where coaches learn about coach-athlete relationship, how to respond to disclosure and coaching policies such as disciplinary methods, physical touching, communication and more. Prevention: A Safe Sport Risk Assessment in Coaching Checklist was developed for coaches to assess their coaching environment and identify the risk their training lies. For high level risk coaching situations, coaches are recommended to follow the Rule of Two. Coaches are also required to abide by the Safe Sport Unified Code, which will be launched at the end of 2021. Incident Management: Safeguarding training is offered to coaches who will join a network of trained Safeguarding Officers who receive and triage reports of concern. A campaign in handling reports of affected persons was launched for all involved in sport. Disciplinary processes for dealing with breaches to Safe Sport practices are also detailed in the NROC Handbook.

\section{Presenter Biography}

Syahirah is with the Coaching Industry Development team under CoachSG. She represented Sport Singapore at the 2018 Safe Sport Conference in Madrid and has been driving the Safe Sport efforts in Singapore. She has presented at the ICCE Global Coach Conference 2019 and facilitated Safe Sport workshops for various stakeholders, including developing and delivering training content and providing support to Sporting Organisations in implementing their Safe Sport policies. Her other portfolio involves implementing recognition programmes and profiling coaches.

\section{Developing Swimming Teacher Competencies: A Practitioner's Perspective}

Lau, Raymond

Loughborough University, UK; University of Oxford, UK

Presented November 21, 2021; published on December 2, 2021

Sports-coaching literature indicates the inconsistent evolution of Continuing Professional Development. This research, submitted as part of a 
dissertation for a Masters degree in 2018, explored the professional development of swimming teachers. The intervention programme focused on the development of the teacher's knowledge and the practical application of pedagogy, mentoring and reflection skills. The collaborative process was geared towards shaping the new curriculum and involved Coach Educators and swimming teachers. The curriculum itself comprised six modules, conducted over eight weeks, utilising a blended-learning approach. The research employed qualitative methods and included analysis of documents, observation of learners' teaching skills, and semistructured interviews with learners regarding their experiences within the formal programme. The findings indicate that curriculum construction is of paramount importance. A blend of technical (content) knowledge alongside an increased emphasis on pedagogical content knowledge strengthened the development of individuals. This study emphasises the value of a blended flexible-learning approach with opportunities for discussion, reflection and activities, with a Coach Educator utilising a variety of methods (including instruction, problem-solving and facilitation) before, during and after sessions. Establishing an online Community of Practice through informal and formal opportunities supported learning. The learners' philosophies and values were sharpened by their capacity to reflect and by workplace application of skills and knowledge. This study has informed my current doctoral research in exploring Coach Developers' pedagogical practice and learning within swimming.

\section{Presenter Biography}

Ray Lau is a full-time PhD Researcher (Sports Coaching and Pedagogy) at Loughborough University. His current research addresses the Coach Developer in Swimming and the improvement of practice in supporting teachers/coaches in the workplace. Ray completed his Master of Science in Learning and Teaching at the University of Oxford, focused on Swimming. He has more than 25 years of experience as a Coach Educator in Swimming/Lifesaving. Ray has also been an inspector of schools and a secondary school principal.

\section{M}

\section{The Perceived Knowledge of Adolescent Development, Specifically Menstruation, By Swimming Coaches}

Marais, Nadine ${ }^{1}$; Morris-Eyton, Heather ${ }^{1} ;$ \& Janse van Rensberg, Natasha ${ }^{1}$

\section{${ }^{1}$ University of Johannesburg, Johannesburg, South Africa}

A large part of sport development takes place from childhood into adolescence. During adolescence, developing athletes' experience changes in their physical growth and abilities, and for females, the onset of menstruation. The question arises on how well coaches are educated about adolescent development, their needs, and working with young female athletes. This multimethod study focused on the awareness and behaviours of swimming coaches who work directly with adolescent female swimmers (aged between 12-18 years) especially with regards to menstruation. Data was collected in the form of questionnaires and interviews with 61 participants at a swimming club based in South Africa. Coaches' awareness of their female swimmers' biological changes was based more on observation than communication from the swimmer. Coaches explained that training is adjusted based on their observations, but whether this is being done correctly during the menstrual cycle requires more research. Coaches seem to have minimal knowledge of the effects of puberty on adolescent females, its effects on training, and how to adapt to, or overcome those effects during training or competition. In future, this knowledge could ensure the longevity of female swimmers in the sport. It could also provide a framework for coaches to utilize when working with a unique population like adolescent females, which could provide athlete longevity after puberty, not only within swimming but other sporting disciplines as well. Educating clubs and coaches could ensure extended and more successful participation and may also assist in dealing with the "taboo" surrounding puberty, specifically menstruation and the female athlete.

\section{Presenter Biography}

Nadine Marais completed her Master's degree in Sport Science in 2020 with a special focus on swimming and adolescent female swimmers. As a South African female swimming instructor and coach, Marais aspired to increase her knowledge, and the knowledge of other coaches, around puberty and its effects on sports performance.

\section{Using Realist Evaluation to Evaluate Coach Education Programmes: A Case Study with the English Football}

McCarthy, Liam ${ }^{1}$; North, Julian²; \& Muir, Bob ${ }^{3}$

${ }^{1}$ University of Central Lancashire, UK; ${ }^{2}$ Leeds Beckett University, UK; ${ }^{3}$ Leeds Beckett University, UK

Sports coaching makes an important contribution to society and as such, the quality of coaching practice is of paramount concern (North, 2017). In many countries around the world, professional development opportunities are available for sports coaches and perhaps the most common are largescale national governing body (NGB)/federation-led coach education programmes. However, despite the significant resource (e.g., finance, expertise) invested in the design and delivery of these programmes, alarmingly little sophisticated evaluation work has been carried out. Indeed, calls for this type of work have been made over the last two decades (e.g., Gilbert \& Truel, 1999). For this reason, we suggest that the area requires urgent attention and within this presentation, we propose a way forward. Realist evaluation is a theory-driven approach to evaluation, with epistemological roots in critical realism. Realist evaluation is sensitive to the idea that programme participants will reason with and respond to programmes in different ways, thus, seeks to explain how and why this is the case (Pawson \& Tilley, 1997). Within this presentation, we intend to share an overview of realist evaluation in use, specifically how it has been used to evaluate a particular feature (project-based assessment) of the FA Level 3 (UEFA B) in coaching football programme.

\section{References}

Gilbert, W., \& Trudel, P. (1999). An evaluation strategy for coach education programs. Journal of Sport Behavior, 22(2), 234-250.

North, J. (2017). Sport coaching research and practice: Ontology, interdisciplinarity and critical realism. Taylor \& Francis.

Pawson, R., \& Tilley, N. (1997). Realistic Evaluation. Sage.

\section{Presenter Biography}

Liam has a track record of high-quality teaching, research and international knowledge exchange activity in the field of coach education. Liam currently works at the University of Central Lancashire, as a lecturer in sports coaching and development, and at the Premier League where he contributes to the design and delivery of coach development programmes. Further, Liam is currently project manager for an International Council for Coaching Excellence (ICCE) working group, exploring assessment as a feature of coach education.

\section{Developing Online Bachelor Program in Sport Coaching}

Medgard Skår, Magnhild ${ }^{1} \&$ Stefansson, Axel $^{1}$

${ }^{1}$ Inland Norway University of Applied Sciences, Elverum, Norway 
A recent study, profiling 5977 Norwegian coaches (Chroni et al., 2018), identified many challenges in completing coach education. Critical factors that influenced the inability to complete, were lack of time, lack of available courses, and work-life balance challenges. One way of dealing with the inherent challenges of completing coach education is to develop online coach education programs. An online learning environment offers coaches flexibility (Mallett \& Dickens, 2009). To strengthen coaches' capacity to complete coach education programs, our university decided to develop a digital, part-time, bachelor program in sport coaching. In contrast to many other European countries, there are few formal requirements necessary to coach at various levels in Norway. A program like this will bring opportunities for professional coaches to gain education in addition to prepare professional athletes on the transition from athlete to coach. Key elements in this online coach education will be how to ensure learning progression with good interaction between theory and practice. The students are challenged to apply theoretical perspectives from academia in their practice in local clubs throughout the whole course. In addition to receiving a bachelor's degree, the students also have accreditation from national sport federations. In the presentation, we will focus on what assessments we made to make the coach education flexible. Examples is on target groups, admissions requirements, gatherings, practice, workload, progression, digitization of academic material, and changes in content of topics, for example, more focus on coaches' self-care.

\section{References}

Chroni, S., Medgard, M., Nilsen, D. A., Sigurjonsson, T., \& Solbakken, T. (2018). Profiling the coaches of Norway: A national survey report of sports coaches and coaching. Høgskolen i Innlandet. https://brage.bibsys.no/ xmlui/handle/11250/2569671

Mallett, C. J., \& Dickens, S. (2009). Authenticity in formal coach education. International Journal of Coaching Science, 3(2), 79-90.

\section{Presenter Biography}

Magnhild Medgard Skår is an assistant professor of Sport Science and Sports Coaching with the Department of Public Health and Sports Science of Inland Norway University of Applied Sciences. She has 10 years of experience in academia. The research topics she has been involved in is coaching, gender equality in sports, and digital learning tools for teaching in higher education. She is also the project leader and head of the study program of the online Bachelor in sport coaching.

\section{Time to Play: Understanding the Role of Play in Sport for Children and Coaches}

Mooney, Owen ${ }^{1,2,3}$; Lara-Bercial, Dr Sergio ${ }^{1,2} ;$ \& Clarke, Dr Nicola ${ }^{1}$

${ }^{1}$ Leeds Beckett University, Leeds, United Kingdom; ${ }^{2}$ ICOACHKIDS, Leeds, United Kingdom; ${ }^{3}$ Dublin Gaelic Athletic Association, Dublin, Ireland

Children's play is "any behaviour, activity or process initiated, controlled and structured by children themselves; it takes place whenever and wherever opportunities arise" (The United Nations, 1989). In addition, Bergen (2014) states that play is unique in its potential to develop a child's creative, decision making, physical, cognitive, social, emotional, and communicative skills. Youth sport offers a unique context for children to access play experiences. When coaches utilise play within a safe, fun learning environment, this has the potential to enhance children's holistic development, deepen children's understanding of the sport they take part in, and harness internal motivation that will keep children playing their chosen sport for longer; consequently, helping to increase engagement and minimise dropout (Witt \& Dangi, 2018).
However, there are various barriers to coaches embracing play in sport including: a lack of understanding of the value of play; few development opportunities that focus on learning through play in sport; the belief that play is frivolous; and that play opportunities take time away from "true learning" (UNICEF, 2018). To begin to address these barriers, this presentation will outline an emerging framework of play in sport for coaches, that synthesises existing play theories and presents example activities that coaches can adopt in their practice to create more opportunities for play, and more playful experiences for children within youth sport contexts. Drawing on the author's professional practice, recommendations for coaches and coach developers regarding the potential challenges and benefits of facilitating "time to play" in youth sport will be discussed.

\section{References}

Bergen, D. (2014). Foundations of play theory. In L. Brooker, M. Blaise, \& S. Edwards (Eds.), The SAGE handbook of play and learning in early childhood (pp. 5-21). SAGE Publishing.

United Nations Children's Fund. (2018). Learning through play: Strengthening learning through play in early childhood education programmes. UNICEF. https://www.unicef.org/sites/default/files/2018-12/UNICEFLego-Foundation-Learning-through-Play.pdf

The United Nations. (1989). Convention on the Rights of the Child. Treaty Series, 1577, 3.

Witt, P. A., \& Dangi, T. B., (2018). Why children/youth drop out of sports. Journal of Park and Recreation Administration, 36(3).

\section{Presenter Biography}

Owen Mooney is the Learning and Games Development Coordinator for the Dublin Gaelic Athletic Association in Ireland; he is a Doctor of Professional Practice candidate at Leeds Beckett University, and he is host of the ICOACHKIDS Podcast. He has worked for Special Olympics Ireland as a National Coach and Sport Development Coordinator, in New York as Games Development Officer for the Rockland Gaelic Athletic Association and as a Department of Education Physical Literacy Curriculum Coach, working with children from 4-8 years.

\section{What do Performance Pathway Coaches in Australia Want to Learn From Online Coach Development?}

Morley, David ${ }^{1}$; Turner, Graham ${ }^{2}$; Roberts, Alex ${ }^{1}$; Lidums, Maris ${ }^{1}$; Melvin, $\operatorname{Ian}^{2}$; Nicholson, Mark ${ }^{1} ;$ \& Donaldson, Alex ${ }^{1}$

${ }^{1}$ La Trobe University, Melbourne, Australia; ${ }^{2}$ Australian Institute of Sport, Canberra, Australia

This study explored what coaches want to learn about identifying, developing, supporting and progressing athletes through a national performance pathway within an online learning programme. Coaches about to undertake an online training course were asked to: i) brainstorm what they wanted to know; (ii) group the brainstormed ideas around perceived similarity; and (iii) rate the ideas for importance and impact on coaching practice on fivepoint scales. Data was collected and analysed (multidimensional scaling, hierarchical cluster analysis and mean rating calculation) using the Concept Systems groupwisdomTM online platform. Thirty-two coaches brainstormed 42 statements that the research team synthesised and edited to 47 unique statements. Forty coaches sorted and rated these 47 statements. An 8-cluster solution best represented the sorted data (number of statements in cluster; mean cluster importance rating; mean cluster impact rating): Develop: sport psychology and athlete engagement (8: 3.98; 4.01); Develop: training and competition environments (5: 3.84; 3.87$)$; Support: athlete wellbeing $(5: 3.63 ; 3.55)$; Progress: monitoring and modelling (6; 
3.48; 3.40); Identify: talent ( $7 ; 3.42 ; 3.22)$; Coach learning and support: supporting coaches to work with stakeholders $(3: 3.37 ; 3.52)$; Support: transition and significant others $(6 ; 3.25 ; 3.15)$; and Progress: benchmarking and performance pathway design $(7 ; 2.93 ; 2.90)$. Nineteen statements from seven clusters were rated above the all-statement mean for importance (3.49) and impact (3.45). The eight clusters of desired knowledge identified in this study, when integrated with national strategic objectives and research evidence can inform professional development training for coaches working with athletes through national performance pathways.

\section{Presenter Biography}

Dave Morley is Professor of Sport Coaching within the Discipline of Sport and Exercise Science at La Trobe University, Melbourne. He has led numerous national and international projects exploring coaching practices, children's movement development, talent development and inclusion. For example, he is leading on the development of Nike's "Movement for Sport Playkit" and helping to power the Australian Institute of Sport's Elevate Coach courses. He has a passion for using sport to improve the lives of everyone involved.

\section{The Coach-Athlete Relationship and Its Influence on the Development of Brazilian Squash Coaches}

Motta, Mairin Del Corto ${ }^{1} \&$ Galatti, Larissa Rafaela ${ }^{2}$

${ }^{1}$ Faculty of Physical Education, State University of Campinas, Campinas, Brazil; ${ }^{2}$ Faculty of Applied Sciences, State University of Campinas, Campinas, Brazil

In individual sports, the intense experience with a given athlete can be a milestone in the trajectory of a sports coach; however, this is a topic that has been little discussed in the literature. The study aimed to describe experiences with a given athlete in the development trajectory of squash coaches with more than 20 years of experience. Four Brazilian squash coaches with at least 20 years of experience ( 3 men and 1 woman) participated in the study, who performed a timeline (Nash et al., 2019) and an unstructured interview to better understand the timeline. For data analysis, thematic analysis was used (Braun et al., 2016). The coaches pointed out, during the construction of the timeline, a certain experience resulting from a relationship with a certain athlete, being a positive experience (victory in a tournament) or negative (defeat in a tournament or withdrawal from the sport). The positive experience boosted characteristics such as determination, responsibility, and focus on the coach, in addition to boosting the search for knowledge about the sport. However, the negative experience allowed reflections on their performance, and as a consequence a self-assessment about aspects that should be improved as a squash coach, which triggered the search for knowledge. It is concluded that during the trajectory of squash coaches, many relationships are built with their students or athletes, but a specific relationship can enable reflections, consolidation of positive aspects, and the need to expand knowledge to improve their performance.

\section{References}

Nash, C., Culver, D., Koh, K. T., Thompson, M., Galatti, L. R., \& Duarte, T. (2018). The coaching journey: Learning as lifelong and life-wide. In R. Thelwell, \& M. Dicks (Eds.), Routledge research in sports coaching: Professional advances in sports coaching research and practice (pp. 4462). Routledge.

Braun, V., Clarke, V., \& Weate, P. (2016). Using thematic analysis in sport and exercise research. In B. Smith, \& A. C. Sparkes (Eds), Routledge handbook of qualitative research in sport and exercise (pp. 191-205). Routledge.

\section{Presenter Biography}

Mairin Del Corto Motta is a former squash athlete (Brazilian Youth Team 2010 to 2012). Motta has a Master's degree from the Faculty of Physical Education of the State University of Campinas and is part of the Laboratory of Studies in Sport Pedagogy (LEPE) and the Interdisciplinary Research Group on Racquet Sports (GRIPER), both located at the Faculty of Applied Sciences of the State University of Campinas. Motta participates as a volunteer in the management of women's squash at the São Paulo Squash Federation (FPS).

\section{The Research Project QuaTroPLUS: Acquiring Competence in the Coach Education of the DOSB}

Möhrle, Annalena ${ }^{1}$; Liebl, Sebastian ${ }^{1}$; \& Sygusch, Ralf ${ }^{1}$

${ }^{1}$ Friedrich-Alexander-University Erlangen-Nürnberg, Erlangen-Nürnberg, Germany

The main goal of coach education is acquiring competence (ICCE, 2013). To achieve this goal, the German Olympic Sports Confederation (DOSB) cooperated with education and practice experts to develop the DOSB-competence-model as a framework for coach education. Based upon competence theoretical approaches (i.e., Baumert \& Kunter, 2013), the model recommends aligning learning objectives, learning, and performance tasks with requirement situations (Sygusch et al., 2020). Funded by the Federal Institute of Sport Science, we are testing the theoretical model together with four top sports federations (field hockey, judo, athletics, and skiing federation) in the research project QuaTroPLUS from 2019 to 2022. In this context, we focus on the question: To what extent is the DOSB-competence-model suitable as a framework for coach education? To answer the question, we distinguish between the module's implementation and evaluation. For the implementation, we have set up cooperative planning groups (Rütten \& Gelius, 2013) in the participating federations. Each group adapted the DOSB-competencemodel to their conditions under our guidance. For the evaluation of the further developed courses, we used document analyses, video observations and interviews that we evaluated content analytically (Mayring, 2015). The top sport federations identified specific requirement situations of their coaches, derived learning objectives, as well as developed and implemented learning and performance tasks. The evaluation points to a high practical orientation and a strong implication connection between the components of the DOSB-competence-model. From the results of the participating federations, we can derive recommendations for further federation-specific implementation processes of the DOSB-competencemodel.

\section{References}

Baumert, J., \& Kunter, M. (2013). The COACTIVE model of teachers' professional competence. In M. Kunter, J. Baumert, W. Blum, U. Klusmann, S. Krauss, \& M. Neubrand (Eds.), Cognitive activation in the mathematics classroom and professional competence of teachers (pp. 25-48). Springer.

International Council for Coaching Excellence. (2013). International Sport Coaching Framework: Version 1.2. Human Kinetics.

Mayring, P. (2015). Qualitative content analysis. Theoretical background and procedures. In A. Bikner-Ahsbahs, C. Knipping, \& N. Presmeg (Eds.), Approaches to qualitative research in mathematics education: Examples of methodology and methods (pp. 365-380). Springer.

Rütten, A., \& Gelius, P. (2013). Building policy capacities: An interactive approach for linking knowledge to action in health promotion. Health Promotion International, 29(3), 569-582. 
Sygusch, R., Muche, M., Liebl, S., Fabinski, W., \& Schwind-Gick, G. (2020). Das DOSB-Kompetenzmodell für die Trainerbildung. Teil 1 [The DOSBcompetence-model for coach education. Part 1]. Leistungssport, 50(1), 41-47.

\section{Presenter Biography}

Annalena Möhrle studied teaching mathematics and sports at the University of Bayreuth/Germany before starting as a research assistant at the Chair of Sports Education at Friedrich-Alexander-University ErlangenNürnberg/Germany in January 2019. Her research focus is on coach competences and their acquisition. In addition to the research project QuaTroPLUS, she is also working on a cumulative doctorate with the focus on national and international competence approaches in coach education as well as trainer-specific requirement situations.

\section{$\mathbf{P}$}

\section{Training Needs of Young Football Coaches}

Paixão Paulo' ${ }^{1}$ Giméez, Javier² ${ }^{2}$ \& Abad, Manuel ${ }^{2}$

${ }^{1}$ Polytechnic Institute of Beja, Portugal; ${ }^{2}$ University of Huelva, Spain

Coaches have the obligation to have a good level of training and to continue their training throughout their sporting life. It is especially important that their training is embraces an ethical and scientific point of view, since their performance directly affects the sporting behavior of their players, especially the younger ones. The aims of this study were to identify the training needs of the football coach in the training stages of young players in the region of Beja (Portugal), and establish the training contents and strategies of greatest interest to coaches. To this end, 124 grassroots football coaches in Beja were surveyed. The data showed that the coaches assume that the daily experience is not enough. Considering the content of most interest of these coaches were: "Theory and methodology of sports training", "Technique and tactics", "Methodology of football training", and "Physical/motor skills". The contents of less interest to coaches are the "Fight against doping" and "Sport for people with disabilities". As for training strategies, the coaches surveyed attached special importance to being able to talk directly to other coaches and be able to attend other training sessions and football matches. However, the great need for training coaches identified in this study was the fact that most coaches do not even have Grade I basic training of the qualification of a football coach to perform their functions. These results are compounded with the fact that some of these trainers also have no academic training around sport.

\section{Presenter Biography}

Paulo Paixão is a Representative for the International Mobility of the Sports Course Department of Arts, Humanities and Sport Higher School of Education Polytechnic Institute of Beja https://orcid.org/0000-0002$5367-8830$

From a Youth Coach/Researcher to a University Coach Course Facilitator: Learnings Experienced

Palma, Bartira Pereira ${ }^{1}$; Santos, Yura Yuka Sato dos ${ }^{1}$; Passero, Julia Gravena $^{1}$; Marques Filho, Cesar Vieira ${ }^{1}$; Moura, Graziela Higino de ${ }^{2}$; Santim, Julia Odas ${ }^{1}$; Motta, Mairin Del Corto ${ }^{1}$; Ferreira, Luca ${ }^{1}$; Brok, Eloisa Nobrega ${ }^{1}$; Gryszczenko, Henrique Borgato ${ }^{1}$; Simarelli, Paula ${ }^{1}$; Verginelli, Carla Abrahão ${ }^{1}$; Bizetti, Mateus de Seixas ${ }^{1}$; \& Galatti, Larissa Rafaela $^{1}$

${ }^{1}$ State University of Campinas, Faculty of Applied Sciences, Limeira-SP, Brazil; ${ }^{2}$ Faculty of Sport - University of Porto, Porto, Portugal
This report aims to share the experiences of 9 coaches and/or graduate students acting as volunteer learning facilitators in a coaching course designed within the Learner-centered Teaching (LCT) at the State University of Campinas - Brazil. The facilitators attended all 15 classes (mean age 29.1 years, seven women, five master's and four Ph.D. candidates), led by an experienced professor (16 years at high education and sport pedagogy/coaching research). Although the course was originally offered face-to-face, it was adapted to distance learning due to the COVID-19 pandemic. The main role of facilitators was to assist in classes dynamics and to support students' development. They answered a questionnaire about their experience in the process. We identified four categories: (1) horizontal environment; (2) initial insecurity; (3) sharing network, (4) need for initial alignment. The facilitators felt insecure at the beginning of the course due to lack of information about the LCT and what was expected of them. They reported that the course leader guaranteed a safe environment with shared power, in which facilitators and leader established a good relationship and sharing network, allowing them to learn with each other and improve their mediating skills. They reported having learned competencies such as communication, leadership, self-evaluation, and self-knowledge, however a distance learning format hindered communication and using of practical activities. They suggested that an initial stronger training would enable alignment in strategies and increased confidence. We conclude that this experience allowed learning with practice, and it is an efficient strategy for other coach development courses.

\section{Presenter Biography}

Pereira has a Bachelor's degree and Master's degree in Physical Education at the University of Sao Paulo (USP), Brazil; and a Doctorate in Sport Pedagogy in progress at the State University of Campinas (UNICAMP), Brazil. Currently studying sports for people over 60 years old.

\section{Think Aloud for Reflective Practice and Experiential Learning in a Coaching Bachelor in Norway}

Pettersen, Jannicke Nikolaisen ${ }^{1}$; Stefansson, Axel $^{1} ;$ \& Lunde, Gry Anita ${ }^{1}$

${ }^{1}$ Inland Norway University of Applied Sciences, Elverum, Norway

Reflective practice has been identified as key in coach development and it has been argued that reflective practice should be central to coach education programmes (Knowles et al., 2005). Traditionally, coaches are introduced to reflective practice through retrospective reflection, often in the form of written journals. Scholars have questioned whether this practice is too mechanistic, focusing on the negative aspects or searching for problems (Dixon \& Ghaye, 2013). This critique led researchers in identifying a need for developing methods that encourage, aid, and facilitate coaches to reflect-in-action (e.g., Stephenson et al., 2020). Think Aloud (TA) as a tool has been used successfully to develop self-awareness and reflection in coaches' practice in (Stephenson et al., 2020). TA is recognized for offering the potential to personalise reflective practice, as it enables the coach to engage in a reflective process that is specific to the coach and the coaching context. Considering the weaknesses identified in the literature and strengthen the development of reflective practice during coaching education, we implement the TA protocol as an educational tool in HiNN's 3 -year sport coaching bachelor programme. We employ a progressive approach; at first facilitate coach reflection-in-action; then facilitate reflection-on-action; and lastly facilitate overall coaches' learning via reflection. We will share our approach, the challenges experienced and how we continue to work with it.

\section{References}

Dixon, M., Lee, S., \& Ghaye, T. (2013). Reflective practices for better sports coaches and coach education: Shifting from a pedagogy of scarcity 
to abundance in the run-up to Rio 2016. Reflective Practice, 14(5), 585599. https://doi.org/10.1080/14623943.2013.840573

Knowles, Z., Borrie, A., \& Telfer, H. (2005). Towards the reflective sports coach: Issues of context, education and application. Ergonomics, 48(1114), 1711-1720. https://doi.org/10.1080/00140130500101288

Stephenson, J., Cronin, C., \& Whitehead, A. E. (2020). "Suspended above, and in action": Think Aloud as a reflective practice tool. International Sport Coaching Journal, 7(1), 11-21 https://doi.org/10.1123/iscj .2018-0022

\section{Presenter Biography}

Jannicke Nikolaisen Pettersen is a Ph.D. student with the Department of Public Health and Sports Science of Inland Norway University of Applied Sciences. She has 13 years of experience in academia as a coach educator/ assistant professor of Sport Psychology, Pedagogy, and Sports Coaching. She also has experience working as a coach for children, youth and adults, and as a sport psychology consultant for youth national athletes in Norway.

Learning in Lockdown: Online Professional Development Experiences of Sport Coaches in the UK and IRL

Phelan, Simon ${ }^{1}$; Stodter, Anna ${ }^{2} ; \&$ Consterdine, Alexandra ${ }^{3}$

${ }^{1}$ Oxford Brookes University; ${ }^{2}$ Anglia Ruskin University; ${ }^{3}$ Manchester Metropolitan University

Within sport coaching there has been increased attention paid to the use of online collaborative learning tools (web2.0 technologies) as education designers have sought to "layer" face-to-face and virtual learning opportunities to support knowledge creation (Piggott, 2015). Recent restrictions around the COVID-19 pandemic have seen a meteoric rise in the provision of online Professional Development (PD) activities, hosted by an array of independent agencies, national governing bodies, and coaching "gurus". The aim of this study was to investigate the navigation of this changing landscape and explore how coaches exercised their autonomy through their engagement with, and filtering of, online PD content. An online survey sampled coaching practitioners $(n=105)$ from the UK and Ireland across a range of sporting contexts, utilising open and closed questions to collect data on participants' online PD experiences. Data were analysed using reflexive thematic analysis, conceptualising personal learning dispositions in respect to participants intentionality (open-mindedness) and reciprocity (accommodation of alternative views) (Griffiths \& Armour, 2013). Analyses highlighted practitioners' social media circles as a primary source for PD identification, where opportunities that afforded dedicated time to engage in reflective peer discussions were most valued. That said, participants warned that such provisions did not guarantee positive learning experiences, as often the desire to "pump out" content led to disconnected/unstructured experiences lacking participant voice. The data provides evidence to support a call for governing bodies and education providers to move beyond simple "content" provision and consider learners, pedagogy, and pedagogic design within online learning contexts (Cushion \& Townsend, 2019).

\section{References}

Cushion, C. J., \& Townsend, R. C. (2019). Technology-enhanced learning in coaching: A review of literature. Educational Review, 71(5), 631-649.

Griffiths, M. A., \& Armour, K. M. (2013). Volunteer sport coaches and their learning dispositions in coach education. International Journal of Sports Science \& Coaching, 8(4), 677-688.

Piggott, D. (2015). The open society and coach education: A philosophical agenda for policy reform and future sociological research. Physical Education and Sport Pedagogy, 20(3), 283-298.

\section{Presenter Biography}

Simon Phelan is a Senior Lecturer in Sport, Coaching and Physical Education at Oxford Brookes University. His research interests revolve around coaches' learning, knowledge creation and the interplay of organisational culture on these practices. Simon has consulted with several NSOs (e.g., The FA, British Athletics, UK Sport)

\section{$\mathbf{R}$}

\section{Blind Football and Sporting Capital: Managing Participation Among} Youth Blind Football Players

Richardson, Keon

University of Tsukuba, Tsukuba, Japan

The relationship between sporting capital and participation experiences in low-income countries, such as Zimbabwe, especially amongst people with visual impairments, is hitherto unknown. This paper examines the participation experiences of Zimbabwean youth blind football players and questions how the accumulation of sporting capital helps in managing and sustaining participation in blind football. The paper employs a mixed method approach and draws upon data from semi-structured interviews, participant observation, personal photographs, and questionnaires to analyse the sporting capital development of 14 youth blind football players from nine of Zimbabwe's ten provinces. The players' sporting capital domains were established early through a diversified range of formal participation in various sports, including goalball, athletics, and volleyball during primary school. Increased sporting capital highlighted transferability to different teams and environments to help manage and sustain participation in blind football. Sporting capital is increased by a varied sport offer, empathetic and skilled teachers and coaches, and opportunities to develop independence and a strong peer network, for example, through having access to specialist equipment. Taken together, this bank of capital empowered players to surmount a range of barriers, helping them to manage sustained participation. Findings will help stakeholders, including national blind sport federations, coaches, National Paralympic Committees, educational institutions, and blind football teams, among others, to develop management structures and educational programmes to help increase youth blind football players' sporting capital and identify and manage negative incidents that can affect lifelong participation in blind football.

\section{Presenter Biography}

Keon Richardson is an internationally recognised sociologist with a particular research interest in the accumulation of different forms of capital through sport participation for marginalised youth. He recently completed his Master of Art Degree in Sport and Olympic Studies at the University of Tsukuba in Japan. Keon has a growing body of peer-reviewed journal articles, is a UEFA B Futsal Licenced Coach, and has evolved the game of blind football across Southern Africa.

\section{The Impact of a Coach Developer Working in a High Performance Organisation}

Ross, Ashley ${ }^{1} \&$ Mason, Robert ${ }^{2}$

${ }^{1}$ South Australian Sports Institute; ${ }^{2}$ University of Melbourne

The South Australian Sports Institute (SASI), part of the Australian National Institute Network, has employed a full-time Coach Developer (CD) since 2018. This presentation seeks to describe the role of the CD in the high-performance environment at SASI, providing information about the services and roles the CD undertakes. Additionally, there have been 
calls in the literature for increased collaboration between academics and coach development practitioners, so that a greater understanding of coach development can be attained (Horgan \& Daly, 2015). Therefore, an evaluation project with a coaching academic was undertaken to collect interview evidence on the impact of a $\mathrm{CD}$ on the professional development of seven high performance coaches who currently work with the CD. Results reveal what the coaches' thought was most impactful, what type of PD they preferred, what they believe are the characteristics of the ideal CD and the importance or otherwise of specific sport knowledge of the $\mathrm{CD}$.

\section{References}

Horgan, P., \& Daly, P. (2015). The role of the coach developer in supporting and guiding coach learning: A commentary. International Sport Coaching Journal, 2, 354-356.

\section{Presenter Biography}

A graduate and return presenter of the ICCE/NCDA, Ashley Ross has been involved in coaching athletes and coaches from grass roots to world championship teams across sports and genders with experience around the globe for more than 36 years. He currently leads Coach Development for the High-Performance coaches of the South Australian Sports Institute.

\section{$\mathbf{S}$}

\section{Learner-Centered Coach Education: Making it Feasible on the Online COVID-19 Scenario}

Santos, Yura Yuka Sato ${ }^{1}$; Galatti, Larissa Rafaela ${ }^{1}$; \& Barnes, Luke ${ }^{1}$

${ }^{1}$ University of Campinas, Brazil

In 2020, the emergence of the global pandemic caused by the coronavirus (SARS-Cov2) accelerated the process of adopting digital technologies (DT) in coach education programs. It is no longer an alternative or complement to face-to-face education, but an imperative in times of social isolation. With that, an undergraduate coaching course in Brazil, based in a learner-centered teaching (LCT) approach, has changed to an online model. The purpose is to share our first practical lessons that we have learned from the use of DT to make feasible a LCT approach in an undergraduate coaching course. We have developed the online model based upon the five dimensions of LCT by Weimer (2002), and McCombs and Vakili's (2005) LCT framework for e-learning. Our practical lessons are: 1) verify with the learner their internet access conditions and provide flexible schedule if possible; 2) consider the learners' prior knowledge about DT, not everyone is digital native; 3 ) dispose of different options of DT in the teaching-learning process; 4) develop your skills - instructors might understand the LCT principles that are incorporated into the use of DT; 5) provide a support and feedback environment through different DT; 6) use DT to create environments for collaboration and discussion; 7) provide opportunities for control and choice of DT by learners; 8) assess the effectiveness of technology to meet the diverse and emerging needs of learners. The LCT principles aligned with the practical application guidelines for DT as presented can serve as a basis for future implementations in coach education programs.

\section{References}

Mccombs, B. L., \& Vakili, D. (2005). A learner-centered framework for eLearning. Teachers College Record, 107(8), 1582-1600. https://doi.org/10 .1111/j.1467-9620.2005.00534.x

Weimer, M. (2002). Learner-centered teaching: Five key changes to practice (1st ed.). Jossey-Bass.

\section{Presenter Biography}

Yura Y. S. dos Santos: Ph.D. candidate in Physical Education at the University of Campinas in Brazil (UNICAMP). Researcher in the Laboratory of Studies in Sports Pedagogy at UNICAMP. Basketball coach of men's grassroots teams.

Larissa R. Galatti: Associate Professor and Coordinator of the Sport Sciences Course at UNICAMP. Researcher in the Laboratory of Studies in Sports Pedagogy and in the Graduate Program at the School of Physical Education at UNICAMP.

\section{The Learner-Centered Teaching (LCT) in an Online Coach Education Course Inducted by COVID-19}

Santos, Yura Yuka Sato ${ }^{1} \&$ Galatti, Larissa Rafaela ${ }^{1}$

${ }^{1}$ University of Campinas, Brazil

The pandemic transformed coach education programs (CEP) into online programs. Evidence regarding learner-centred teaching (LCT) in online $\mathrm{CEP}$ are scarce. Our aim was to investigate the opinions of student-coaches about LCT in the "Sports Coach" course, conducted in an emergency online environment amidst the pandemic in 2020, at University of Campinas, Brazil. The university provided Google's teaching platform. The course had the professor, five of the professor's assistants, and 32 studentcoaches. We focused on the development of Weimer's LCT dimensions (2013): the role of the teachers; the balance of the power; the function of the content; the responsibility for learning; the purposes and processes of evaluation. We conducted four online focus groups (Group1 = 9; Group2= 7), at the middle and the end of the semester (313 minutes), approved by the Ethics Committee. The analysis followed the inductive-deductive thematic analysis, through NVivo 11, using the reliability criteria of internal coherence, credibility, and transparency. The student-coaches reported accessibility, usability, and stress issues related to the online environment, and benefits such as ease access and organization of information, and agility in communication. The pandemic triggered insecurity, domestic adversities, and the feeling of missing interactions on campus. The teaching support, and the collaboration in a sense of community, helped the student-coaches to continue the studies. The opinions converged towards engagement and motivation, enhancing the student-coaches' learning skills. Although the resources in the online environment were specific, the principles and purposes of the LCT remained, being important the creation of an environment conducive for learning.

\section{References}

Weimer, M. (2013). Learner-centered teaching: Five key changes to practice (2nd ed.). Jossey-Bass.

\section{Presenter Biography}

Yura Santos, Ph.D. in Physical Education, Faculty of Physical Education of the State University of Campinas (UNICAMP) (2021). Master's Degree in Nutrition and Sport Sciences and Metabolism, with an emphasis on Biodynamics of Human Movement (2015), and Bachelor's Degree in Sports Science (2012), Faculty of Applied Sciences at UNICAMP. Member of the Laboratory of Studies in Sport Pedagogy (LEPE) and basketball coach of boys under 12 and 16 years-old at Nosso Clube de Limeira/Brazil.

\section{A Joint Model for Competence-Oriented Education in the German Olympic Sports Confederation (DOSB)}

Sygusch, Ralf ${ }^{1}$; Fabinski, Wiebke ${ }^{2}$; \& Muche, Martin ${ }^{1}$

${ }^{1}$ Friedrich-Alexander University Erlangen-Nürnberg, Germany; ${ }^{2}$ German Olympic Sports Confederation (DOSB), Frankfurt, Germany 
Under the umbrella of the German Olympic Sports Confederation (DOSB), more than 450,000 coaches qualified according to the DOSB Framework Guidelines for Qualification. These Guidelines describe competences of coaches and thus, set common quality standards for coach education. On this basis, education experts from member associations and sports scientists developed the DOSB Competence Model (Sygusch et al. $2020 \mathrm{a}$; b) jointly as part of a cooperative planning process. The model refers to the discussion on competences in educational science (Baumert \& Kunter, 2011). With the understanding of competences as capability to solve problems in variable situations (Weinert, 2001), the model is based on a broad concept of competence. The starting point of the DOSB Competence Model are requirement situations of coaches' everyday training and competition life. An important principle of competence development is the systematic interaction of knowledge and skills to cope with these requirement situations in training. The DOSB Competence Model includes a systematically aligned learning target, task, and examination culture. With the learning target culture, concrete competence orientated learning targets are formulated and operationalised via a learning target taxonomy (Anderson \& Krathwohl, 2001). The task culture initiates and accompanies systematic teaching-learning processes with which the selected competences are developed. The examination culture ensures the verification of competences for which there are justified goals and learning processes have been initiated. The DOSB Competence Model thus forms a basis for the methodological-didactic development of coach education. Furthermore, the model serves as a basis for empirically evaluating the implementation and effectiveness of competence-based coach education.

\section{References}

Anderson, L. W., \& Krathwohl, D. R. (2001). A taxonomy for learning, teaching and assessing. Longman.

Baumert, J., \& Kunter, M. (2013). The COACTIVE model of teachers' professional competence. In M. Kunter, J. Baumert, W. Blum, U. Klusmann, S. Krauss, \& M. Neubrand (Eds.), Cognitive activation in the mathematics classroom and professional competence of teachers (pp. 2548). Springer.

Sygusch, R., Muche, M., Liebl, S., Fabinski, W. \& Schwind-Gick, G. (2020a). Das DOSB-Kompetenzmodell für die Trainerbildung: Teil 1. Leistungssport, 50(1), 41-47.

Sygusch, R., Muche, M., Liebl, S., Fabinski, W. \& Schwind-Gick, G. (2020b). Das DOSB-Kompetenzmodell für die Trainerbildung: Teil 2: Aufgaben und Prüfungskultur. Leistungssport, 50(2), 45-49.

Weinert, F. E. (2001). Vergleichende Leistungsmessung in Schulen: eine umstrittene Selbstverständlichkeit. In F. E. Weinert (Hrsg.), Leistungsmessungen in Schulen (17-31). Beltz.

\section{Presenter Biography}

Dr. Ralf Sygusch is a professor and head of the Education in Sport Department at FAU Erlangen-Nuremberg. One of his areas of research focuses on competence orientation in coach education and in physical education. He is the Principal Investigator in the QuaTroPLUS project, in which the coach education of the DOSB member organisations is being further developed and evaluated. Wiebke Fabinski is Deputy Head of Education at the German Olympic Sports Confederation. Her work focuses on DOSB licence education, digital education, and knowledge management.

\section{How to Develop Video Stories to Promote Effective Psychosocial and} Sociocultural Coaching Practice

Szedlak' Christoph ${ }^{1}$; Callary, Bettina ${ }^{2}$; Johnston, Daniel ${ }^{2}$; \& Gearity, Brian ${ }^{3}$
${ }^{1}$ University of Southampton, UK; ${ }^{2}$ Cape Breton University, Canada; ${ }^{3}$ University of Denver, USA

Stories are a valuable and effective tool to disseminate research findings to coaches. However, the use of stories, although encouraged, is not mainstream in coach education and usually represented (i.e., written) as realist tales (e.g., case studies) (Van Maanen, 2011). In contrast, recent research suggests that coaches prefer stories in video format due to the communication of emotional, verbal, and non-verbal behaviors, which underpins the complexity of psychosocial and sociocultural coaching practice (Szedlak et al., 2018). Thus, the aim of this presentation is to outline practical steps of (1) how to write research-based stories using creative analytical practices and (2) the process of developing video stories to highlight their potential to promote effective psychosocial and sociocultural coaching practice. We wrote and produced three video stories that portrayed ineffective psychosocial and sociocultural coaching practice, including issues such as: ableism, ageism, sexism, racism, and unequal power-relationships. As part of a broader project (funded by the Social Science and Humanities Council of Canada), these video stories will be utilized as a learning tool for strength and conditioning coaches to reflect on opportunities and gaps within their formal coach education to identify psychosocial and sociocultural competencies. Outlining the steps taken to develop and utilize these video stories, we aim to demystify the process of how to effectively use video stories and encourage coach educators to more readily include video stories as a learning tool in coach education.

\section{References}

Szedlak, C., Smith, M., Day, M., \& Callary, B. (2019). Examining the use of diverse vignette formats to translate knowledge to strength and conditioning coaches. International Sports Coaching Journal, 6(2), 199-210. https://doi.org/10.1123/iscj.2018-0027

Van Maanen, J. (2011). Tales of the field: On writing ethnography. University of Chicago Press.

\section{Presenter Biography}

Dr. Christoph Szedlak is an academic, researcher and the Lead S\&C coach at the University of Southampton and has worked with a variety of different level athletes including Olympic, and World champions for over thirteen years. His research focuses on examining the psychological and social aspects of coaching and their impact on athletes' development. With a specific emphasis on innovative qualitative methods to present and disseminate findings, his research has gained international recognition within S\&C coach development and education.

\section{$\mathbf{T}$}

Coaches' Beliefs, Emotional Intelligence and Reactive Behaviors in Soccer Games

Teques, Pedro ${ }^{1,2} \&$ Duarte, Daniel ${ }^{1}$

${ }^{1}$ N2i, Instituto Politécnico da Maia, Maia, Portugal; ${ }^{2}$ CIPER, Faculdade de Motricidade Humana, Universidade de Lisboa, Portugal

Emotional intelligence (EI) has become an increasingly popular topic of research in psychology but has been largely unexplored in terms of its potential influence on coaching behaviors in competitive settings. Coaches' perceptions of their emotional ability can be considered a personal characteristic that is predictive of their efficacy beliefs, which, in turn, is predictive of their behavior in competitive settings (Horn, 2008). Thus, the purpose of this study was to determine whether coaches' efficacy 
beliefs mediated the relationship between EI and coaches' reactive behaviors during a game using a mixed method approach. Observations using Coaching Behavior Assessment System were carried on 258 football games during two seasons. At the end of each game, coaches were approached and asked to complete the Wong and Law Emotional Intelligence Scale and the Coaching Efficacy Scale. Findings revealed that motivation efficacy mediated the association between regulation of emotion and positive coaches' reactions, and the relationship between regulation of emotion and negative coaches' reactions was mediated by motivation efficacy and character building. Findings of this study would seem to suggest that an emotional intelligent coach would perceive high beliefs of coaching efficacy to motivate and to build character of their athletes, and this perception has an impact on their coaching positive reactions in response to both positive and negative athletes' performances.

\section{References}

Horn, T. (2008). Coaching effectiveness in the sports domain. In T. Horn (Ed.), Advances in sport psychology (3rd Ed.). Human Kinetics.

\section{Presenter Biography}

Pedro Teques is a lecturer in sport psychology in the Polytechnic Institute of Maia. He is also a chartered psychologist with the Order of Portuguese Psychologists. For over a decade, he has consulted with coaches, parents, athletes, and referees across several sports (e.g., football, gymnastics, trap shooting). At this moment he collaborates with the Referees' Committee of the Portuguese Football Federation.

\section{Coach Like a Woman in Combat Sports}

Tuunainen, Sari \& Erdogan, Sanna

\section{Finnish Coaches Association, Helsinki, Finland}

The initiative called "Coach Like a Woman" was founded in the autumn of 2013. The initiative ran very successfully from autumn 2013 to end of 2019 with a focus on team ball sports. From the beginning of 2020, a new 2 year-long project started within the Coach like a Women initiative focusing specifically on combat sports and weightlifting. The goal of this project is to increase the number of female coaches and especially at the elite level, as well as supporting and building a network for the women who are already on their coaching paths. The goal is pursued through two different aspects: (1) by inspiring former athletes, or athletes at the end of their competition carriers, to become coaches, and (2) by encouraging female coaches to extend their coaching competences and take on new challenges. Altogether, 10 sports associations as well as Professional Coaches of Finland, Finnish Olympic Committee and the Finnish Paralympic Committee are project partners. The project lead is the Finnish Coaches Association, and the initiative is financially supported by the Ministry of Education and Culture. The main finding of the project was that it is possible to increase equality in coaching with long-term activities which are executed with determination. The number of female coaches increased within national teams' staff as well as at the highest league level.

\section{Presenter Biography}

Sari Tuunainen holds a master's degree in Sport Sciences from the University of Jyväskylä. She also graduated with an Executive Masters in Sport Organisations Management (MEMOS) under the supervision of the Université de Poitiers. Her current position is Executive Director at the Finnish Coaches Association, which is the home base for around 4000 coaches in Finland.

\section{W \\ Understanding the Flow of Informal Coaching Knowledge in Social Networks}

Walker, Lauren

Elon University, Elon, NC, United States

Coaches frequently engage in and show a clear preference for informal means of learning, specifically from other currently practicing coaches (Erickson et al., 2008; Walker et al., 2018). However, these informal social networks of coaches are not well understood. To better understand how these informal coach networks function, the purpose of this study was to compare the structure of two informal coach adviceseeking networks and understand the type of knowledge shared between coaches. As the first part of a mixed method study, a social network analysis was conducted with coach members of two USA Swimming local swim committees (LSCs). Roughly $15 \%$ of the total coaches within each LSC participated in the study $(\mathrm{N}=97)$. Results, across both LSCs, reflected connection in the coaching network that transcended geography and/or competing clubs. Further, each network had coaches who exhibited both high closeness centrality (i.e., they were at the center of the network) and high betweenness centrality (i.e., they helped connect disparate parts of the network), reflecting their importance in connecting coaches who may not normally interact. Results also highlighted that coaches prefer seeking coaching advice and knowledge from other coaches on a variety of topics, with no clear topical preference present in coach-to-coach interactions. In seeking to continually grow coaching knowledge, this study highlights the potential use of identifying and using social capital, in the form of central coaches in a regional sport network, to quickly and effectively transmit best practice or new information to coaches in sport.

\section{References}

Erickson, K., Bruner, M., MacDonald, D., \& Côté, J. (2008). Gaining insight into actual and preferred sources of coaching knowledge. International Journal of Sports Science and Coaching, 3(4), 527-538.

Walker, L.F., Thomas, B., \& Driska, A. (2018). Informal and non-formal learning for sport coaches: A systematic review. International Journal of Sports Science and Coaching, 13(5), 694-707.

\section{Presenter Biography}

Lauren Walker is an Assistant Professor of Exercise Science at Elon University in North Carolina. Her recent research work has examined the spread of implicit bias through social networks and the impact of informal meanings of learning (e.g., social media groups, social networks) in the education of a youth sport coach. She has worked in conjunction with several sport community partners at the state and national level in the United States in applied research-to-practice projects.

\section{Coaching on the Talent Pathway: The Influence of Developmental Experiences on Coaching Philosophy}

Williams, Graham ${ }^{1} \&$ MacNamara, Áine ${ }^{2}$

${ }^{1}$ Faculty of Science and Health, School of Health and Human Performance, Dublin City University, Dublin, Ireland and Millfield School, Street, United Kingdom; ${ }^{2}$ Faculty of Science and Health, School of Health and Human Performance, Dublin City University, Dublin, Ireland

There is compelling evidence supporting the critical role of high-quality coaching practice in supporting talented youth athletes through and beyond 
the talent pathway. The purpose of this study was to explore the coaching philosophies of ex-pathway athletes and explore how the meaning and purpose of their coaching was influenced by their previous pathway experience. Driven by a pragmatic research philosophy, a qualitative research strategy was adopted utilising semi-structured one to one interviews. Nine participants were purposefully sampled based upon their prior involvement as a youth athlete in a talent pathway and current involvement coaching in a talent pathway. Participants identified how their pathway experience influenced their coaching philosophy and applied coaching practice. Specifically, participants described how their own youth sport experience influenced their current coaching practice; specifically, the importance of emphasising personal skill development and the need to support each individual athlete through their dynamic developmental journey. These findings suggest the philosophy underpinning talent pathway coaches' practice was influenced by their own pathway experience and the purpose of their practice was orientated to positively impacting youth development. Thus, talent pathways in sport have the capability to be recognised as positively influencing the developmental experiences of future coaching practitioners. Talent pathway stakeholders could provide the opportunity to prepare youth athletes for a career in coaching through, but not limited to, the early exposure to sport coaching courses, supporting practical sport coaching experience and scaffold discussions about their lived experiences as a youth athlete and the transferable skills they have acquired.

\section{Presenter Biography}

Graham Williams is an accredited strength and conditioning coach working in a leading talent development environment in the United Kingdom. Graham has a master's degree in strength and conditioning and is undertaking a professional doctorate in the field of talent development in sport. Graham's research explores the true value of the talent pathway from those youth athletes that didn't make it to the top, previous pathway athletes now coaching on the pathway and early years talent pathway athletes.

\section{The Best of Both Worlds? A Joint Reflection on One Higher Education Coach Education Program}

Wilson, Charles ${ }^{1} \&$ Murphy, John ${ }^{1}$

${ }^{1}$ Georgia Southern University, Statesboro, GA, USA

Sport coaching has been clearly established as a complex activity that can vary widely by context. Similarly, coach education (CE) programs mirror that complexity in their curriculum and delivery. The two primary delivery methods of formal $\mathrm{CE}$ are through higher education (HE) or through National Governing Bodies, federations, or other sport-specific organizations. There are numerous studies on sport-specific CE, such as recent examples examining women coaching Australian Rules Football (Carson et al., 2021) and women coaching rugby (Barrett et al., 2021). However, Trudel and colleagues (2020) noted a lack of studies on CE in higher education. The purpose of this presentation is to share a joint reflection on a fully online, higher education CE master's program at Georgia Southern University from the perspective of an alumnus with extensive sport-specific training from US Soccer and UEFA and a professor who helped guide the program through national accreditation. Following Madden \& GillardOwen's (2018) example from nursing, the goal of this joint reflection is to collaboratively share individual experiences that provide a deeper understanding of the impact of a higher education CE program and its effectiveness for coach development. Together, we reflected on the program in its entirety, including the technology utilized in coursework. Furthermore, the significance of this joint reflection lies in sharing insights that may help guide curriculum and delivery improvements in both HE and sport-specific
CE, while respecting Garner, Roberts, Turnnidge, \& Côté's (2021) assertion that coach eductors should be allowed flexibility in their specific behaviors.

\section{References}

Barrett, G. M., Sherwin, I., \& Blackett, A. D. (2021). Women rugby union coaches? Experiences of formal coach education in Ireland and the United Kingdom: A qualitative study. Women in Sport \& Physical Activity Journal, 29(1), 29-37.

Carson, F., McCormack, C., McGovern, P., Ralston, S., \& Walsh, J. (2021). Coach like a woman: Learnings from a pilot coach education program. Women in Sport \& Physical Activity Journal, 29(1), 68-73.

Garner, P., Turnnidge, J., Roberts, W., \& Côté, J. (2021). How coach educators deliver formal coach education: A full range leadership perspective. International Sport Coaching Journal, 8(1), 23-33.

Madden, G., \& Gillard-Owen, L. (2018). "What you put in, you get out”. A joint reflection on practice development days. International Practice Development Journal, 8(2), 1-7. https://doi.org/10.19043/ipdj.82.009

Trudel, P., Milestetd, M., \& Culver, D. M. (2020). What the empirical studies on sport coach education programs in higher education have to reveal: A review. International Sport Coaching Journal, 7(1), 61-73.

\section{Presenter Biography}

Charles "Hal" Wilson, Jr. Ph.D. is an Associate Professor of Coaching Education at Georgia Southern University, just the second university in the US to earn national accreditation in coach education at both the undergraduate and graduate levels. Wilson is also on the Board of Directors of the United States Center for Coaching Excellence (USCCE), the Sport Coach America Coach Development Team, and is an Inclusive Excellence Faculty Fellow.

\section{$\mathbf{Y}$}

\section{My 1st Coach: DEX Your Way Through FUNdamentals}

Yusof, Azhar; Ng, Bryan; \& Ng, Annabelle

\section{CoachSG Singapore}

Children's key milestones in life often start at home. Parents' own competencies, abilities to provide teachable moments, and create a positive environment around the child during these key formative years often set the foundation for shaping of important character and values, life skills, habits, essential problem-solving skills and physical literacy. Research has shown that Fundamental Movement Skills (FMS) are a crucial contributor to a healthy lifestyle in early childhood and a significant factor that is associated with an adolescents; participation in organised physical activity (Okley et al., 2001) and therefore is considered a vital part of a child's development. A recent study also showed that parent education as well as the home physical environment was positively associated with a child's locomotor skills. (Nan Zeng et al., 2019). Thus, parents are indeed every child's first coaches, yet this crucial group of stakeholders are often overlooked and under emphasised in the development of educational curriculum in our ecosystem today. Conceived based on the importance of developing Physical Literacy through FMS, the My 1st Coach Programme aims to equip parents with pedagogical knowledge and experience in creating a positive environment for the exploration of FMS with their child. Through this session, CoachSG hope to share the pedagogical design behind the My 1st Coach Programme and our innovative approaches to aid parents' learning through the creation of user-friendly acronyms, such as the importance of ensuring "F.U.N" (Fundamentals; Understanding; Nurturing), "Developing Ambi(DEx2)terity" through "Discover. Explore. Experiment". 


\section{References}

Nan Zeng, S., Johnson, R., Bellow, B., \& Bellow, L. (2019). Socialecological correlates of fundamental movement skills in young children. Journal of Sport and Health Science, 8(2), 122-129.

Okley, A., Booth, M., \& Patterson, J. (2001). Relationships of physical activity to fundamental movement skills among adolescents. Medicine and Science in Sports and Exercise, 33(11). 1899-1904.

\section{Presenter Biography}

Azhar Yusof is the Head of CoachSG; leading the coaching education and development across all sports in Singapore. Azhar has a diverse background; having been a former national athlete, an international referee, and a coach of multiple sports. A teacher by training, he headed the PE Department in school before joining the National Institute of Education (NIE)/Nanyang Technological University (NTU) where he was a Senior Lecturer and Assistant Head (Teaching) at the PE \& Sport Academic Group.

\section{My 1st Coach - A Game Changer in Athletic Development}

Yusof, Azhar; Ng, Annabelle; \& Ng, Bryan

CoachSG, Singapore

Parents play an important role in guiding the child through their foundational experiences with physical literacy, health, fitness, character and values inculcation. Extensive research has shown that parents can affect their children's physical activity involvement through their role-modelling of physical activity and beliefs about their child's competence (Bois et al., 2005). Parents also facilitate the involvement of their children in sport by providing children with resources, equipment, encouragement, and opportunities for participation in sport (Fraser-Thomas \& Côté, 2009). Thus, parents are indeed every child's first coaches. Born out of the recognition that parents are key multipliers of the sport ecosystem, the My 1st Coach Programme embraces the belief that \#SportStartsAtHome. Carefully curated to cater to the needs and challenges that parents face in their interaction with their child or family, parents were equipped with knowledge and skills of the key building blocks of FMS, Health and Wellness habits, as well as Character and values, to aid in nurturing their child's holistic development at home. Parents were also able to apply what they have learned after each session by co-creating games with their children to inculcate joy of learning through play. This helps to cultivate a positive environment that promotes experiential learning. Thus, we will share with participants what we have done in our pilot programme to encourage cocreation of games with children at home.

\section{References}

Bois, J., Sarrazin, P., Brustad, R.,Trouilloud,D., \& Cury, F. (2005). Elementary school children's perceived competence and physical activity involvement: The influence of parents' role modelling behaviours and perceptions of their child's competence. Psychology of Sport and Exercise, 6, 381-397.

Fraser-Thomas, J., \& Côté, J. (2009). Understanding adolescent's positive and negative developmental experiences in sport. The Sports Psychologist, 23(1), 3-23.

\section{Presenter Biography}

Azhar Yusof is the Head of CoachSG; leading the coaching education and development across all sports in Singapore. Azhar has a diverse background; having been a former national athlete, an international referee, and a coach of multiple sports. A teacher by training, he headed the PE Department in school before joining the National Institute of Education (NIE)/Nanyang Technological University (NTU) where he was a Senior Lecturer and Assistant Head (Teaching) at the PE \& Sport Academic Group.

\section{DREAM: An Innovative Strategy for Teaching and Coaching}

Yusof, Azhar; Ng, Annabelle; \& Ng, Bryan

CoachSG, Singapore

As research and practices in physical education (PE) and sport advance, they inform us on new and innovative ways to better engage our learners effectively. The introduction of contemporary pedagogies such as constraints-led and non-linear pedagogies often challenge current practitioners as they may be set in their ways of teaching and coaching, and their idiosyncrasies. It may also leave many practitioners struggling to interpret them correctly thereby rendering their application less than optimal. There is a need therefore to simplify new theories, connect them to existing theories and practice, and develop an approach that integrates them coherently. DREAM is an innovative approach to teaching and coaching sport that achieves all that. It is a learner and game-centred approach that integrates Teaching Games for Understanding (TGFU), Spectrum of Teaching Styles (SOTS), Constraints-Led and Non-Linear Pedagogies and more, in teaching and coaching, encapsulated in the acronym, DREAM. This approach seeks to develop better learners, better movers, and better athletes from grassroots to high performance. In this presentation, participants will be introduced to the DREAM approach and how it can be applied in creating activities and games that truly engages learners effectively.

\section{Presenter Biography}

Azhar Yusof is the Head of CoachSG; leading the coaching education and development across all sports in Singapore. Azhar has a diverse background; having been a former national athlete, an international referee, and a coach of multiple sports. A teacher by training, he headed the PE Department in school before joining the National Institute of Education (NIE)/Nanyang Technological University (NTU) where he was a Senior Lecturer and Assistant Head (Teaching) at the PE \& Sport Academic Group. 


\section{Coaching Practice}

(in alphabetical order by first author's last name) 


\section{A}

\section{Expert, Effective and Ethical Coaching Olympic Sport Settings - Finding the Line}

Abraham, Andrew ${ }^{1}$; Lyle, John ${ }^{1}$; North, Julian ${ }^{1}$; Bercial, Sergio Lara ${ }^{1}$; Till, Kevin ${ }^{1}$; Ashford, Mike ${ }^{2}$; \& Norris, Luke ${ }^{3}$

${ }^{1}$ Research Centre for Sport Coaching, Leeds Beckett University, UK; ${ }^{2}$ Faculty of Health and Life Sciences, Coventry University, Coventry, UK; ${ }^{3}$ Hartpury University, Gloucestershire, UK

Relatively little is known about coaching systems within Olympic sport settings. Subsequently, professional development programmes for coaches in these settings lack evidence to draw upon to support design and delivery. Being aware, UK Sport commissioned a review of coaching in four funded sport settings assumed to be expert, effective and ethical (3 Es). Paralympic (2) and Olympic (2) sports were purposefully contacted. From each sport, a senior manager, head coach, assistant coach, sport scientist, and a focus group of athletes were asked and agreed to participate in the study. Interviews lasted 45 - 90 minutes. Interviews were structured to access views on the 3 Es. The need for expertise was contextualised as being an essential underpinning for effectiveness. The six domains of expertise previously identified by (Abraham et al., 2010) were highlighted. The importance of being able to predict future sport demands for medals was highlighted. Numerous strategies for effectiveness were identified. A universal strategy was the development of critical, trusting, relationships across athlete and support team. Examples of ethical practice as deductively aligned with ideas from medical ethics were consistently apparent. However, alignment was largely based upon being good people with good values. In conclusion, an effective coach in this setting was defined as one who evidences consistent achievement of medals or highly challenging goals through an ethical integrated system and interpersonal problemsolving approach. Effective environments existed where there was a culturally and strategically aligned environment. Ethical practice was typical, but its development was not formal.

\section{Reference}

Abraham, A., Muir, B., \& Morgan, G. (2010). UK Centre for Coaching Excellence Scoping Project Report: National and International Best Practice in Level 4 Coach Development. Sports Coach UK.

\section{Presenter Biography}

Dr. Andrew Abraham is the Head of Subject for Sport Coaching at Carnegie School of Sport, Leeds Beckett University. He has been at the university since 2007. The group supports the Research Centre for Sport Coaching while also providing undergraduate, postgraduate and doctoral programmes in sport coaching and coach development.

Coach Decision-Making in Futsal: From Preparation to Competition Almeida, João ${ }^{1}$; Travassos, Bruno ${ }^{2}$; Sarmento, Hugo ${ }^{3}$; \& Kelly, Seamus ${ }^{4}$

${ }^{1}$ Loughborough University, Loughborough, United Kingdom; ${ }^{2}$ Beira Interior University, Covilhã, Portugal; ${ }^{3}$ Coimbra University, Coimbra, Portugal; ${ }^{4}$ University College Dublin, Dublin, Republic of Ireland

The purpose of this paper was to analyse the process of decision-making from preparation to competitive moments of expert futsal coaches. Ten expert and professional coaches $(M=46,9$ - 7,93 years old and $M=15,4$ 7,22 years of coaching experience) from different countries were interviewed using a semi-structured interview (quantitative and qualitative) with two different goals: (1) evaluate the preparation for decision-making moment during the game; (2) classifying the importance of different game related points for decision-making during match moment. The data analysis was processed through combination of deductive and inductive methods through software QSR NVivo 11. The results revealed that coaches' share similar ideas to prepare their teams. That is, coaches focus first on their own team identity and frame and second on opposition team behaviour and frame. It was also possible to identify clear coaching behavioural signs possible to be structured as cues and guiding lines for their decision-making process and actions before and during competitive moments. Such information can be important for the development of most appropriated coaching education curriculums according to game demands specificities and to improve futsal coaches' decision-making capacity, thus improving their effectiveness and impact during games.

\section{Presenter Biography}

João Almeida has a Master's degree in Sports Science from Beira Interior University, is a UEFA B Futsal Coach, and currently a Loughborough University Futsal Head Coach and programme lead. Previously Almeida was Head Coach of Bahrain National Team. Almeida has coaching experience in Portugal in several clubs and was U20 National Champion. Parallel to it, Almeida was also a Physical Education Teacher in different schools and contributor to Futsal Programme Development projects with different FA's.

\section{B}

Stress and Mental Well-Being Experiences of Elite Football Coaches Baldock, Lee ${ }^{1}$; Cropley, Brendan ${ }^{1}$; Neil, Rich $^{2} ;$ \& Mellalieu, Stephen. D. ${ }^{2}$

${ }^{1}$ University of South Wales, Pontypridd, Wales; ${ }^{2}$ Cardiff Metropolitan University, Cardiff, Wales

Despite researchers examining the stress and coping experiences of elite coaches (see Norris et al., 2017), many have considered the components of the stress process in isolation, lacked sport-specific insights, and overlooked the wider impact of stress on mental well-being. Consequently, we aimed to explore: (a) the stress experiences of elite football coaches; and (b) the impact of these experiences on their well-being and how they function in their personal and professional lives. Following receipt of institutional ethics-board approval, semi-structured interviews were conducted with eight, purposively sampled English Premier League first-team coaches. Data were analysed via thematic and causal network analyses, identifying that: (a) a range of contextually dependent demands were experienced and interpreted in relation to their situational properties; (b) many demands were appraised and emotionally responded to in a negative manner; (c) a range of coping strategies were adopted, but many were reported as being ineffective; and, (d) stress experiences often led to negative implications for participants' mental well-being. Positive adaptations to some demands experienced were reported, which augmented perceptions of mental well-being. These findings highlight the importance of elite football coaches becoming more aware of, and becoming better equipped, to cope with the demands associated with their roles to avoid potential negative implications for 
their mental well-being. The findings have led to the development of coach education interventions, aimed at helping elite football coaches become more aware of their own role-related stress and mental wellbeing experiences. These have been integrated into a national association's UEFA Professional Licence.

\section{References}

Norris, L., Didymus, F., Kaiseler, M. (2017). Stressors, coping, and wellbeing among sports coaches: A systematic review. Psychology of Sport and Exercise, 33, 93-112. https://doi.org/10.1016/j.psychsport.2017.08.005

\section{Presenter Biography}

Lee Baldock is a doctoral student and lecturer in the School of Health, Sport and Professional Practice at the University of South Wales. His primary research interests lie in exploring the stress and well-being of elite football coaches and attempting to better support coaches with the demanding nature of their roles. He is also a first team player/coach in the second tier of Welsh football and has provided a range of sport psychology consultancy services to athletes and coaches.

\section{Coaching Behavior as Predictor of Athlete Satisfaction}

Belleza, Saramie S.

\section{UM Tagum College, Philippines}

This study determines which domain in the coaching behavior of coaches significantly predicts athlete satisfaction. A quantitative nonexperimental design using correlational method was used in this study. A total of 179 respondents belonging to the randomly selected high school and college athletes in UM Tagum College. The researcher utilized the two standardized questionnaires to measure the two variables. To measure coaching behavior, the researcher used the Coaching Behavior Scale for Sport and for the athlete satisfaction, Athlete Satisfaction Questionnaire was used. Results indicated that coaching behavior of athletes is high while satisfaction of athletes is much satisfied. There is a significant relationship between coaching behavior and athlete satisfaction. Physical training and conditioning, technical skills, goal setting, competition strategies and personal rapport are domains in coaching behavior of coaches that significantly predicts satisfaction of athletes. On the other hand, mental preparation does not significantly predict athlete satisfaction. The findings of this study provide important inputs to the coaches to strengthen and achieve extreme satisfaction of athletes.

\section{Presenter Biography}

Saramie S. Belleza, is a graduate of Bachelor of Science in Physical Education at Mindanao State University, Marawi City, Philippines. She took her Master's degree at St. Mary's College Inc., at Tagum City, Philippines with the degree of Master's of Arts in Education, major in Physical Education. She is now currently enrolled at the University of the Visayas, Cebu City, taking up Doctor of Education in Physical Education. She is presently teaching at UM Tagum College as an Associate Professor.

\section{A Systematic Review on the Influence of Practice Design and Coaching on Skill Acquisition in Soccer}

Bergmann, Fynn ${ }^{1}$; Gray, Rob ${ }^{2}$; Wachsmuth, Svenja ${ }^{1}$; \& Hüner, Oliver ${ }^{1}$

${ }^{1}$ University of Tuebingen, Tuebingen, Germany; ${ }^{2}$ Arizona State University, Phoenix, USA
One major challenge for soccer coaches is to design practice sessions that effectively foster players' acquisition of soccer-specific skills (Williams \& Hodges, 2005). To support coaches within this process, research should provide evidence-based information about the effectiveness of practice and coaching methods to determine which of these offer the best potential for the acquisition of skills within distinct sport domains. The aim of this systematic review was to investigate "pitchbased" intervention studies that investigated the influence of different practice designs and coaching behaviors on perceptual-motor and perceptual-cognitive outcomes in soccer. A systematic review protocol providing detailed information on the review process was pre-registered in the Open Science Framework (Bergmann et al., 2020). The analysis focuses on three overarching aspects. First, theoretical approaches on skill acquisition as well as applied practice designs and coaching behaviors are examined. Second, the research methodologies - in particular the study designs and instruments used, as well as the quality in reporting and risk of bias (Downs \& Black, 1998; Hoffmann et al., 2014) - are investigated and compared. Third, the interventions' effectiveness on perceptual-motor and perceptual-cognitive outcomes are evaluated. In total 35 individual studies, including theory-driven but also atheoretical interventions on a multitude of aspects were identified. Large heterogeneity regarding methodological approaches, dependent variables, and effects were present. Nevertheless, the reviewed studies provide insights into the potential of different practice methods. For instance, studies investigating instructional approaches allow the cautious conclusion that methodologies encouraging players' self-exploration within representative scenarios seem to facilitate the development of both perceptual-motor and perceptual-cognitive skills. Future research would benefit from more high-quality studies regarding clearly outlined research hypotheses, detailed intervention descriptions, and sufficient statistical power.

\section{References}

Bergmann, F., Gray, R., Wachsmuth, S., \& Hüner, O. (2020). The influence of practice design and coaching behavior on skill acquisition in soccer: A systematic review protocol (PRISMA-P). https://doi.org/10 .17605/OSF.IO/NUYZP

Downs, S. H. \& Black, N. (1998). The feasibility of creating a checklist for the assessment of the methodological quality both of randomised and nonrandomised studies of health care interventions. Journal of Epidemiology and Community Health, 52(6), 377-384. https://doi.org/10.1136/jech.52 .6 .377

Hoffmann, T. C., Glasziou, P. P., Boutron, I., Milne, R., Perera, R., Moher, D., Altman, D. G., Barbour, V., Macdonald, H., Johnston, M., Lamb, S. E., Dixon-Woods, M., McCulloch, P., Wyatt, J. C., Chan, A. W., \& Michie, S. (2014). Better reporting of interventions: template for intervention description and replication (TIDieR) checklist and guide. BMJ, 348, g1687. https://doi.org/10.1136/bmj.g1687

Williams, A. M. \& Hodges, N. J. (2005). Practice, instruction and skill acquisition in soccer: Challenging tradition. Journal of Sports Sciences, 23(6), 637-650. https://doi.org/10.1080/02640410400021328

\section{Presenter Biography}

Fynn Bergmann is a research assistant and Ph.D. student within the research group of Sport Psychology and Research Methods at the Institute of Sports Science of the University of Tuebingen, Germany. His research focuses on sports coaching, skill acquisition, and talent development. Fynn is currently enrolled within the UEFA A-License and holds the Goalkeeping Coach for Performance Football certificate from the German 
Football Association. He has multiple years of experience coaching both youth soccer teams as well as senior sides.

\section{Learning to Lead: Developing a Leadership Structure in a Team Environment}

Bowles, Richard \& O’Dwyer, Anne

Mary Immaculate College, Limerick, Ireland

The development of effective leadership structures impacts positively on the functioning of sports teams (Cotterill \& Fransen, 2016). Athlete empowerment can be facilitated when coaches help their athletes to develop leadership and personal responsibility (Miller \& Kerr, 2002). In team sport contexts, coaches can scaffold effective athlete leadership though mentoring (Mallett et al., 2015), with potential benefits for individual players, and for the whole team (Mead \& Gilson, 2017). In this paper, two coach-researchers adopted a self-study research approach (LaBoskey, 2004) to explore how our coaching practices supported athletes to take on leadership roles within a female Gaelic football team over the course of a university-level playing season. We selected five players to form a leadership group and linked closely with this group throughout the season to mediate feedback and communication amongst the team. We, as coaches, facilitated much of the leadership group's actions. Data generation included coaches' reflective diaries, coaches' discussions with two critical friends, and a focus group interview with the player leaders designed to gain insight into their perspectives and experiences as leaders. We conducted a thematic analysis of the qualitative data, and our learning as coaches is summarized in the form of three central themes: (1) Understanding the specific team context, (2) Negotiating expectations, and (3) Agreeing tangible roles and tasks. These findings identify effective strategies to support players' efforts to lead and highlight some areas where we could improve our practice. It builds on existing research suggesting leadership development is a complex, nonlinear process.

\section{References}

Cotterill, S. T., \& Fransen, K. (2016). Athlete leadership in sport teams: Current understanding and future directions. International Review of Sport and Exercise Psychology, 9(1), 116-133. https://doi.org/10.1080/ 1750984X.2015.1124443

LaBoskey, V. K. (2004). The methodology of self-study and its theoretical underpinnings. In J. Loughran, M. L. Hamilton, V. K. LaBoskey, \& T. Russell (Eds.), International handbook of self-study of teaching and teacher education practices (pp. 817-869). Springer.

Mallett, C. J., Rynne, S., \& Emmett, M. (2015). Mentoring high-performance athletes. In F. Chambers (Ed.), Mentoring in physical education and sports coaching (pp. 172-179). Routledge.

Mead, J., \& Gilson, T. A. (2017). One high school basketball coach's selfstudy of leadership development. Sports Coaching Review, 6(1), 1-19. https://doi.org/10.1080/21640629.2016.1173447

Miller, P. S., \& Kerr, G. A. (2002). Conceptualizing excellence: Past, present, and future. Journal of Applied Sport Psychology, 14(3), 140-153. https://doi.org/10.1080/10413200290103464

\section{Presenter Biography}

Richard Bowles is a teacher educator, lecturing in the area of primary school physical education. He is also a volunteer Gaelic football coach. His interest in the self-study research methodology has enabled him to explore his own teaching and coaching practices. In a physical education context, this involves a focus on providing meaningful experiences through his research with the Learning About Meaningful PE (LAMPE) group; in coaching, it centres on a collaborative self-study of athlete-centred coaching with Anne O'Dwyer.

\section{The Role of Coaches in the Integration of Young Refugees Through Sports}

Capalbo, Lucas S. ${ }^{1}$ \& Carlman, Peter $^{2}$

${ }^{1}$ Mission 89, Geneva, Switzerland; ${ }^{2}$ Karlstad University, Karlstad, Sweden Sport participation can help refugees rebuild trust and cope with traumas (Oliff, 2008), as well as promote prosocial behaviors and lower peer problems (Nathan et al., 2013). The literature recommends "integration to mainstream clubs" in the country of resettlement as the ideal format to promote integration (Block \& Gibbs, 2017). However, many clubs and coaches may be unprepared to host young refugee athletes. For instance, clubs lack integration policies and coaches are untrained to promote integration (Agergaard \& Sørensen, 2010). Coaches often question whether integration should be promoted through equal treatment or more leeway (Agergaard, 2011). Based upon these obstacles, this study discusses the role of coaches in two sport-based programs for the integration of young refugees in Sweden and the US. The Swedish program used federal government fund to help provide newly arrived refugees with the opportunity to play sports in established clubs, whereas the US program was a local initiative that promoted integration and academic advancement of adolescent refugees through soccer. Data was collected from interviews with 16 participants (7-16 years old) from the Swedish program and 9 participants (15-18 years old) from the US program. The results showed that the US coaches had a better cultural understanding and promoted integration deliberately. Conversely, the Swedish coaches were more experienced in coaching, but did not adapt their programs to the refugees' needs. Even though the participants did not perceive to have adjusted to the local sport culture nor made friends with non-refugee peers, most mentioned similar benefits from taking part, such as connecting with other refugees and learning the local language.

\section{References}

Agergaard, S. (2011). Development and appropriation of an integration policy for sport: How Danish sports clubs have become arenas for ethnic integration. International Journal of Sport Policy and Politics, 3(3): 341-353.

Agergaard, S., \& Sørensen, J. K. (2010). Policy, sport and integration: The case of talented ethnic minority players in Danish football club. International Journal of Sport Policy, 2(2): 205-221.

Block, K., \& Gibbs, L. (2017). Promoting social inclusion through sport for refugee-background youth in Australia: Analyzing different participation models. Social Inclusion, 5(2): 91-100.

Nathan, S., Kemp, L., Bunde-Birouste, A., MacKenzie, J., Evers, C., \& Shwe, T. A. (2013). We wouldn't of made friends if we didn't come to football united: The impacts of a football program on young people's peer, prosocial and cross-cultural relationships. BMC Public Health, 13, $1-16$.

Oliff, L. (2008). Playing for the future: The role of sport and recreation in supporting refugee young people to "settle well" in Australia. Youth Studies Australia, 27(1): 52-60. 


\section{Presenter Biography}

Lucas Capalbo holds a Ph.D. in Kinesiology specializing in the psychosocial aspects of sports. Lucas has focused his research and applied practice for the promotion of refugee integration and life skills. He has a vast international experience in the field and has developed and assessed various sport-for-development and coaching education programs. Lucas currently serves as a Research Assistant for Mission 89 where he investigates human trafficking and modern slavery in sports, and as a professional youth soccer coach.

\section{From a Punitive to a "Wise(r)" Model of Coaching: A Case Study in a Women's Artistic Gym in Brazil}

Costa, Vítor Ricci ${ }^{1} \&$ Nunomura, Myrian ${ }^{2}$

${ }^{1}$ State University of Campinas, Campinas-São Paulo, Brazil; ${ }^{2}$ University of São Paulo, Ribeirão Preto-São Paulo, Brazil

In Women's Artistic Gymnastics (WAG), the coach-gymnast relationship is at the heart of coaching. This unique relationship has been criticized for producing authoritarian coaches, harsh, and "disciplinary" training practices, which creates docile gymnasts with little voice to question. In addition, the athletes are commonly children and youth and their health and wellbeing are at stake. Therefore, the purpose of this research was to explore the potential effects of power on both coaches' and athletes' outcomes, including wellbeing and performance within a WAG coaching micro-reality. The research was designed as a case study within a highperformance gymnasium in Brazil. The data production included participant observations and interviews with coaches, gymnasts, and parents. We present the data as an essayist research story to encourage readers to think with and about the story, but not finalize any interpretations that might be made. The story highlights the case of the gymnast Isis (11-years-old), who faced troubles regarding her performance and her wellbeing (safety and fulfillment). Drawing upon this context we discuss the difference between the counter-productive use of condition as punishment and an open communication between the coach and the gymnast to find "smart(er)" solutions for the troubles. Not least, following the story, drawing on a Foucauldian framework, we discuss how particular unwritten norms become normalized in WAG coaching practice. Finally, we reflect about coaches and gymnast active roles (in shifting from punishment to discipline and training hard to training wise[r]) as subjects within a context of particular discourse, power relations, and practices.

\section{Presenter Biography}

Vítor Ricci Costa is a Ph.D. student at the State University of Campinas Brazil. In the last years, he has been investigating the current situation of WAG coaching practice, using their knowledge in qualitative research in the sociological studies of Sport and through a Foucauldian lens.

Professor Myrian Nunomura's expertise relates to coaching and training practices; career development; and coach education. Since 2012, she has been a consultant for artistic gymnastics coach education with the Brazilian Olympic Committee.

From Paper to Pitch: Applying a Masters Team Sport Model to Community Sport Practice

Currie, Chelsea ${ }^{1}$; Callary, Bettina ${ }^{2}$; \& Young, Bradley W. ${ }^{3}$

${ }^{1}$ Cape Breton Regional Municipality \& Cape Breton University, Sydney, Nova Scotia, Canada; ${ }^{2}$ Cape Breton University, Sydney, Nova Scotia, Canada; ${ }^{3}$ University of Ottawa, Ottawa, Ontario, Canada
Women's sport is often part of a woman's identity (Stevenson, 2002), acts as a venue for social engagement (Kirby \& Kluge, 2013), and improves overall health and wellbeing (Bennett et al., 2017). Women's sporting identities and motives can be supported by a coach through developing and nurturing interdependent relationships (Currie et al., under review). My master's thesis resulted in the development of the Masters Team Sport Model of Interdependence (TSMI) to illustrate how coaches can foster relationships in a team between coach-athlete dyads, between athletes, and amongst the team as a whole in coached Masters sport (Currie et al., 2019). Now, as the Recreation Program Coordinator for adult and senior recreation in the Cape Breton Regional Municipality, I plan, develop, facilitate, and coach women's Masters sport programs. Much like Vallée \& Bloom's (2017) implementation of her graduate research to high performance basketball coaching, I have been applying the coaching approaches grounded in the TSMI to coached community sport programs catered to women in Nova Scotia to offer efficient, informative, and meaningful sport experiences to participating athletes. Women's sport planning, development, and facilitation have taken into consideration aspects of team interdependence including commitment, complementarity, mutuality, and roles which will be discussed in relation to the experiences of the coach and participants. We will discuss the versatility of the TSMI, the importance of indirect coaching functions and collaboration, and how it may be suitable for and appropriately adapted to suit the needs of coaches and athletes in women's community sport.

\section{References}

Bennett, E. V. Clarke, L. H., Kowalski, K. C., \& Crocker, P. R. E. (2017). From pleasure and pride to the fear of decline: Exploring the emotions of older women's physical activity narratives. Psychology of Sport \& Exercise, 33, 113-122.

Currie, C., Callary, B., \& Young, B. W. (under review). Glitter and guts: Narrative portrayal of sportswomen's experiences on a coached masters team. Manuscript under review.

Currie, C., Young, B. W., \& Callary, B. (2019, Oct. 31). Coaching a female masters team sport: Considerations of interdependent relationships [Conference session]. 12th International Council of Coaching Excellence Global Coach Conference, Tokyo, Japan.

Kirby, J. B., and Kluge, M. A. (2013). Going for the gusto: Competing for the first time at age 65. Journal of Aging \& Physical Activity, 21, 290-308.

Stevenson, C. L. (2002). Seeking identities: Towards an understanding of the athletic careers of masters swimmers. International Review for the Sociology of Sport, 37, 131-146.

Vallée, C. N., Bloom, G. A. (2016). Four keys to building a championship culture. International Sport Coaching Journal, 3, 170-177. https://doi.org/ 10.1123/iscj.2016-0010

\section{Presenter Biography}

Chelsea Currie holds an MA from the University of Ottawa in the field of sport psychology. As a Program Coordinator for Cape Breton Regional Municipality Recreation, she is involved in planning, developing, and implementing active-living programs for adult community members. She is an active community coach from grassroots to Masters level, is a parttime professor in Sport and Physical Activity Leadership at Cape Breton University, and is a research associate to Dr. Callary and Dr. Young, researching Masters sport coaching. 
D

\section{Effective Coaching Under Stress: Challenge and Threat Cognitive Appraisals and Coaching Behaviours}

Dixon, Martin

Department of Kinesiology at San Francisco State University, San Francisco, California, USA.

Research has established the stressful nature of sports coaching at a variety of levels (Norris et al., 2017). Contemporary stress theory proposes that individual responses to stress are determined by cognitive appraisals broadly consisting of perceptions of situational demands and personal resources, thus coaches can experience stress in useful (challenge) or debilitative (threat) ways (Meijen et al., 2020). This presentation synthesizes the findings of a recent body of research which examined coaches' behavioural responses to challenge and threat cognitive appraisals. Firstly, a cross sectional study of youth soccer coaches revealed how challenge and threat cognitive appraisals were related to coaching practice through associations with autocratic behaviour, positive feedback, and social support (Dixon et al., 2017). Secondly, a qualitative investigation of stress appraisals amongst soccer academy coaches suggested that key elements of coaches' specific resource appraisals included social support, efficacy beliefs established through reflection, and perceptions of control (Dixon \& Turner, 2018). Moreover, findings revealed how cognitive appraisals of stress can impact coaching behaviour, the provision of social support, and an awareness which leads coaches to "mask" stress to protect their athletes. These studies are synthesized with contemporary challenge and threat theory to better understand the stress process in coaches, explaining how cognitive appraisals can impact coaching practice. The collective research culminates in practical recommendations, such as the use of reflective practice, to help coaches appraise stressful situations as a challenge and promote effective coaching behaviours.

\section{References}

Dixon, M., \& Turner, M. J. (2018). Stress appraisals of UK soccer academy coaches: An interpretative phenomenological analysis. Qualitative Research in Sport, Exercise and Health, 10(5), 620-634. https://doi .org/10.1080/2159676X.2018.1464055

Dixon, M., Turner, M. J., \& Gillman, J. (2017). Examining the relationships between challenge and threat cognitive appraisals and coaching behaviours in football coaches. Journal of Sports Sciences, 35(24), 24462452. https://doi.org/10.1080/02640414.2016.1273538

Meijen, C., Turner, M., Jones, M. V., Sheffield, D., \& McCarthy, P. (2020). A theory of challenge and threat states in athletes: A revised conceptualization. Frontiers in Psychology, 11, 126. https://doi.org/10 .3389/fpsyg.2020.00126

Norris, L. A., Didymus, F. F., \& Kaiseler, M. (2017). Stressors, coping, and well-being among sports coaches: A systematic review. Psychology of Sport and Exercise, 33, 93-112. https://doi.org/10.1016/j.psychsport.2017 .08 .005

\section{Presenter Biography}

Martin Dixon is a lecturer in kinesiology at San Francisco State University. Martin is a UEFA qualified soccer coach and has previously coached academy and university teams in the UK. He is currently technical director and coach at Belmont United Soccer Club in California. Martin's research examines mediating factors and behavioural responses to stress amongst sports coaches. Additionally, Martin investigates reflective practice in sports coaching and coach education, with a focus on collaborative and strengths-based reflection.

\section{$\mathbf{E}$}

Soccer Coaches' Training Tasks Planning Influence in Internal and External Training Load

Espada, Mario ${ }^{1,2} ;$ Bagão, João $^{2} ;$ Figueiredo, Teresa $^{1,2} ;$ Ferreira, Cátia $^{1,3} ; \&$ Santos, Fernando ${ }^{1,2,4}$

${ }^{1}$ Polytechnic Institute of Setobal, School of Education, Setobal, Portugal; ${ }^{2}$ Quality of Life Research Centre, Rio Maior, Portugal; ${ }^{3}$ Faculty of Sports Science Caceres, University of Extremadura, Caceres, Spain; ${ }^{4}$ Faculty of Human Kinetics, University of Lisbon, Oeiras, Portugal.

Soccer is a team sport of great technical-tactical complexity, that requires an efficient collective organization and simultaneously a specific development of each player based on the individual and group perspective (Santos et al., 2021). This study sought to evaluate the training load in U-15 soccer players relationship to different conditions small-sided games (SSGs). Sixteen soccer players performed two consecutive SSGs with 3 min duration followed by 3 min interval rest: i) 4 vs 4 ball possession and ii) 4 vs. 4 plus goalkeepers with goal objective. Both SSGs were played in 16 x 24 m pitch size. Subjects carried Ultra-Wide Band based positiontracking systems units' devices (WIMU PROTM, RealTrack System). Regarding heart rate (HR), HRmax and HRmean were not significantly different ( $p>0.05$ ) between SSG1 and SSG2 (191.50-6.99 vs. 190.50-7.89 beats-min-1 and $178.88-9.25$ vs. $181.13-8.37$ beats-min-1). Significant differences comparing SSG1 and SSG2 were only observed in one HR interval percentage, HR70-80\% (11.91-9.80 vs. 5.85-3.82, $\mathrm{p}<0.05)$, the same was observed considering horizontal impacts (1177.13-98.63 vs. $1039.75-65.51, \mathrm{p}<0.01)$ and step counts $(437.25-24.98$ vs. $390.38-20.46$, $\mathrm{p}<0.01)$. Cohen's d effect size also revealed medium effects $(0.50)$ in HR50-60\%, Edwards' TRIMP, high impacts count and jumps count. In soccer, manipulating task constrains in SSGs requires special attention from the coach and staff members involved in training planning, since changing small details in practice can result in different effects on the internal and external load of the players. Monitoring soccer training is very important aiming players and team performance enhancement.

\section{References}

Santos, F. J., Ferreira, C. M., Figueiredo, T. P., \& Espada, M. C. (2021). Influence of different 1v1 small-sided game conditions in internal and external load of U-15 and U-12 soccer players. TRENDS in Sport Sciences, 29(1), 45-53. https://doi.org/10.23829/TSS.2021.28.16

\section{Presenter Biography}

Mario Espada holds a Ph.D. in Human Motricity in the area of Sports Sciences from the Faculty of Human Kinetics of the University of Lisbon. Espada is a full-time lecturer at the Polytechnic Institute of Setobal and researcher at the Life Quality Research Centre (LQRC-CIEQV). He regularly attends technical-scientific events of relevance in the scientific area of Sports Sciences and is also the author and co-author of several scientific articles published in journals with impact factor.

G

\section{An Exploration of the Coaching Approaches Used by Mi'kmaw First} Nation Coaches

Gurgis, Joseph ${ }^{1} \&$ Callary, Bettina ${ }^{1}$

${ }^{1}$ Cape Breton University, Sydney, Nova Scotia, Canada

Indigenous sport functions as a mechanism for teaching Indigenous children and youth social and personal values of respect, honesty, 
courage, individual excellence, and gratitude, for the counsel of elders, parents, and communities (Canadian Heritage, 2005). The realization and socialization of these values is highly dependent on Indigenous coaches, who play an essential role in educating youth about the value of sport and contribute towards facilitating strong relationships between sport and Indigenous culture (Bennie et al., 2019). However, Sport Canada reported the participation of Indigenous peoples in sport is hindered by a lack of Indigenous coaches (Canadian Heritage, 2005). Thus, sport has been largely taught, led, and internalized to Indigenous people through a Western lens. The research of the leadership of Indigenous sport programs and teams in Canada is sparse; and therefore, it's unknown how coaches integrate Indigenous ways of knowing when leading sport. To fill this gap, the following study sought out to understand the coaching approaches of Mi'kmaw First Nation coaches. Eight Indigenous coaches from across six Mi'kmaw First Nation communities in Nova Scotia, Canada, participated in a semi-structured interview to discuss their methods of coaching. The interviews were audio-recorded, transcribed verbatim and thematically analyzed. The findings were conceptualized to suggest three concurrent approaches to Mi'kmaq coaching: two-eyed seeing, multifaceted coaching, and medicine wheel coaching. These approaches highlight the perceived importance and desire to blend Indigenous and Western ideologies of coaching to ensure Indigenous customs and traditions are considered when participating within a predominantly Western conception of sport.

\section{References}

Bennie, A., Apoifis, N., Marlin, D., \& Caron, J. G. (2019). Cultural connections and cultural ceilings: Exploring the experiences of aboriginal Australian sport coaches. Qualitative Research in Sport, Exercise, and Health, 11(3), 299-315. https://doi.org/10.1080/2159676X.2017.1399924

Canadian Heritage. (2005, May). Sport Canada's policy on aboriginal peoples' participation in sport. Government of Canada. https://www.canada. $\mathrm{ca} /$ content/dam/pch/documents/services/sport-policies-acts-regulations/ aborignial_v4-eng.pdf

\section{Presenter Biography}

Joseph Gurgis is a Postdoctoral Fellow in the Department of Experiential Studies in Community and Sport at Cape Breton University, where he is exploring the coaching experiences of Mi'kmaw First Nation coaches. Joseph's area of research is in behavioural sport psychology. He has conducted and published research primarily in the areas of Safe Sport and coach development. Additionally, he has consulted on several coaching and Safe Sport projects as a program evaluator and researcher with organizations such as the Coaching Association of Canada, Alpine Canada Alpin, and the International Council for Coaching Excellence.

\section{H}

\section{0-2021: A Challenge Like No Other for Volunteer High-Perfor-} mance Coaches: An Irish Story

Harrison, Hayley

\section{Sport Ireland Coaching}

Planning for the 2020 athletics season was clear cut; there were two major competitions to focus on: the Olympic Games in Tokyo and the European Championships in Paris. Unfortunately, however, COVID-19 hit in early 2020 and one by one, the competitions were cancelled. On the international stage, some athletes had no restrictions placed on them and they had full access to facilities with their training not interrupted at all. Yet, others were denied access to facilities and were not able to train from March through to August. What was once a level playing field became quite the opposite. As restrictions were relaxed in Ireland, professional sports people were able to work, meaning athletes could train and coaches could coach; however, most athletics coaches in Ireland, including those working at World and Olympic level, are volunteer coaches and so the restrictions remained in place. The High-Performance athletics coach in Ireland has had to adapt to remote coaching, to their HP athletes not having their usual training partners to train with, the possibility of few, if any, competitions in 2021 to prepare the athletes for Tokyo, ever-changing travel restrictions and the psychological pressure all that puts on both themselves and their athletes. This presentation will tell the story of the specific challenges posed by COVID-19 and how those challenges were met by three High Performance athletics coaches in Ireland.

\section{Presenter Biography}

Hayley Harrison has over 30 years of experience as a volunteer High Performance athletics coach, specialising in the sprints and hurdle events. She has coached athletes to World and Olympic finals and has received several awards for her coaching expertise. Hayley's profession is also coaching related as she is the Head of the Coach Developer Programme with Sport Ireland Coaching and is a Master Trainer with the ICCE.

\section{Heroes and Villains: A Mixed Methods Pilot Evaluation of the UEFA Playmakers Programme}

Hill, Megan ${ }^{1} \&$ Lara-Bercial, Sergio ${ }^{1}$

\section{${ }^{1}$ Leeds Beckett University}

Increasing female participation in football is a central goal of UEFA's current strategy. One of the flagship initiatives to achieve this objective is the Playmakers programme. In conjunction with Disney, UEFA have designed and implemented a pan-European programme to introduce young girls aged five to eight years old to football. Through story-telling and imaginative play built around Disney characters and films, the programme aims to fulfil the needs and desires of this specific population, including fundamental movement skills, basic football skills, life skills, and to foster a love for physical activity and football. The premise is to achieve this in a custom-designed safe environment which promotes learning, fun and friendship (Lara-Bercial et al., 2019). This study evaluated the impact, experience, and perception of the programme from the perspective of the participating coaches, girls, and their parents. A mixed-methods approach including surveys, interviews and focus groups was used. Across numerous countries, all participants in the programme were sent an online postprogramme survey to share their experience and perceptions. A sub-sample was subsequently selected to participate in focus groups or interviews to gather further information on the impact of the programme. Both the quantitative and qualitative data was analysed to form a rich, contextualised understanding. Preliminary findings show participants perceived the programme to attract and engage young girls to the sport, while also increasing their basic football and movement skills in a fun and safe way. Participants felt the story-telling pedagogy suited the targeted age range, but the programme lacked a competitive element for some.

\section{References}

Lara-Bercial, S., Stride, A., Fitzgerald, H., Brazier, R., Staples, M. \& Piggott, S. (2019). UEFA PlayMakers Programme Literature Review. Nyon. UEFA. https://symplectic-web.leedsbeckett.ac.uk/viewobject.html? cid=1\&id=135011 


\section{Presenter Biography}

Megan Hill is Post-Doctoral Research Fellow at Leeds Beckett University. Her interests include youth growth and development, talent development, coach education and the development, implementation, and evaluation of sports-based initiatives which encourage active and healthy living through positive coaching.

\section{$\mathbf{K}$}

\section{Ethical Leadership in Everyday Sports Coaching}

Korhonen, Auli

\section{University of Eastern Finland, Joensuu, Finland}

Coaches have been identified as the most critical stakeholders when it comes to impacting the moral behaviour of athletes. The present study explored how ethical leadership emerges in sports coaching and how the coaches see themselves as ethical leaders. The main goal of the study was to find out good, positive practices in everyday coaching. For this, five Finnish female coaches in ball sports participated in a semi-structured interview. The interviews were analysed with a six-phase thematic analysis. The results demonstrated how ethical leadership in daily operations emerges in coaching practices, coaching atmosphere, and in coaching environment. Coaches saw themselves as ethical leaders through their own activities, and coaching was interpreted as interaction. Self-reflection, twoway feedback, positive reinforcement and continuous self-development interpreted the activities of promoting ethical behaviour. Peer-support as well as support from the athletes and clubs were important for coaches in dealing with any ethical issues in practice. On this basis, the study suggests that peer-groups should be created to discuss the matters and mentoring and mental training should be made available to the coaches. Coaches need to be educated to self-reflect to avoid ethical blindness, and tools and methods to do so should be created for this. A culture should be established where intervening is possible at a low threshold without losing face or facing any negative consequences, and a tool to do so should be created. The findings can be used at all levels of sports and applied in coaching education at national sports federations.

\section{Presenter Biography}

Auli Korhonen holds two Master's degrees, in Arts (Adult Education) and in Business Administration. She is working as a General Secretary in the Finnish Dance Sport Federation. She is also an entrepreneur in the education and consulting sector. She is particularly interested in ethical leadership and ethics in sports, especially in sports management.

\section{$\mathbf{L}$}

\section{Coaching Volleyball: Principles from a Personal 'Practice Theory'}

Lyle, John ${ }^{1} \&$ Dowens, Thomas ${ }^{2}$

${ }^{1}$ Carnegie School of Sport, Leeds Beckett University, Leeds, United Kingdom; ${ }^{2}$ Scottish Volleyball Association

There are insufficient examples of practising coaches' personal theories of practice; such dissemination is necessary for encouraging the sharing of good practice. This is particularly true of examples in which a process of deep reflection has identified the principles underlying these theories. This presentation describes some of the principles on which a personal theory about coaching volleyball is based. These principles are elaborated in the publication Coaching Volleyball (Dowens, 2021), and are coached in terms of a rebound, team sport. In relation to technique development, the importance of physical literacy, particularly rhythm and timing, is emphasised, along with the management of balance. The significance of momentum in game play is highlighted, along with the development of an appropriate mind-set. Further principles include balancing process versus product and maintaining rhythm in the practice session by judicious use of coach interventions and the need for goal-orientated practices. The presentation concludes with a checklist of useful, experience-honed pointers to good practice. The principles identified have considerable resonance for coaches in other sports and across domains.

\section{References}

Dowens, T. (2021). Coaching volleyball. The Ruth Nicholls Volleyball Foundation.

\section{Presenter Biography}

Dr. John Lyle is a Professor of Sport Coaching in the Carnegie School of Sport, Leeds Beckett University. John is the author of a number of influential textbooks, with a research interest in conceptual development in sport coaching. His academic experience is complemented by experience as a coach, an involvement in the development of coaching policy in the UK, and the delivery of high-performance coach development. He was an international player and coach in volleyball and also a professional footballer.

\section{M}

\section{Secondary School 1st XV Players' Perceptions of Their Coaching Environment}

McKenzie, Samuel $^{1}$; Harrison, Craig $^{2}$; \& Walters, Simon ${ }^{3}$

${ }^{1}$ AFL, Melbourne Australia, AUT, Auckland, New Zealand; ${ }^{2}$ AUT, Auckland, New Zealand; ${ }^{3}$ AUT, Auckland, New Zealand

The physical, social, and psychological benefits of participating in secondary school-level sport are mediated by coaches. This study explores $1 \mathrm{st}$ XV secondary school New Zealand rugby players' perceptions of their coaching environment and how this affects their experience of playing sport. In this qualitative descriptive study, research questions were framed around these athletes' perceptions regarding their experiences of the 1st XV secondary school coaching environment. Descriptive data was gathered from three focus groups comprising secondary school rugby players (16-18 years old), competing in a $1 \mathrm{~A}, 1$ st XV competition in New Zealand. Findings revealed that coaches influenced athletes' brotherhood and controlled what sports participants played, how they played during games and their ability to express themselves during games. Participants sometimes resisted this control through covert and overt displays of power. Participants experienced a high level of expectation and pressure from coaches. This research extends the literature by offering insight into secondary school-level 1st XV coaching environments in New Zealand and suggests coaches need to be cognisant of how their actions may influence athletes' experiences.

\section{Presenter Biography}

Sam is passionate about taking a humanistic approach to sport and coaching. He has spent the last decade in national and regional sporting organisations in New Zealand and Australia working across both player and coach development. In 2019, Sam completed his Master of Sport and Exercise at AUT University looking at secondary school 1st XV players' 
perceptions of their coaching environment. As a coach, coach developer, and researcher, he aims to bridge the gap between research and application.

\section{The Evaluation of a Psychosocial Development Programme Within an English Soccer Academy}

Mitchell, Tom ${ }^{1}$; Cowburn, Ian ${ }^{1}$; Piggott, Dave ${ }^{1}$; Alder, Dave ${ }^{1}$; Cook, Tony $^{2}$; \& Till, Kevin ${ }^{1}$

${ }^{1}$ Leeds Beckett University, Leeds, England; ${ }^{2}$ Doncaster Rovers Football Club, Doncaster, England

The possession and development of psychosocial characteristics can be advantageous for young athletes (Gledhill et al., 2017). The aim of this study was to evaluate a programme (the 8 Pillars) designed to develop prescribed psychosocial components in English male academy soccer players. The 8 Pillars programme (including Communication, Control, Commitment, Concentration, Confidence, Resilience, Presence, and Selfawareness; Till et al., 2021) is a theoretically, empirically, and practically driven programme to support the development of psychosocial components in youth sport participants. The programme delivery included player workshops, coach development activities, and coach observation across a season. To assess programme efficacy, 25 male academy players (Mage 14.7+1.34) completed the Psychological characteristics of Development Excellence Questionnaire-2 (PCDE-2, Hill et al., 2019) preand post-season. Players also completed the 8 Pillars self-report form at 5 time points across the season. Paired samples t-tests reported significant increases for 3 of the PCDE-2 subscales, namely "Imagery and Active Preparation" $(3.42+0.87$ vs $4.10+1.02, \mathrm{p}<0.001)$, "Seeking and using Social Support" $(4.20+0.79$ vs $4.87+0.76, \mathrm{p}<0.01)$ and "Active Coping" $(4.21+0.78$ vs $4.85+0.66, \mathrm{p}<0.001)$. Multivariate analysis of variance (MANOVA) reported significant increases over time all pillars apart from Presence. The findings demonstrate that the 8 Pillars programme may support development of psychosocial characteristics in academy soccer players over a season. Any programme seeking to develop psychosocial components should consider integration of psychosocial components into the practical coaching programme, through additional development, planning and evaluation activity to optimise impact.

\section{References}

Gledhill, A., Harwood, C \& Forsdyke, D. (2017). Psychosocial factors associated with talent development in football: A systematic review. Psychology of Sport and Exercise, 31, 93- 112.

Hill A, MacNamara, Á, \& Collins D. (2019) Development and initial validation of the Psychological Characteristics of Developing Excellence Questionnaire version 2 (PCDEQ2). European Journal of Sport Science, 19(4), 517-528. https://doi.org/10.1080/17461391.2018.1535627

Till, K., Eisenmann, J., Emmonds, S., Jones, B., Mitchell, T., Cowburn, I. H., Tee, J., Holmes, N., \& Lloyd, R. S. (2021) A coaching session framework to facilitate long-term athletic development. Strength and Conditioning Journal, 43(3), 43-55. https://doi.org/10.1519/SSC .0000000000000558

\section{Presenter Biography}

Tom is a Senior Lecturer in Sport Coaching Leeds Beckett University with a research interest in the lived experiences of youth and professional soccer players and how organisational culture in professional soccer influences the psychosocial development and subsequent career progression. Tom has over 10 years of engagement with professional football supporting psychosocial development initiatives in academy settings and offering educational support to scholars for five years as part of their soccer apprenticeship programme.

\section{Young Finnish Elite Athletes' Perceptions of Their Coach-Athlete Relationships}

Mononen, Kaisu; Blomqvist, Minna; Pusa, Sanna; \& Mäkinen, Jarmo

\section{Research Institute for Olympic Sports, Jyväskylä, Finland}

Coaches have a crucial role in providing supportive learning environments. The quality of coach-athlete relationships can be determined by the degree of closeness, commitment to the relationship, and complementarity (3 Cs) between both parties (Jowett \& Ntoumanis, 2004). A large survey was conducted in 2020, aiming to find out young Finnish national team athletes' everyday experiences as an athlete, including the quality of the coach-athlete relationships. A total of 399 16-20-year-old Finnish youth national team athletes (individual, team ball, and other team sports) completed a Coach-Athlete Relationship Questionnaire (CART-Q). The questionnaire contained 11 items under three subscales (closeness, commitment, complementarity). The items were assessed with 7-point Likert scale indicating the athlete's level of agreement/ disagreement with the item. Overall, the athletes perceived that their relationship with their coach was good $(\mathrm{M}=6.3 ; \mathrm{SD}=0.7)$. The athletes were characterized by high closeness $(M=6.3 ; \mathrm{SD}=0.9)$, commitment $(\mathrm{M}=6.1 ; \mathrm{SD}=0.9)$, and complementarity $(\mathrm{M}=6.4 ; \mathrm{SD}=0.7)$ with their coach. In team ball sports $(M=6.1 ; S D=0.8)$, the athletes perceived the quality of their relationship lower compared to the athletes in individual sports $(M=6.4 ; S D=0.7)$ and in other team sports $(M=6.4 ; S D=0.7)$ $(\mathrm{H}(2)=15.13, \mathrm{p}=.001)$. Generally, the young elite athletes seemed to have a good relationship with their coach. There was also some indication that the type of sport may have an impact on the relationship between coach and athlete.

\section{References}

Jowett, S., \& Ntoumanis, N. (2004). The Coach-Athlete Relationship Questionnaire (CART-Q): Development and initial validation. Scandinavian Journal of Medicine and Science in Sports, 14, 245-257.

\section{Presenter Biography}

Kaisu Mononen is a Senior Researcher at KIHU: Research Institute for Olympic Sports in Finland. She has worked in applied research of elite sports for 25 years and has also close involvement in the development of the Finnish Athlete's Path. Today, her work is focused on the research and development of youth sports and Paralympic sports. She is highly motivated by exploring the individual athlete's perspective and personal experience.

\section{Leadership Efficacy in Youth Football: Athletes' and Coaches' Perspectives}

Morais, Catarina ${ }^{1}$; Gomes, Rui $^{2}$; Gonñalves, Alexandre ${ }^{2}$; Simães, Clara ${ }^{3}$; $\&$ Resende, Rui ${ }^{4}$

${ }^{1}$ Research Centre for Human Development, Faculty of Education and Psychology, Universidade Catolica Portuguesa. Portugal; ${ }^{2}$ Psychology Research Centre. School of Psychology. University of Minho. Portugal; ${ }^{3}$ Health Sciences Research Unit: Nursing (UICISA: E). School of Nursing, University of Minho. Portugal; ${ }^{4}$ Life Quality Research Centre. University Institute of Maia. Portugal. 
According to the Leadership Efficacy Model, leadership efficacy increases if leaders make linear relations between leadership philosophy, practice, and criteria (i.e., congruence of leadership cycles); if leaders make these linear relations by using the optimal leadership profile; and if leaders consider the antecedent factors of leadership (favourability of conditions for leadership). This study compared the perceptions of athletes and their coaches regarding leadership cycles and tested the moderator role of optimal leadership profile and leadership favourability in the relationship between leadership cycles and leadership efficacy. The study included 92 football athletes (ages under-17 years and under-19 years) and respective coaches $(n=5)$ and evaluated leadership cycles, leadership styles, leadership favourability, and sport performance perception. Athletes and coaches agreed on coaches' need to increase leadership cycles. Regression analyses confirmed that leadership congruency predicts higher perceptions of team performance in athletes. Moreover, optimal leadership profile and higher leadership favourability were associated with higher team and individual performance. However, these two factors did not moderate the relationship between leadership congruency and efficacy. Coaches should clarify better their leadership cycles; they have advantages in using the optimal leadership profile and considering the antecedent factors of leadership to establish the leadership cycles.

\section{Presenter Biography}

Catarina Morais teaches at the Faculty of Education and Psychology, Universidade Catolica Portuguesa, since 2019 and is a member of the Centre for Studies in Human Development. Her Ph.D. in Social Psychology was awarded by the University of Kent (United Kingdom), where she developed her research on the impact of ethical and unethical leadership on group dynamics. Currently, Catarina's research interests focus on leadership in sports context, as well as the development of psychological skills to promote sport performance.

\section{Football Coaches Perceived Role in Young Players Moral Character} Development

Murray, Eoin ${ }^{1,2}$; Backhouse, Susan ${ }^{2} ; \&$ Stanger, Nick ${ }^{2}$

${ }^{1}$ University Academy 92 (UA92), Manchester, UK; ${ }^{2}$ Leeds Beckett University, UK

Sport has been widely recognised and promoted as a vehicle for holistic development, particularly among young people. However, little research has examined the perceived role of the coach in the psychosocial, and particularly moral character, development of young athletes and how they may aim to promote such development across differing competitive standards or gender contexts. Through an interpretivist lens this research explored youth football (soccer) coaches of boys $(\mathrm{N}=14)$ and girls $(\mathrm{N}=15)$ perceived role in young players moral character development across performance (e.g., academy) and participation (e.g., grassroots) domains, and the mechanisms (or approaches) they employed in such development. The findings suggested that youth football coaches of boys and girls perceived moral character development of young players to be a key part of their coaching role and offered insights about the reasons why coaches aimed to develop moral character. These findings also suggested that the coaches moral character development rationale is orthogonal in nature. Moreover, coaches expressed a range of mechanisms by which they aimed to facilitate moral character development in young players, such as setting expectations and the clear disapproval of undesirable behaviours. Although the mechanisms were mainly similar across coaches, how these were implemented appeared somewhat specific to the competitive domain or gender context the coach was operating in. In turn, this research offers new insights about how the domain and gender context coaches operate in, may have some role to play in these aspects of their coaching practice.

\section{Presenter Biography}

Eoin Murray successfully passed his Ph.D. Viva (with minor amendments) in November 2020 within the Carnegie School of Sport, Leeds Beckett University. He is currently a lecturer in Sports and Exercise Science at University Academy 92, Manchester, and is Director of Performance of a youth female soccer academy in the North of England. Eoin is keen to help bridge the gap between theory and practice by bringing coaches voices to the forefront of psychosocial coach education discussions.

\section{$\mathbf{N}$}

\section{Talent-Mindset of Sports Coaches in Norway and Their View of} Athlete Talent

Nilsen, Dag André ${ }^{1,2}$; Chroni, Stiliani “Ani”, ; Sigurjonsson, Thorsteinn ${ }^{1}$; $\&$ Pensgaard, Anne Marte ${ }^{2}$

${ }^{1}$ Inland Norway University of Applied Sciences, Elverum, Norway; ${ }^{2}$ Norwegian School of Sport Sciences, Oslo, Norway

According to Dweck (2000; 2006; 2009), a coach's mindset influences both coaching behaviour and cognition, including how the coach evaluates and relates to athlete capabilities and sport-talent. Coaches with a fixed mindset believe talents and abilities are limited, innate capacities, and therefore, having talent is deemed as necessary for sporting success and becoming a champion. These coaches prioritise finding and nurturing talent. In contrast, coaches with a growth mindset believe talents and abilities can develop through effort and practice. These coaches are concerned with developing and inspiring each athlete to achieve success by reaching their potential. Following Dweck's conceptualisation of mindset, we investigated the talent-mindset distribution among sports coaches in Norway. A modified version of "Theories of Intelligent Scale" was employed (Dweck, 2000). Furthermore, we asked the coaches to indicate at what age (if at all) they determine that an athlete can be exceptionally good. The data was collected as part of a national survey of sports coaches in Norway (Chroni et al., 2018). Responses from 5035 active coaches of the national survey were analysed, consisting of 1224 women and 3797 men between the ages of 15 to 83 years old $(M=42.10$; $\mathrm{SD}=10.4$ ). Analyses revealed differences in mindset between age groups, as well as between type of sport. Mindset also related to the age at which coaches believe they can determine sporting talent. Results and conclusion will be presented, and coaching development and practice issues related to coaches' talent-mindset will be discussed.

\section{References}

Chroni, S. A., Medgard, M., Nilsen, D. A., Sigurjonsson, T., \& Solbakken, T. (2018, March). Profiling the coaches of Norway: A national survey report of sports coaches \& coaching. Høgskolen i Innlandet. https://brage .inn.no/inn-xmlui/handle/11250/2569671

Dweck, C. S. (2000). Self-theories: Their role in motivation, personality, and development. Psychology Press.

Dweck, C. S. (2006). Mindset: The new psychology of success. Random House.

Dweck, C. S. (2009). Mindsets: developing talent through a growth mindset. Olympic Coach, 21(1), 4-7. 


\section{Presenter Biography}

Dag André Nilsen resides at Inland Norway University of Applied Sciences, Department of Public Health and Sports Science. He is currently working on his Ph.D. at Norwegian School of Sport Sciences, with the project "Mindsets in Youth Sport" the coach's role for athletes' resilience and belief in sports abilities." Dag André works as a sports psychology consultant at The Norwegian Olympic Sports Centre, Region Inland.

Exploring Ethical Coaching Practice: Developing and Utilising a Multi-Dimensional Framework

North, Julian; Cowburn, Ian; \& Rongen, Fieke

Research Centre for Sport Coaching, Carnegie School of Sport, Leeds Beckett University

Ethical issues are increasingly visible in sport coaching across a range of domains and contexts. When problems occur, the outcome is typically a demand for system and workforce change. Existing research exploring ethical coaching practice has tended to utilise French social theorists (e.g., Denison, 2007), and caring theory (e.g., Cronin \& Armour, 2019), descriptively and normatively; and virtue ethics (e.g., Hardman \& Jones, 2011) normatively. Existing research has also tended to explore ethical issues at either a macro or micro level, as well as bracketing the discussion of ethical coaching from effective coaching. This work will overview the early stages of the development of a multi-dimensional framework to explore the ethical dimensions of coaching practice drawing on several descriptive and normative theories or frames. These include psychological, sociological, and emerging interdisciplinary and practicebased theories (e.g., Haidt, 2012; Sayer, 2011). The work will also explicitly attempt to show the relationship between macro and micro-level concerns and reintegrate understandings of ethical coaching with effective coaching. The end game is the development of a conceptual frame that integrates ethics more centrally and explicitly into the embedded, relational, emergent (ERE) model (North, 2017). The presentation will also draw on data gathered through two long-term - 18 months to 2-years - ethnographic case studies in Podium Potential triathlon and Paralympic swimming, with coaches, athletes, and entourage. The case studies highlight that ethical issues are often a result of, and can be understood through the influences of, and interactions between, individual, interpersonal, institutional, and socio-cultural layers.

\section{References}

Cronin, C., \& Armour, K. (2019). Care in sport coaching. Routledge.

Denison, J. (2007). Social theory for coaches: A Foucauldian reading of one athlete's poor performance. International Journal of Sports Science \& Coaching, 2, 369-383.

Haidt, J. (2012). The righteous mind: Why good people are divided by politics and religion. Penguin.

Hardman, A., \& Jones, C. (2011). Sports coaching and virtue ethics. In A. Hardman \& C. Jones (Eds.), The ethics of sports coaching (pp. 72-84). Routledge.

North, J. (2017). Sport coaching research and practice: Ontology, interdisciplinarity, and critical realism. Routledge.

Sayer, A. (2011). Why things matter to people: Social sciences, values and ethical life. Cambridge University Press.

\section{Presenter Biography}

Dr. Julian North is the Director of the Research Centre for Sport Coaching, in the Carnegie School of Sport, Leeds Beckett University, UK. He has been a social and sport researcher for approaching 30 years in a variety of policy, practice and academic roles in the UK and Australia. He previously worked for UK Coaching (Director of Research, 2003-2010), the Australian Sports Commission (Research Consultant, 2002-2003) and UK Sport (Research Manager, 1999-2002).

\section{Investigation of Communication Practice and Behaviours of Coaches at Half Time in Competitive Youth}

O'Connor, Gerard; Mooney, Owen; Tolan, Paul; \& McEntee, Terry

Dublin Gaelic Athletic Association, Dublin, Ireland

Reviewing coaching behaviour during game day and the impact of the coach's interventions at half time is important to understanding effective coaching. A mixed method approach was used to identify the type of behaviour and the content of the message reported by the coaches at half time. The behaviours were coded using a modified version of The Arizona State University Observation Instrument (ASUOI). Coaches then conducted reflective practice on their own behaviour recorded. Furthermore data was collected to analyse the player's perception of the coach behaviour. The results showed the coaches' behaviours during the team talk were dependent on the outcome of the game. When the team was losing, the feedback was generally negative and very little achievable goals were set for the duration of the second half. The reflective practice revealed that the coaches were unaware of the mixed and generally negative messages presented to players at half time. For the coaches, this is a great opportunity to review their current practice and see how effective their communication is on game day. These results offer some clues about specific coach behaviours that may be game action dependent and point to the importance of interventions to improve coaches' behaviour.

\section{Presenter Biography}

Gerard is the Director of Coaching with the Dublin Gaelic Athletic Association (GAA) where he is responsible for the management of the Games Development programme. He has been involved in sports development for over 25 years where he has played a leading role in the development and delivery of the GAA Coach Education Programme at national level. He has authored a series of books with his most recent book publication being the 2nd edition of "Give Us A Game"

\section{$\mathbf{P}$}

\section{Supporting Practitioners in Talent Identification in International Football}

Piggott, David

\section{Leeds Beckett University, UK}

In this session I aim to provide an insight into the process of supporting practitioners (coaches, psychologists, analysts, doctors, and physical conditioning coaches) in the identification and grading of potential future international footballers in a national team system. Recent research and academic commentary (e.g., Till \& Baker, 2020) is beginning to provide useful and practical ideas and tools to support talent ID and development systems, and, as the research lead at the English FA between 2018-2020, part of my role was to ensure that the systems and processes for selection and grading of players in the men's pathway were informed by such research. In this session I draw on the concepts of "Sensemaking" (Weick, 
1995) and "insight generation" (Klein, 2013), to explain and demonstrate some of the strategies and tools that were created to support national team selections (from the U15s to U21s). I also share some of the developmental histories data that were generated internally with the players and show how this was beginning to inform the highly complex and multifaceted decision-making process behind the regular grading of players (i.e., the process of defining 'potential' and predicting the likelihood of future success). I aim to provide a practical example using mock data for the audience to work through to illustrate the complexity of the problem and how we helped practitioners come to better informed solutions.

\section{References}

Klein, G. (2013). Seeing what others don't: The remarkable ways we gain insights. Public Affairs.

Till, K., \& Baker, J. (2020). Challenges and (possible) solutions to optimising talent identification and development in sport. Frontiers in Psychology. https://doi.org/10.3389/fpsyg.2020.00664

Weick, K. (1995). Sensemaking in organisations. Sage.

\section{Presenter Biography}

David is a senior lecturer in sports coaching at Leeds Beckett University where he currently leads the master's programme. He also has parallel roles as a professional basketball coach and coach developer (and developer of coach developers) over the last 10 years. Between 2018 and 2020, David was the research lead in the Team Strategy and Performance department at the English FA where he conducted research with international players and coaches to inform the talent system.

\section{$\mathbf{R}$}

\section{Coaching Efficacy in Sports: The Leadership Efficacy Model}

Resende, Rui ${ }^{1} \&$ Gomes, Antonio Rui ${ }^{2}$

${ }^{1}$ Life Quality Research Centre, University Institute of Maia, Portugal; ${ }^{2}$ Psychology Research Centre, School of Psychology, University of Minho, Portugal

The leadership effectiveness model applied to sports coaching is presented. It is proposed in the model that leadership efficacy depends on the congruence between the conceptual cycle of leadership and the practical cycle of leadership and by considering the leadership styles assumed by coaches and the moderating influence of the antecedent factors of leadership. This chapter discusses how these three elements of the model (leadership cycles, leadership styles, and the antecedent factors of leadership) apply to sports coaches and concur to explain their efficacy in leading athletes and teams. The model includes four hypotheses (congruence of leadership cycles, optimal leadership profile, favourability of conditions for leadership, and optimized congruence hypothesis of leadership) that will be presented according to empirical finding about leadership and sports coaching.

\section{Presenter Biography}

Rui Resende is an Assistant Professor at University Institute of Maia ISMAI, Portugal. He does research manly in coach education. He was a volleyball athlete and coached teams at the high competition level in Portugal and the junior national coach of the Portuguese national team. Presently, he is an editor director of the Journal of Sport Pedagogy \& Research and recently made his graduation as Coach Developer in the ICCE.

\section{Coaching Life Skills to Young Athletes in Sport Participation Contexts}

Resende, Rui ${ }^{1} \&$ Gomes, Antonio Rui ${ }^{2}$

${ }^{1}$ Life Quality Research Centre, University Institute of Maia, Portugal; ${ }^{2}$ Psychology Research Centre, School of Psychology, University of Minho, Portugal

People who engage in sports participation who are not on a performance pathway may benefit from formal training that stimulates the pleasure and challenges of sports, stimulates learning and developing of life/sports skills, stimulates the benefits of being physically active, and that are not necessary interested in sports for competition purpose. Despite the interest of generalizing sports activity, there are few findings about the relevance of developing sports participation training programs as an alternative of organized sports for youth and recreational sports for adults. In this presentation, we propose the organization of sports participation programs by considering the framework of life skills as a possibility to set the purpose and activities of participation sports. To fulfill this goal, we present the definition of sports participation, and then discuss the relation between sports and life skills. Finally, we present a theoretical proposal of life skills applied to sports participation, as a framework that can be used in youth sports.

\section{Presenter Biography}

Rui Resende is an Assistant Professor at University Institute of Maia ISMAI, Portugal. He does research manly in Coach Education. He was a volleyball athlete and coached teams at the high competition level in Portugal and the junior national coach of the Portuguese national team. Presently, he is an editor director of the Journal of Sport Pedagogy \& Research and recently made his graduation as Coach Developer in the ICCE.

\section{Development or Performance? The Role of the Coaches' Eye During Talent Identification}

Roberts, Alex ${ }^{1,2,3}$; Raynor, Annette ${ }^{1}$; Humberstone, Clare ${ }^{2}$; Iredale, Fiona $^{1} ;$ \& Greenwood, Daniel ${ }^{4}$

${ }^{1}$ School of Medial and Health Sciences, Edith Cowan University, Joondalup, WA, Australia; ${ }^{2}$ Australian Institute of Sport, Bruce, ACT, Australia; ${ }^{3}$ Sport and Exercise Science, La Trobe University, Bundoora, VIC, Australia; ${ }^{4}$ School of Health Studies, University of Memphis, Memphis, TN

Current talent identification literature relies on performance profiling of athletes, typically using coach opinions to validate the results of athlete profiling. The inherent assumption present in this methodology is that all coaches will identify the same athletes as talented. However, it has recently been demonstrated that coaches do not necessarily agree on athlete talent. To understand coach selections, the interaction between the coach and the athlete within the talent identification setting must be better understood. Based upon a series of studies involving 34 elite combat sport coaches (Roberts et al., 2019; Roberts et al., 2020; Roberts et al., 2021) this new model encapsulates the coaches' eye during talent identification - the lens through which view athletes in order to make a selection. This model introduces the idea of forecasting and uses the theoretical framework of ecological dynamics to understand why coaches select the athletes they do. The model of the coaches' eye during talent identification demonstrates how a coach's constraints influence their perception of an athlete's talent and, in turn, the coach's decisions. The way a coach attunes to both the athlete's constraints and their own is dependent on their experience, the time available, the context of the identification, and 
the coach's abilities all of which differ between coaches. This model provides coaches and coach educators with insight into mechanisms that underpin coach decision-making during talent identification. By understanding these factors and their interrelationship, we can enhance the efficacy and consistency of talent identification and selections between coaches.

\section{References}

Roberts, A. H., Greenwood, D, Humberstone, C., \& Raynor, A. J. (2020). Pilot study on the reliability of the coach's Eye: Identifying talent throughout a 4-day cadet judo camp. Frontiers in Sports and Active Living, 2. https://doi.org/10.3389/fspor.2020.596369

Roberts, A. H., Greenwood, D. A., Stanley, M., Humberstone, C., Iredale, F., \& Raynor, A. (2019). Coach knowledge in talent identification: A systematic review and meta-synthesis. Journal of Science and Medicine in Sport, 22(10), 1163-1172. https://doi.org/10.1016/j.jsams.2019.05.008

Roberts, A. H., Greenwood, D., Stanley, M., Humberstone, C., Iredale, F., \& Raynor, A. (2021). Understanding the "gut instinct" of expert coaches during talent identification. Journal of Sports Sciences, 39(4), 359-367. https://doi.org/10.1080/02640414.2020.1823083

\section{Presenter Biography}

Alex lectures in Sport and Exercise Science at La Trobe University, working in sport coaching and related fields. As an applied sport scientist, coach developer, and researcher, Alex has worked with coaches and athletes at all levels from club to elite, across both Australia and the USA. Alex has recently completed her Ph.D. with Edith Cowan University, investigating the role of the coaches' eye combat sport talent identification. Her current research focuses on talent identification, coaching science and skill acquisition.

\section{Resistance Training for Young Athletes}

Rodrigues, Leonel

\section{Agrupamento de Escolas de Estarreja, Portugal}

Given the many benefits associated with resistance training, it should be included as a training component within any strength and conditioning programme for athletes. French et al. (2014) suggested that: a) strength training represents an effective strategy to improve the development of muscle strength and power in children and young populations; b) in training programs, several variables must be valued, namely: physical differences (maturational status), capacity to tolerate exercise, technical competence and levels of mental maturity, and c) there is a need for supervision and instruction of certified professionals. In this presentation, we provide a literature review of a number of rules for implementing strength training programs for young and inexperienced athletes, including: Provide qualified supervision and instruction; Ensure that the space where the activity takes place is safe and free of dangers; Start each training session with a warm-up period (5 to 10 minutes); Start the program with a light series of 10 to 15 repetitions with different exercises; Perform 8 to 12 exercises for different body segments; Gradually increase the resistance as the strength increases (5 to $10 \%$ ); Focus attention on the correct exercise technique at the expense of training load; Frequency 2 to 3 times a week on interpolated days; Use an individualized training record to monitor progress; Keep the program fresh and challenging through systematic training variation. These guidelines can be implemented by coaches and provide some information to coaches for their professional development.

\section{References}

French, D. N., Jones, T., Kraemer, W. J. (2014). Strength development in youths. In R. Lloyd \& J. Oliver (Eds.), Strength and conditioning for young athletes: Science and application. Routledge.

\section{Presenter Biography}

Leonel Rodrigues is a Physical Education teacher and a Futsal and Volleyball coach. Rodrigues has a Master's in Sport Sciences, with a specialization in Sport for Recreation and Leisure, from the University of Porto Faculty of Sport Sciences and Physical Education (Portugal). He has an Advanced Studies Diploma (DEA) in Qualitative Research, Quantitative Research and his research capacity is in the field of Physical Education and Sports knowledge, conducted through the University of Lleida (Spain). Rodrigues has a Master's in Educational Sciences, with a specialization in Administration and Educational Policies from the University of Aveiro Portugal.

\section{S}

An Insight into Short-Sprint Coaches' Knowledge and Use of Periodisation Models and Training Methods

Sellathurai, Jeganenthiran ${ }^{1,2,3}$ \& Draper, Nick ${ }^{1}$

${ }^{1}$ University of Canterbury, New Zealand; ${ }^{2}$ Sabaragamuwa University of Sri Lanka; ${ }^{3}$ Sri Lanka Track and Field Coaches Association

Recent developments in applied sports coaching that use periodized training strategies to improve athletic performance have become increasingly attractive to coaches, athletes, and strength and conditioning practitioners. Coaches' knowledge and skills are crucial to the successful application of periodisation and training methods for improving performance. Despite its popularity and importance, little is known about the Sri Lankan context. As a result, the aim of this formative exploratory study was to examine the knowledge of, and application of, periodisation and training methods used by Sri Lankan elite-level coaches working with short-sprint athletes to achieve desired goals. Ten $(n=10)$ expert shortsprint coaches volunteered to participate in the study, with data collected via semi-structured interviews. The data were analysed inductively, involving discovering patterns, themes and categories using the NVivo 12 qualitative software. The techniques and procedures of Braun and Clarke (2006) were also followed. Four primary themes emerged from the interview data. These included Periodisation models, Monitoring training, Strength development, and Speed development. Results revealed that while coaches reported minimal or inadequate knowledge on periodised training, there appears to be a gap between coach knowledge of periodised training, strength and speed training load, and practice such as monitoring training load. They believed that their knowledge was inadequate to transfer athletes to the Olympics. The findings also highlight the importance of providing adequate coach education and development to enable coaches better prepare their athletes in Sri Lanka.

\section{References}

Braun, V., \& Clarke, V. (2006). Using thematic analysis in psychology. Qualitative Research in Psychology, 3(2), 77-101.

\section{Presenter Biography}

Jeganenthiran Sellathurai is a lecturer in Sports Science and the director of coaching, Sri Lanka Track and Field Coaches Association working with 
track and field coaches and athletes. He holds IAAF levels 1 and 2 (Sprint and Hurdles) coaching qualifications and has coached over 20 years from club to National level in Sri Lanka, the UK and New Zealand. He is completing his Ph.D. through the University of Canterbury (Christchurch, New Zealand).

\section{Running Involvement, Loyalty to Running, and Subjective Well-} Being: A Cluster Analysis for Coaches

Silva, Alfredo \& Sobreiro, Pedro

Polytechnic Institute of Santarém, Portugal

One of the main aims in policies of Sports and Health Government Departments is to increase sports participation to promote citizens health and well-being. Running is perhaps the most popular physical activity. Thousands of cities around the world host races from various distances: marathon, half marathon and road race $(10 \mathrm{~km}, 5 \mathrm{~km})$. The coaches of the groups of runners prescribe training, help us achieve goals and overcome personal challenges. Studies that analyze the effects of running on subjective well-being are rare, and there appears to be several gaps. The aim of the study was to find segments of runners based upon running involvement, loyalty to running and subjective well-being, through cluster analysis. A sample of 736 runners from one of Portugal's most popular athletics races completed a questionnaire, assessing, running involvement, loyalty to running, subjective well-being and socio-demographic variables. The number of clusters was determined using the Bayesian Information Criterion. Four significant clusters were identified, reflecting, one (cluster 4) surprising levels and the other (cluster 2) the lower levels of subjective well-being. The surprising result showed that the cluster with the highest level of subjective well-being was not the group of runners with the highest level of loyalty to the race. Some clusters reflect relevant age and gender differences. The results allow us to draw a conclusion: The need for coaches to design training strategies focusing on the clusters' characteristics, which aim to promote sports participation, should seek to increase running involvement and subjective well-being.

\section{Presenter Biography}

Alfredo Silva is a professor of Sport Management at the Sport Science School of Rio Maior. He was chief at the Sports Institute of Portugal. His areas of interest are sports participation and performance evaluation. Silva is an editor and author of several books for coaches - judo, swimming and innovation in sport. He has published 6 articles in the last 2 years. He is a trainer in coaching courses. He was the winner of the National Research Award in Sport Management 2020.

Examining the Influence of Remote Coaching on Psychosocial Skill Development in Elite Athletes

Szedlak, Christoph ${ }^{1}$; Smith, Matthew ${ }^{2} ; \&$ Callary, Bettina ${ }^{3}$

${ }^{1}$ University of Southampton, Southampton, United Kingdom; ${ }^{2}$ University of Winchester, Winchester, United Kingdom; ${ }^{3}$ Cape Breton University, Sydney, Canada

Remote coaching methods have the potential to encourage a learnercentred coaching approach, which not only develops sporting skills but also psychosocial skills (Ciampolini et al., 2019). Focusing on psychosocial skill development is even more pertinent during a period where athletes have limited opportunities to practice and perform their sport, which could have a negative influence the athletes' mental well-being (Ravizza, 2002). Thus, the aim of this study was to examine how elite coaches perceive their actions when remote coaching, and how their athletes perceive that remote coaching can positively influence psychosocial skill development during a period of reduced social support and movement restrictions, as experienced through the United Kingdom COVID-19 lockdown between March and June 2020. In collaboration with British Sailing Team, we interviewed 9 coaches and 18 athletes and data were analysed using a thematic analysis. Our results highlight that inherent attributes of remote coaching (i.e., limited emotional awareness) impact on the athletes by encouraging autonomy and promoting reflection. Furthermore, remote coaching enhances connectivity and provides nontechnical support, which stimulates the development of athletes' psychosocial skills including self-worth, coping with stress, motivation, confidence, and strengthens the relationship by developing closeness. Our findings provide a novel contribution to literature as they highlight that remote coaching is an effective strategy to encourage the holistic development of the athlete. In addition, our findings suggest that remote coaching approaches provide a useful and innovative way to support and structure learning when in-person delivery is restricted (Stoszkowski et al., 2015).

\section{References}

Ciampolini, V., Milistetd, M., Rynne, S. B., Zeilmann Brasil, V., \& Viera do Nascimento, J. (2019). Research review on coaches' perceptions regarding the teaching strategies experienced in coach education programs. International Journal of Sports Science \& Coaching, 14(2), 216-228.

Ravizza, K. (2002). A philosophical construct: A framework for performance enhancement. International Journal of Sport Psychology, 33, 4-18.

Stoszkowski, J., Collins, D., \& Olsson, C. (2015). Using shared online blogs to structure and support informal coach learning- part 2: The participants' view and implications for coach education. Sport, Education \& Society, 22(3), 407-425.

\section{Presenter Biography}

Dr. Christoph Szedlak is an academic, researcher, and the Lead S\&C coach at the University of Southampton and has worked with a variety of different level athletes including Olympic, and World champions for over thirteen years. His research focuses on examining the psychological and social aspects of coaching and their impact on athletes' development. With a specific emphasis on innovative qualitative methods to present and disseminate findings, his research has gained international recognition within S\&C coach development and education.

\section{$\mathbf{T}$}

\section{Team-Talks: A Coaches' Perspective in Youth Football}

Tomlinson, Joe

\section{Ulster University, Northern Ireland}

An important role for the coach is to prepare athletes for competition. While the majority of preparation will be done during training, teamtalks allow coaches to influence performance one final time before competition and during intermission periods. It is surprising to see such limited research into team-talk practice. This study specifically aimed to find coach perceptions of team-talks from coaches in England working in development environments from U9-U18 and explores the content of team-talk and how this content is delivered. This study used a mixed-methods design, where data was collected by 30 questionnaires and 6 SSI's. These methods of data collection explored coach 
perceptions, content, and delivery, where they learnt to deliver teamtalks, differences between pre-, intermission and post-game speeches as well as factors which impact their team-talk. Results found all coaches used team-talks on matchday as a way to prepare players for the game by providing information and regulating player emotion. This study highlighted the type of informational and emotional content in coaches' team-talks and highlighted how coaches use challenges to guide performance and motivation. In terms of delivery, coaches highlighted player input as a key element for an effective team-talk. This study found Q\&A and Command coaching styles to be preferred and $88 \%$ of coaches used a whiteboard as a resource to aid delivery. Other aspects of the team-talk were highlighted such as how the coach uses other staff.

\section{Presenter Biography}

Joe Tomlinson is an academy football coach residing in England. He has been coaching since he was 16 years and has experience working in a variety of set-ups from grassroots to academy, specialising in the Foundation Phase (U8-U12). Joe graduated from Ulster University with an M.Sc in Sports Coaching \& Performance in September 2020.

\section{V}

How do Coaches Develop Facets of Performance They Deem to be Highly Influential on Match Outcomes?

Vickery, Will ${ }^{1} \&$ Nichol, Adam ${ }^{2}$

${ }^{1}$ Deakin University, Melbourne, Australia; ${ }^{2}$ Durham University, Durham, UK

The purpose of this study was to not only gain insight into those factors which cricket coaches considered to be influential on match outcomes but also, relatedly, what they focused on during practice. Ten cricket coaches (age $=29-57 \mathrm{y}$; coaching experience $=5-28 \mathrm{y}$; minimum of England and Wales Cricket Board Level 3 accreditation) took part in semi-structured interviews. These interviews were transcribed verbatim and reflexive thematic analysis (Braun \& Clarke, 2019) was conducted using an iterative, cyclical approach between data and theory. Three higher-order themes were identified in relation to key factors which coaches perceived to influence cricketing match performance: Skill-based (individual/specific, team/generic), Psychology/mentality of the players, and External. Unsurprisingly, most of the coaches noted that skill-based factors had a significant impact on match performance from both an individual and team perspective (e.g., number of wickets taken in the power-play). Many coaches, though, also noted that psychological (e.g., being in a good mental space) and external (e.g., pitch conditions) factors also had a considerable impact on performance. Despite this, most coaches appeared to focus on skill-based factors when preparing for a match, somewhat neglecting the other factors. These findings highlight that although coaches recognise that the outcome of a match is multifactorial, training environments often do not account for this. To provide a more representative training environment, cricket coaches may want to consider engaging with ecological dynamics (theory) to provide a greater explicit focus on psychological and tactical facets of performance, alongside players? technical skills.

\section{References}

Braun, V., \& Clarke, V. (2019). Reflecting on reflexive thematic analysis. Qualitative Research in Sport, Exercise and Health, 11(4), 589-597.

\section{Presenter Biography}

Will Vickery is a Lecturer of Sport Coaching at Deakin University with research interests in practice design and the impact this has on the development and performance of athletes. His post-graduate research whilst an intern with Cricket Australia examined the impact of smallsided games within the sport of cricket. Prior to his career in academia, Will held a number of coaching positions within cricket (Cricket NSW) and touch football (North East Touch Football) ranging across junior to elite playing levels.

\section{The Coaching Behaviours and Practice Structure Used by a Player- Coach: A Case Study}

Vickery, Will ${ }^{1}$; Nichol, Adam $^{2}$; \& Bhardwaj, Dhanur ${ }^{1}$

${ }^{1}$ Deakin University, Melbourne, Australia; ${ }^{2}$ Durham University, Durham, UK

Systematic observations in recent times have provided greater insight into the behaviours used by coaches, particularly head/full-time coaches (Cope et al., 2017). In many cases throughout non-professional sport, however, sports clubs and organisations may not have the capacity to hire a full-time coach, in which case, a current player takes on the additional responsibility. The aim of this case study was to examine the coaching behaviours of a player-coach throughout various points of a cricket season. The participant (age $=34 \mathrm{y}$ ) was the head coach of a sub-elite senior men's cricket team ( $5 \mathrm{y})$ and a member of the first XI team. Examination of behaviour was completed using a modified version of the Coach Analysis and Intervention System (Cushion et al., 2012). A total of 5,874 behaviours were observed during six training sessions (mean duration $=125-25 \mathrm{~min}$ ). The most common behaviour observed was observation on-task $(15.3 \%$ of all behaviours), followed by convergent questioning (9.5\%), and observation off-task $(8.8 \%)$. The least common behaviours exhibited by the coach were punishment, skill-related pre-instruction, and scold (all $<0.5 \%$ ). Unique to this cricket context due to the changing role between coach and player was involvement in training $(1.3 \%)$, in addition to less commonly seen behaviours such as feeding (1.2\%) and conferring with players $(2.9 \%)$. The manner in which the player-coach interacts with their players appears to differ to that of non-player coaches from previous research (Hall et al., 2016; Stonebridge \& Cushion, 2018).

\section{References}

Cope, E., Partington, M., \& Harvey, S. (2017). A review of the use of a systematic observation method in coaching research between 1997 and 2016. Journal of Sports Sciences, 35(20), 2042-2050.

Cushion, C., Harvey, S., Muir, B., \& Nelson, L. (2012). Developing the Coach Analysis and Intervention System (CAIS): Establishing validity and reliability of a computerised systematic observation instrument. Journal of Sports Sciences, 30(2), 201-216.

Hall, E. T., Gray, S., \& Sproule, J. (2016). The microstructure of coaching practice: Behaviours and activities of an elite rugby union head coach during preparation and competition. Journal of Sports Sciences, 34(10), 896-905.

Stonebridge, I., \& Cushion, C. (2018). An exploration of the relationship between educational background and the coaching behaviours and practice activities of professional youth soccer coaches. Physical Education and Sport Pedagogy, 23(6), 636-656. 


\section{Presenter Biography}

Will Vickery is a Lecturer of Sport Coaching at Deakin University with research interests in practice design and the impact this has on the development and performance of athletes. His post-graduate research whilst an intern with Cricket Australia examined the impact of small-sided games within the sport of cricket. Prior to his career in academia, Will held a number of coaching positions within cricket (Cricket NSW) and touch football (North East Touch Football) ranging across junior to elite playing levels. 


\section{Coaching Systems}

(in alphabetical order by first author's last name) 
A

Building the Saudi Arabian Coaching Framework: Analysis of the Process

Avelar-Rosa, Bruno ${ }^{1,2,3}$; Aloqaily, Farah ${ }^{1}$; Macià, Anna ${ }^{1}$; \& Pinillos, Jordi $^{1}$

${ }^{1}$ Qantara Sports (Dubai, EAU); ${ }^{2}$ University of Coimbra, Faculty of Sports Science and Physical Education (Coimbra, Portugal); ${ }^{3}$ Education and Culture Research Group and Chair of Sport and Physical Education Centre of Olympic Studies, University of Girona (Girona, Spain)

The recently created Saudi Arabian Coaching Framework was developed in line with the International Coaching Framework (ICCE, 2013), following the methodological approach proposed by Lara-Bercial et al. (2017) and facilitated by Qantara Sports. The design process was settled according to the following main steps: (1) diagnosis on the experience, needs, and motivations of Saudi sport federations through individual interviews, a customized survey for each federation, and through focus group discussions with all Federation's Coach Developers or Technical Directors; (2) identification of existing coaching frameworks by International Sports Federations or alternative best practice models in search of the characteristics of each international framework and the way they are linked to other national coach systems; (3) design of the Saudi Coaching Framework (consistent to the International Frameworks and local context) through a competence-based approach where the learning outcomes of every-grade (i.e., 3 grades) are consistent with the occupational standards defined for every stage of athlete's development, and designing 9 specific-sport Coaching Frameworks (selecting sports having an international framework managed by the respective International Sport Federation), namely Badminton, Basketball, Badminton, Football, Handball, Judo, Swimming, Volleyball and Tennis; and (4) validation in final consultation of the Saudi Coaching Framework and the 9 Sport-specific Frameworks by the stakeholders. After this process, the Saudi Ministry of Sport adapted and implemented the new Saudi Coaching Framework, thus seeking the accomplishment of the Saudi Vision 2030 objective 2.2.1: Increase public participation in sports and athletic activities.

\section{References}

International Council for Coaching Excellence, Association of Summer Olympic International Federations \& Leeds Metropolitan University. (2013). International Coaching Framework Version 1.2. Human Kinetics. https://www.icce.ws/_assets/files/iscf-1.2-10-7-15.pdf

Kingdom of Saudi Arabia. (2016). KSA vision 2030: Strategic objectives and vision realization programs. KSA.

Lara-Bercial, S., North, J., Petrovic, L., Oltmanns, K., Minkhorst, J., Hämäläinen, \& Livingstone, K. (2017). Understanding, planning and developing a coaching system. CoachLearn Project consortium.

\section{Presenter Biography}

Bruno Avelar-Rosa, partner of Qantara Sports and a researcher in the field of Sport and Coach Education, led the design of the Saudi Coaching Framework. He holds a Ph.D. in Education Psychology and a Bachelor in Sports Science. He has about 15 years working experience as a coach developer in collaboration with different public entities, sport federations and higher-education institutions in different countries. He is a certified coach in Karate and Judo.

\section{Brazilian Table Tennis Federation Coaches' Education Program: First Steps and Future Challenges}

Belli, Taisa ${ }^{1,2} \&$ Galatti, Larissa Rafaela ${ }^{1}$

${ }^{1}$ School of Applied Sciences - University of Campinas - Limeira/SPBrazil; ${ }^{2}$ Brazilian Table Tennis Federation - Rio de Janeiro/RJ - Brazil

Recently, Brazilian Table Tennis Federation launched Table Tennis University, a program which embraces a full three level program for coaches' development (i.e., Beginners, Development of Athletes, and High Performance), to stimulate the entrance of new professionals as well as the continuous improvement for the experienced ones. This presentation describes the development of the Beginners course, including its key points and future challenges. This coaching program will certify both Olympic and Paralympic Table Tennis coaches, in an integrative perspective. This first course has been developed in a partnership between the Brazilian Table Tennis Federation and the University of Campinas. Firstly, we outlined the values of the course, which includes a) a Learner-Centered Coach Education, b) the development of the athletes and recreational participants as well as the development of the person, and c) a game-based and player-centered pedagogical approach. These values permeated the entire course development by means of activities that evidence them into practice. Moreover, the Developmental Model of Sport Participation, the Table Tennis Road to High Level, and the Nonlinear Pedagogy were the theoretical bases for the application of our last two values. Secondly, the course was designed to be delivered in a blended model including 36-h of in-person, 12-h of online courses, and 30-h of coaching practice associated with formative assessment. Finally, our future challenges include the implementation of the course and the recruitment and training of coach developers, who will be responsible to deliver the course in a continental country as is Brazil.

\section{Presenter Biography}

Taisa Belli: Leader of the Table Tennis University at the Brazilian Table Tennis Confederation (CBTM). Professor at the School of Applied Sciences at the University of Campinas (FCA/UNICAMP), acting in the Undergraduate Course in Sports Sciences, in the Graduate Program in Nutrition, Sports and Metabolism Sciences and as Leader of the Interdisciplinary Research Group on Racket Sports (GRIPER). Bachelor's in Physical Education, Master's in Physiological Sciences, Ph.D. in Movement Sciences, and Post-doctorate in Human Movement Sciences.

\section{The Importance of Federative Initiatives to Act as a Gymnastics} Coach Around the World

Bento-Soares, Daniela ${ }^{1} \&$ Schiavon, Laurita Marconi ${ }^{2}$

${ }^{1}$ São Paulo State University, Rio Claro, Brazil; ${ }^{2}$ Univerity of Campinas, Campinas, Brazil

Coach education has been increasingly studied and validated as essential for the development of the different sports. The types of coaching systems attribute significance to diverse programs and influence the development of sports practices. In this research, National Gymnastics Federations (referred to here as NGB) were consulted about their requirements regarding 
coach education to work with gymnastic disciplines and Gymnastics for All. From an online questionnaire hosted on the Google Forms platform and offered in four languages, 44 responses were obtained from institutional managers, responsible for Education segments or specialists in Gymnastics for All. It was found that eight institutions require university degrees and thirty require specific education in Gymnastics, among which technical-pedagogical courses $(n=19)$, complementary academic courses $(n=7)$, the course offered by International Gymnastics Federation $(n=1)$ and their own coach education programs $(n=2)$ are included. Although academic literature points out that university degrees can potentialize coach education (International Council for Coaching Excellence [ICCE], 2013; Jones et al., 2012; Milistetd, 2015; Morgan et al., 2013), the data highlight the great importance of learning opportunities offered by NGB. It seems specific education is valued over comprehensive education, which attributes to such programs the responsibility of considering socio-educational and cultural issues, in addition to strictly technical training. The data indicate that there is a need to analyse the programs offered by the NGB and to encourage partnerships between universities and sports institutions.

\section{References}

International Council for Coaching Excellence, Association of Summer Olympic International Federations \& Leeds Metropolitan University. (2013). International Coaching Framework Version 1.2. Human Kinetics. https://www.icce.ws/_assets/files/iscf-1.2-10-7-15.pdf

Jones, R. L., Morgan, K., \& Harris, K. (2012). Developing coaching pedagogy: Seeking a better integration of theory and practice. Sport, Education and Society, 17(3), 313-329. https://doi.org/10.1080/ 13573322.2011 .608936

Milistetd, M. (2015). A aprendizagem professional de treinadores esportivos: análise das estratégias de formação inicial em Educação Física. [Doctoral thesis, Universidade Federal de Santa Catarina].

Morgan, K, Jones, R. L., Gilbourne, D., \& Llewellyn, D. (2013). Changing the face of coach education: Using ethno-drama to depict lived realities. Physical Education and Sport Pedagogy, 18, 520-533. https://doi.org/10 $.1080 / 17408989.2012 .690863$

\section{Presenter Biography}

Daniela Bento-Soares has her doctorate in Physical Education (University of Campinas) and visiting student at Cardiff Metropolitan University (Wales) in 2017. Leader of the Gymnastics Study Group AGIR (Centro Universitario Unieduk) and member of the Study Groups GPG and Lapegi (Unicamp). Member of the Gymnastics for All Committee in the São Paulo Gymnastics Federation. University professor. Daniela is interested in studying and promoting learning opportunities in connection with the contexts of the coaches and through the promotion of good relationships among peers and mediators.

\section{Para Sports-High-Performance Para Coach Development - Olym-} piatoppen Norway

Bjørkøy, John Anders; Heggeb $\varnothing$, Frank; \&Vik, Iwonka

Olympiatoppen, The Norwegian Centre for Elite Sports, Oslo, Norway

The Para Coach Academy is a coach development program for high performance Para coaches in Norway. Participants in the program are potential Paralympic coaches. During the design and delivery of the program we have explored how to effectively develop Paralympic coaches, what competencies are important for these coaches, and the importance of being part of an effective and relevant network. During the last 18 months we've had regular meeting points and each of the 8 participants have had their own mentor from Olympiatoppen. Contributors into the program have been experienced Paralympic coaches and athletes, researchers, and specialists on themes with special relevance for our group of coaches. Development of Para coaches are integrated into regular coach development systems and programs in Norway. The Para Coach Academy have explored whether our future Paralympic coaches also have a need for other competencies than our regular programs deliver, what competencies that are of importance, and how to build an effective and positive network for Para coaches.

\section{Presenter Biography}

John Anders Bjørkøy is a former professional football player now working as head of coach development at Olympiatoppen, The Norwegian Centre for Elite Sports. Frank Heggebø is a former cross-country athlete and coach, now working with coach development at Olympiatoppen. Iwonka Vik have massive experience form working closely with different high performance Paralympic athletes and coaches at Olympiatoppen.

\section{C}

Female Mentorship Programs: The Importance of Mentee Training Callary, Bettina ${ }^{1}$; Belalcazar, Catalina ${ }^{1}$; \& Johnson, Andrea ${ }^{2}$

${ }^{1}$ Cape Breton University, Nova Scotia, Canada; ${ }^{2}$ Coaching Association of Canada, Ottawa, Canada

The Coaching Association of Canada (CAC) has been leading Women in Coaching programs for over 20 years and uses mentorship within their programs to strengthen the development of coaches. Over the past year, the CAC has been able to support over 100 women coach mentees working with mentors. The CAC uses the Female Coach Mentorship Model (FCMM; CAC, 2017) to guide mentorship programs. A key component is preliminary mentor training to ensure their roles and responsibilities are understood. An evaluation of the mentorship programs revealed that mentees need more support to understand the mentorship process and mentee role expectations. Therefore, this presentation outlines the creation of a Mentee Training resource for effective mentee training, which can be used by all mentorship programs in the sport community. We firstly conducted focus groups with the cohorts of mentees from the 2020-2021 female mentorship programs to determine what they liked, what they wanted, and what they needed regarding their training as mentees. Based upon these findings, we created a pilot mentee training program which included a kickoff webinar, two training sessions, and homework to do alone and with their mentors. The pilot was implemented with the 2021-2022 cohort of the Enhanced Female Mentorship program mentees. We evaluated the relevance and effectiveness of the new mentee training by conducting focus groups with the mentees, mentors, and an interview with the facilitator, and created the Mentee Training resource for future mentorship program cohorts. Funding provided by the CAC and the Sport Canada's Researcher/Practitioner Match Grant.

\section{References}

Coaching Association of Canada. (2017). Female coach mentorship model. Coach. https://coach.ca/female-coach-mentorship-model

\section{Presenter Biography}

Dr. Bettina Callary is the Canada Research Chair in Sport Coaching and Adult Learning and an Associate Professor at Cape Breton University, in 
Nova Scotia. She researches coach education and development, coach developers, and psychosocial understandings of inclusive coaching. Dr. Callary is the Editor-in-Chief of the International Sport Coaching Journal. She recently co-edited two books, Coach Education and Development in Sport: Instructional Strategies and Coaching Masters Athletes: Advancing Research and Practice in Adult Sport, published by Routledge.

\section{Coaching Practice \& Education in the Digital Space}

Chng, Lynnette ${ }^{1} \&$ Chua, Yong Joo $^{2}$

${ }^{1}$ Deputy Director (Coaching Industry Development), Sport Singapore; ${ }^{2}$ Senior Manager (Coaching Development), Sport Singapore

The impact of COVID-19 on coaches and coaching was immediate and significant. Coaches had to pivot very quickly onto the online space and that posed a challenge to communities that did not possess the knowledge and skills to not only adapt but thrive in this new space. This presentation shares CoachSG's efforts and key strategies in supporting and enabling Coaches to navigate the digital space for their coaching practices and education in 2020-21. One key strategy was to develop online resources that coaches can easily plug and play for their athletes and teams and in tandem to this, the upskilling of the coaches through professional development. To this end, CoachSG developed a suite of over 30 Home-Based Learning packages in collaboration with our National Sports Associations and user-friendly guides for coaches to bring their coaching into the digital space in both synchronous and asynchronous formats. We supported their Continuing Coaching Education needs with over 60 live e-workshops, which included over 5,000 in attendance and extended viewing of 45,000 on our social media channels. The introduction of a new SportSG Education \& Development (SportSG-ED) online learning platform has become a game changer in coach education. It enables the adoption of contemporary pedagogical approaches to coach education (i.e., blended, active and social collaborative learning) and facilitates an online Communities of Practice. This includes charting the coaches? training roadmaps based on their profile. The presentation will showcase the platform and our experience in developing the content.

\section{Presenters Biography}

Lynnette Chng leads the Coaching Industry Development Team in CoachSG that drives the employment-related policies and develops partnerships to raise the profile of coaches in Singapore. She had attended the NSSU-ICCE Coach Developer Programme in 2016 and obtained a Graduate Diploma in Coaching from the University of Queensland, Australia.

Yong Joo Chua is a Senior Manager (Coaching Development) since 2017. His work includes curriculum development, policy development, course delivery and implementation of the SG- Coach Education and Development Pathway. He also oversees the Coach Developer programmes and network in partnership with international organisations.

\section{D}

Experiential Learning in Action: The Development of a Coaching Fellowship Programs

Darnell, Clark

The University of North Carolina Greensboro and The Charlotte Country Day School

The presentation is designed to showcase the framework of the Charlotte Country Day School Strength and Conditioning Coaching Fellowship Program. The fellowship is a cooperative effort designed to provide current or recent university graduate students with the opportunity to obtain professional experience in the field of strength \& conditioning with a nationally recognized strength \& conditioning program (NSCA Strength of America Award Winner). The purpose of the fellowship is to augment formal classroom instruction, to experiment with theory and concepts, to utilize practical applications, and to begin the development of professional competency for a full year. Charlotte Country Day is a junior kindergarten (JK) through 12th-grade independence school in Charlotte, North Carolina. Charlotte Country Day's strength and conditioning department services 70 athletic teams within 26 different sports. The strength and conditioning department have one director, two full-time staff, and multiple coaching fellows and interns.

\section{Presenter Biography}

Darnell Clark CSCS*D, RSCC*D, is the Director of Strength and Conditioning at Charlotte Country Day School. He oversees the athletic development pathways for 70 teams within 26 sports. He holds degrees from Northwestern University, Arizona State, and is a doctoral candidate in kinesiology at the University of North Carolina at Greensboro. Coach Clark is a long-time member of the National Strength \& Conditioning Association, where he was awarded the National High School Coach of the Year in 2014 and has served as the North Carolina State Director, Southeast Regional Coordinator, and Board of Directors (Vice President).

\section{Communication, Relationships and Individual Differences: Does “One Size Really Fit All”?}

Davis, Louise ${ }^{1}$; Jowett, Sophia ${ }^{2} ; \&$ Sürman, Daniel ${ }^{3}$

${ }^{1}$ Department of Psychology, Umeå University, Sweden; ${ }^{2}$ School of Sport, Exercise and Health Sciences, Loughborough University, United Kingdom; ${ }^{3}$ Department of Health, Education and Technology, Luleå university of Technology, Sweden

Many world class athletes attribute their inspiration, development, and success to high quality relationships with their coach. Yet relationships can be difficult to manage, and poor-quality coach-athlete relationships contribute to unfavourable outcomes. Research (Davis et al, 2019) has suggested that one way to enhance the effectiveness of the coach-athlete relationship is through the use of communication strategies (COMPASS). That said, research also identifies that there may be potential variation in the utility of specific communication strategies across individual difference characteristics (e.g., personality). Therefore, the present study aimed to examine the moderating role of athlete attachment on the relationship between athletes' perceptions of communication strategies, the quality of their coach-athlete relationship, and athletes basic psychological need satisfaction. Swedish athletes $(\mathrm{N}=350)$ representing individual and team sports and competing at National, International, and Regional levels, completed a multi-section questionnaire. Mediation and moderation analysis found that relationship quality (3Cs) and athletes basic psychological needs were associated via the COMPASS strategies of support, motivation, assurance, and openness. Additionally, it was also found that athletes secure attachment with their coach significantly moderated the mediated effects of motivation and support. The findings provide preliminary evidence to suggest that coaches may have to adapt their communication strategies to their athletes preferred style of interaction to elicit an effective relationship and to satisfy athletes psychological needs of competence, autonomy and relatedness. Future research could examine the efficacy of intervention programs whereby communication strategies are systematically implemented to enhance both relationship quality and its outcomes. 


\section{References}

Davis, L., Jowett, S., Tafvelin, S. (2019). Communication strategies: The fuel for quality coach-athlete relationships and athlete satisfaction. Frontiers in Psychology, 10, 2156. https://doi.org/10.3389/fpsyg.2019.02156

\section{Presenter Biography}

Louise Davis received her Ph.D. from Loughborough University in 2012. She is now an associate professor in sport psychology at the Department of Psychology, Umeå University, Sweden and teaches on the riksidrottsuniversitet (National sports university) elite coaching program. Louise is a member of the research network at Umeå University's school of sport sciences and a post-doctoral researcher for the Swedish research council for sports science (CIF). Louise's research specialises on the psychology of sports coaching, with a focus of examining athletes' psychosocial environment.

\section{The Lived Experience of Coaches From Ethnically Diverse Back- grounds and Lower Socio-Economic Groups}

Douglas, Heather; Konrad, Collao; \& Downham, Lauren

\section{UK CoachingCraft}

The research aimed to understand the experiences of coaches from ethnically diverse communities and lower socio-economic groups (LSEG). Research questions focused on the perceived benefits, challenges of, and barriers to, coaching. The purpose of the research was to collect a series of stories as evidence to inform methods of support for coaches across the United Kingdom (UK). In response to the global pandemic (COVID-19), data were collected digitally through a remote approach. Individual interviews were conducted with twenty coaches $(\mathrm{n}=10$ LSEG, $\mathrm{n}=10$, HSEG and $n=11$ male, $n=9$ female) following the completion of a thematic digital task and a video diary (total 18 hours of footage). Results showed that the benefits of coaching were both inward (e.g., life lessons, self-improvement) and outward facing (e.g., giving back to the local community), while barriers included micro-aggression and veiled discrimination, financial constraints, education-based exclusion, and a perceived lack of opportunities to progress. Implications from the work emphasised the need to increase the relatable profile of coaches and coach developers and improve access to learning and assessment. These findings indicate that research focused on understanding the demographics and recruitment processes of the coach development workforce as well as a review of current pathway and assessment structures is required.

\section{Presenter Biography}

Dr. Lauren Downham is the Market Research Manager at UK Coaching and a Research Associate at Loughborough University. In these roles, Lauren works closely with National Sport Organisations investigating contemporary coaching issues to produce evidence-based implications to support coach development. Lauren has ten years' coaching experience in both participatory and youth performance contexts. This latest research was commissioned by UK Coaching and conducted by Craft an insights agency - who will co-present the work.

\section{H}

Equestrian Coaching in Crisis: Why It's Today's Problem \& Tomorrow's Solution to Our Sport's Future

Halden-Brown, Sue

Equestrian Coach Education International
Equestrians have faced their fair share of crises in the past, but none so immediate nor so compelling as that which confronts us today. The impact of commercialization on equestrian sport has been immense, and the consequences of professionalization are profound. Add to this, the presence of strong market forces, and a vigorous competition culture at all levels, and we have an exciting - but volatile - mix of tradition and innovation in a sport with a proud history of some two thousand years. There's a new sporting demographic in town, too, and this highly vocal cohort is demanding change. The general public, which holds our social license in its back pocket, is also calling us to account. After centuries of traditional coaching, it's now clear that updates are no longer enough. To grow our sport for the future, we must up-skill our coaches. In response to these challenges, I share a major project to reform equestrian coach education and development. It outlines the expanded curriculum and details a new learner-centered pedagogy, designed to better meet the learning needs of the $21 \mathrm{st}$ Century demographic of digital riders. In tandem with this educational initiative, I also propose a new business model, to support the structural hub of the sport, as it transitions from traditional practices to this new working model, amid the concerns and uncertainties of our New Normal world.

\section{Presenter Biography}

Sue Halden-Brown is a former Olympic coach, career coach educator and developer, and author of numerous educational and e-learning resources, books, and articles. Sue is currently engaged in an international project in equestrian coach education. She is also an international keynote presenter, university guest lecturer, Director of Equestrian Coach Education International, and Founding President of Australian National Equestrian Coaches Association. Sue lives in southern Australia, with her husband, horses, multiple dogs, and numerous kangaroos.

\section{K}

\section{Vocational Coaching Qualifications in Finland}

Kokkonen, Maiju ${ }^{1}$; Antikainen, Juha ${ }^{2}$; Asp, Thomas ${ }^{3}$; Hokka, Jukka ${ }^{4}$; Kainulainen, Pekka ${ }^{5}$ Kari, Jaana ${ }^{6}$; Lilli, Jorma ${ }^{7}$; Toivola, Juuso ${ }^{8}$; \& Tossavainen, Aleksi ${ }^{9}$

${ }^{1}$ Sport Institute of Finland; ${ }^{2}$ Varala Sports Institute; ${ }^{3}$ Folkhälsan, Solvalla Sports Institute; ${ }^{4}$ Kisakallio Sports Institute; ${ }^{5}$ Pajulahti Sports Institute; ${ }^{6}$ Vuokatti Sports Institute; ${ }^{7}$ Kuortane Sports Institute; ${ }^{8}$ Santasport Institute; ${ }^{9}$ Eerikkilä Sport \& Outdoor Resort, Finland

The Finnish education system provides multi-level paths to educate coaches in their coaching career. For adult students, there are two vocational possibilities: Further Vocational Qualification in Sports and Coaching and Specialist Vocational Qualification in Coaching. These educations are organized by Sport Institutes. To complete a competence-based qualification, candidates must demonstrate certain skills and competence required in the profession. These skills are outlined in the Requirements of Competence-based Qualifications defined by the National Board of Education. Vocational modules are defined in collaboration with representatives of Sport Life and are directly based upon real-life work tasks. In Further Vocational Qualification of Sports and Coaching programs students can specialize in coaching children, youth, or adults sport. The most common work environments are exercise and sports clubs, coaching centres, sports institutes, and professional sports organisations. Some work as 
coaching entrepreneurs. The Specialist Vocational Qualification in Coaching is planned for National Team coaches, sports academy coaches, youth Olympic coaches and high-performance managers. They can specialize in international level coaching, system developing or management. The program includes 1-2 years of preparatory education and competence demonstrations in their own working environment. Evaluation is made by professionals from both education and work life. The advantage of this system is the adjustability. Students can learn and improve their skills based upon their own sport-specific needs.

\section{Presenter Biography}

Maiju Kokkonen (Master's of Sport and Health Sciences), works as Coach Developer for Sports Institute of Finland. She is an ICCE trained coach developer and has also completed the training requirements for the ICCE Introduction to Trainer of Coach developers Programme. She has been a full time Figure Skating Coach at club level and Education Manager in Finnish Figure Skating Association.

\section{M}

\section{Trends in Education of Sports Coaches in Bulgaria}

Mileva, Eleonora \& Dobreva, Albena

\section{National Sports Academy "Vassil Levski”, Sofia, Bulgaria}

Modern socio-economic conditions in both Europe and Bulgaria and the processes of globalization and internationalization in the field of sports education place higher requirements for the professional training and qualification of coaches. A positive moment in the development and approval of the educational requirements for the coaching profession in Bulgaria is the adoption of Regulation 1 on the coaching staff, adopted in 2019. This official document sets out the requirements for the professional qualification of the sports pedagogical staff in the Republic of Bulgaria as five different positions of the sports coaches in the country, and the minimum requirements for their occupation are given. The current study aims to examine the extent to which future coaches are motivated to work in their professional field. The subject of study are 115 students from the Coaches Faculty at the National Sports Academy in Bulgaria. A specialized questionnaire is created. The analysis of the results shows that young people want to work as coaches after their graduation. The share of respondents who express a desire to continue their education in the future is significant. At the same time, the status of the coaching profession in Bulgaria is assessed as not very high, as the main reason are various social factors in the country.

\section{Presenter Biography}

Professor Eleonora Mileva is a lecturer in Sports Pedagogy at the National Sports Academy in Sofia, where she leads separate educational courses and modules. She has been a lecturer in various seminars and courses for PE teachers and coaches. Professor Mileva specialized at the German Sports University in Cologne. She is the author of numerous books, textbooks and over 190 scientific articles. The author is a participant in many scientific congresses, conferences, and symposia in Bulgaria and abroad as well as in international research and educational projects.

\section{$\mathbf{T}$}

Game for Life: A Structured Mentoring Programme Supporting Coaches to Integrate Values in Coaching

Tan, Eliza ${ }^{1}$; Koh, Koon Teck ${ }^{2}$; Tan, Warrick ${ }^{3} ; \&$ Rahman, Hanif Abdul ${ }^{4}$

${ }^{1}$ CoachSG, Sport Singapore, Singapore; ${ }^{2}$ National Institute of Education, Singapore; ${ }^{3}$ National Institute of Education, Singapore; ${ }^{4}$ Physical Education \& Sports Teacher Academy, Singapore

The emphasis on the integration of affective domain in coaching practice is not widespread amongst the coaching fraternity in Singapore. Based upon a review conducted amongst stakeholders, training and upskilling of our coaches was identified as a key strategy for Character and Leadership Development through Sport (CLDS). Specifically, the provision of support programmes and competency certifications to allow employers to identify competent CLDS coaches were identified as key components. This led CoachSG to initiate the first formal structured mentoring programme to develop and certify coaches who are competent in using sport as a platform for character development. The programme was anchored on the SportSG's Game-for-Life (GFL) framework as the approach for the intentional design to facilitate CLDS outcomes, whereby interested coaches will be matched to an experienced mentor to guide them on effectively layering on the affective domain as part of their coaching practice before being assessed for their competency. Through this programme, CoachSG hopes to bring more clarity to the coaching standards and competencies needed to effectively design sporting experiences to bring about character development. The programme would also allow for the identification and development of role-model coaches around CLDS that the coaching industry can leverage on to nurture more coaches and build best practices. The presentation aims to share about the: 1) conceptualisation and design of the GFL Mentoring Programme, 2) strengths and challenges of a structured mentoring programme, 3) findings on the effectiveness of the programme, and 4) recommendations on how stakeholders can work together.

\section{Presenter Biography}

Eliza Tan is a Manager and Coach Developer at the Character \& Leadership Development Team in CoachSG, where she specialises in developing curriculum and programmes to upskill sport educators to foster character and leadership development outcomes through sport. She also provides consultation and design expertise to various government organisations, schools, and sporting organisations for character and leadership development initiatives. Eliza is also a certified behavioural consultant and has conducted workshops for staff within the organisation to facilitate team development outcomes.

\section{Respect for Coaches' Actions to Promote Appreciation}

Tuunainen, Sari ${ }^{1}$; Hämäläinen, $\mathrm{Kirsi}^{2}$; \& Nieminen, Raino ${ }^{3}$

${ }^{1}$ Finnish Coaches Association; ${ }^{2}$ Finnish Olympic Committee; ${ }^{3}$ Professional Coaches of Finland

Central to the activities of the Finnish Coaches Association is to enhance the public perception of coaches and coaching. The basis for this work is the Coach Matters campaign, which was launched at the end of 2016, in cooperation with the Professional Coaches of Finland and the Finnish Olympic Committee. The principles of good coaching 
and ethical guidelines for all stages of the athlete's path are the foundation materials of the campaign. The Coaches Day, held on 25th of September, was launched in 2019 when Finland oversaw the European Week of Sport (EWoS) due to holding the EU Presidency mandate. The initiators are Finnish Coaches Association, Professional Coaches of Finland, Finnish Olympic Committee, and International Council for Coaching Excellence. The Finnish National Agency for Education is involved as the contact point of EWoS in Finland. The theme of the day is \#ThanksCoach (\#kiittikoutsi in Finnish), and it is held in conjunction with the \#beactive activities of the EWoS. The idea is to highlight the valuable work of sports coaches foremost by sharing thanks on social media. The Hall of Coaching Excellence was launched at the end of 2017. It is a tribute to the people who have actively contributed to Finnish coaching. Other concrete measures promoting the appreciation of coaches include the selection of the Coach of the Year and of Coach of the Month and application of prizes and badges of merits for coaches.

\section{Presenter Biography}

Sari Tuunainen holds a Master's degree in Sport Sciences from the University of Jyväskylä. She also graduated with an Executive Master's in Sport Organisations Management (MEMOS) under the supervision of the Universite de Poitiers. Her current position is Executive Director at the Finnish Coaches Association, which is the home base for around 4000 coaches in Finland.

\section{V}

How Can Public, Private and Academic Partners Work Together in Coach Education? The Flemish Example

Vangrunderbeek, Hans \& Ponnet, Hans

Flemish School for Coach Education, Brussels, Belgium

A recent report outlining the EU coaching landscape (Lara-Bercial et al., 2020) made clear that a wide range of providers (e.g., tertiary education, sport federations, vocational institutions) contribute to the delivery of sport coaching qualifications. These disparate systems can lead to a lack of widespread application of a 'right to practice' and fragmented career structures. Deeper analysis to establish good practice within coaching systems is therefore recommended. This contribution aims to provide more insight in the way public government, sports federations, and universities/ schools of higher education work closely together with regard to coach education in Flanders through a cooperative association, the Flemish School for Coach Education. Each year 9,000 coaches follow one or more of the 4-level coach education programs in 50 different sports (Ponnet et al., 2020; Vangrunderbeek \& Ponnet, 2020). As a result of this partnership, all strategic and operational ruling and decisions regarding coach education in Flanders are always made by consensus between all partners. Common tasks and specific duties of each of the partners will be discussed. Insight will be provided in relation to how different coach education pathways are embedded within one common coach education framework. For example, as a result of the collaboration with university institutes for physical education within the Flemish partnership, since 1996, a specific pathway has existed for university students.

\section{References}

Lara-Bercial, S., Calvo, G., North, J., Moustakas, L., \& Petry, K. (2020). CF21 EU Coaching Landscape Baseline Report 2020. CoachForce21. https://www.coachforce.eu/
Ponnet, H., Vangrunderbeek, H., \& McCarthy, L. (2020). The Flemish Interactive Coaching Monitoring Systems (FICOMS). International Sport Coaching Journal, 1-10. https://doi.org/10.1123/iscj.2020-0093

Vangrunderbeek, H., \& Ponnet, H. (2020). The history of coach education in Flanders. International Sport Coaching Journal, 7(3), 380-389. https:// doi.org/10.1123/iscj.2020-0049

\section{Presenter Biography}

Dr. Hans Vangrunderbeek is coach education manager at the Flemish School for Coach Education. In his Ph.D., he focussed on the scientific development of physical education/sports in Belgium. In 2011, he obtained a grant for a research stay at Harvard University in Cambridge. He published more than 40 papers within the fields of sports (history, sociology, pedagogy, ethics, management, coach education) and gave lectures at several international congresses. In 2019-2020, he successfully completed the NSSU-ICCE Coach Developer program in Tokyo.

\section{Z}

\section{Project Presentation: Coaches in Germany (TrainerInSport- deutschland)}

Zehnder, Eva \& Witusch, Christian

German Olympic Sports Confederation (Deutscher Olympischer Sportbund, DOSB)

The goal of the Coaches in Germany project is to improve the situation of coaches at all levels by implementing the vision Coaches 2026 with its 13 guiding goals. The project is aimed at all coaches in Sports Germany (i.e., full-time, part-time, and voluntary coaches). All areas of sport are considered, such as top-level sport, junior competitive sport, children's sport, popular sport, disabled sport, etc. The transitions between the respective areas are often fluid, but the key function of coaches is equally given. The project, described in this presentation, is designed as a comprehensive and overarching organizational development project. It links the processes, knowledge transfer and competence acquisition within sports organizations. The aim of the DOSB as an umbrella organisation is to develop coaches and to initiate sustainable changes to improve the framework conditions for coaches in the long term. The target is to motivate and to mobilize the various players in the sports organizations for this common goal. The project sets a framework for the topic of coaches in which resources can be brought together and ideas can be jointly developed and implemented. Since the launch of the project in July 2019 by the DOSB and its youth organization German Sports Youth (Deutsche Sportjugend), numerous measures have already been implemented together with the member organizations: For example, in the areas of coach development, coach education, public relations and appreciation.

\section{Presenter Biography}

Eva Zehnder manages the 'TrainerInSportdeutschland' project. She steers and accompanies the activities and networks the various stakeholders. Previously, she worked as a trainee at the German Equestrian Federation. Christian Witusch is a consultant in the High-Performance Sports Division of the DOSB. His main area of responsibility at the DOSB is coaching in competitive sports. He is a member of the 'TrainerInSportdeutschland' project group. Previously, he was a state coach in the Saxony Handball Association. 
Digital Mentoring and Knowledge Management in "Coaches in Germany"

Zehnder, Eva \& Fabinskie, Wiebke

German Olympic Sports Confederation (Deutscher Olympischer Sportbund DOSB)

The German Olympic Sports Confederation (DOSB) has set the promotion of coaches as a core task and therefore is implementing the project Coaches in Germany. To achieve the vision Coaches 2026 and its 13 guiding goals, thematic sub-projects are implemented in the member organizations of the DOSB. The aim of the sub-projects is to develop and implement strategies and activities in one's own association that contribute to the vision. Selected sub-projects are digitally mentored and accompanied by the DOSB to raise the transversal potentials in the sense of an organizational development approach. Mentoring essentially pursues 3 goals: (1) It serves to support the sub-projects fulfilling their project goals, (2) it promotes networking, exchange, knowledge sharing and management between the sub-projects, and (3) it contributes to the long-term establishment of the project in the sports system in Germany. For this purpose, we use our
Online Learning Platform (EdubreakSportcampus) and our digital exchange platform (DOSB-knowledge network). By using these Platforms and their tools, we mentor the projects by reflection tasks, continuous feedback, and exchange. In addition to blog posts, a central tool is social video learning, where videos can be posted, precisely stopped, and annotated and reflected on together. Using the example of the project Coaches in Germany you will hear in this presentation about an innovative approach to knowledge transfer in projects with many partners and stakeholders and how digital learning communities and mentoring can be used to implement project success in a sustainable way.

\section{Presenter Biography}

Eva Zehnder manages the TrainerInSportdeutschland project. She steers and accompanies the individual measures and networks the various stakeholders. Previously, the educational science graduate worked as a trainee at the German Equestrian Federation. Wiebke Fabinski is Deputy Head of Education at the German Olympic Sports Confederation. Her work focuses on DOSB licence education, digital education, and knowledge management. 


\section{Other Coaching Issues}

(in alphabetical order by first author's last name) 


\section{C}

Engaging in Paradigmatic Dialogue: A Bibliometric Analysis of Coaching Scholarship from 1970-2020

Campbell, Sara ${ }^{1}$; Atkinson, Obidiah ${ }^{2}$; Mills, Joseph ${ }^{3}$; Kuklick, Clayton ${ }^{3}$; Gearity, Brian ${ }^{3} ;$ \& McCullick, Bryan ${ }^{1}$

${ }^{1}$ University of Georgia, Athen, Georgia, USA; ${ }^{2}$ The Ohio State University, Columbus, Ohio, USA; ${ }^{3}$ University of Denver, Denver, Colorado, USA

Coaching science (CS) does not belong to a single discipline or paradigm, but instead sits at the intersection of multiple disciplines (i.e., exercise science, psychology, sociology, pedagogy) that span the natural and social sciences (i.e., positivism, constructivism). Despite the interdisciplinary nature of CS, most scholars, coach developers, and coaches operate only within their preferred discipline and paradigm, which limits how coaching is conceptualized and practiced (Cushion et al., 2006; North, 2013). To address this limitation, we used the dialectical approach (Greene, 2007) from mixed methods research to analyze bibliometrics records of CS produced between 1970 and 2020 from both a post-positivist and post-structuralist perspective. Using Web of Science, we identified 2, 522 coaching articles and organized the bibliometric data into a time-ordered matrix representing five decades of CS: (a) number of publications per year, (b) country of origin, (c) institution, (d) journal, (e) author, and (f) most cited articles. Two research groups analyzed the data concurrently and independently using their respective paradigm. Next, the two research groups came together to share their findings and discover areas of convergence and divergence. Both groups determined CS was heavily influenced by Western societies, sport psychology, and the topic of motivation. The postpositivists provided a comprehensive overview of evolutionary trends, while the post-structuralists elucidated relations of power, understudied problems in coaching, and consequences of the dominant knowledge produced. Together, the two paradigms offer different, but useful insights, and provide a more complete understanding of CS than any one paradigm could provide alone.

\section{References}

Cushion, C., Armour, K. M., \& Jones, R. L. (2006). Locating the coaching process in practice: Models for and of coaching. Physical Education \& Sport Pedagogy, 11(1), 83-99. https://doi.org/10.1080/1740898050 0466995

Greene, J. C. (2007). Mixed methods in social inquiry. Jossey-Bass.

North, J. (2013). Philosophical underpinnings of coaching practice research. Quest, 65(3), 278-299. https://doi.org/10.1080/00336297.2013 .773524

\section{Presenter Biography}

Sara Campbell is a Ph.D. candidate and research assistant at University of Georgia. Her research interests are in coach education, program evaluation and mixed methods research. Before commencing her studies at UGA, Sara spent six years as a lecturer at Montana State University Billings, where she taught physical education and exercise science courses. Sara is currently a coach developer for US Soccer and has 15 years of experience as a soccer coach. She is also a former professional soccer player.

\section{Enhanced Knowledge Mobilization Through Strategy and Collaboration}

Charest, Marie-Pier; Niedre Peter; \& Lafreniere, Lorraine

Coaching Association of Canada

The Coaching Association of Canada (CAC) unites stakeholders and partners in its commitment to raising the skills and stature of coaches, ultimately expanding their reach and influence. Through its programs, the CAC empowers coaches with knowledge and skills, promotes ethics, fosters positive attitudes, builds competence, and increases the credibility and recognition of coaches. This presentation will describe the strategy put in place to enhance knowledge mobilization for evidence-based decision making. After an extensive needs analysis on how research could better support the CAC's mission, Knowledge Mobilization and Dissemination was identified as a pillar to the 2018-2022 strategic plan. A strategy was implemented through four areas of intervention: Connecting, Communicating, Creating and Supporting. The CAC previously had great successes in supporting a broad range of research activities. As we continued this work, we doubled the number of funded research projects. We have also developed a network of over 75 coaching researchers and students. Through the support offered, CAC staff and partners seems to develop more interest and trust with research. More detailed results will be offered in the presentation to feature how research is now embedded in the organization's programs. As "Scholars from a range of disciplines have lamented the "gulf" between sport research and practice/policy for many years" (Holt et al., 2018, p. 1111), the CAC is grateful to share how established and developing collaborations through a formal strategy seems to positively enhance knowledge mobilization for evidence-based decision making.

\section{References}

Holt, N. L., Pankow, K., Camiré, M., Côté, J., Fraser-Thomas, J., MacDonald, D. J., Tamminen, K. A. (2018). Factors associated with using research evidence in national sport organizations. Journal of Sports Sciences, 36, 1111-1117. 10.1080/02640414.2017.1357830

\section{Presenter Biography}

Marie-Pier is a Coaching Consultant at the Coaching Association of Canada (CAC). She leads the Research portfolio for the organization, as well as the NCCP Advanced Coaching Diploma from a national perspective. She also works directly with 8 National Sport Organizations to support the development and implementation of their coaching programs.

\section{E}

Norms That Prevent Women from Becoming Sport Coaches: A Sociocultural Analysis of the Underrepresented

Eliasson, Inger

Umeå University, Umeå, Sweden

Despite numerous interventions for equality between women and men in sports, the number of women sport coaches has not increased. Even though women's participation in sports and qualification for coaching has increased, the representation of women in sports coaching has rather 
declined (La Voi, 2014). That said, scholars have recently argued that the underrepresentation of women in the coaching role is a cultural problem related to male dominance, rather than related to women's personal qualification deficits (Kane, 2016). Thus, the overall aim of this study was to explore coaches' perceptions and understandings of the underrepresentation of women as sport coaches within organized sports in Sweden and what action is required to facilitate future involvement of women coaches. Data were gathered through semi-structured focus group interviews with 16 floorball coaches in Sweden, 8 women and 8 men. The results show how sociocultural patterns of interactions, behaviour, and perceptions related to gender do influence the women's opportunities, difficulties, or choices to become a sport coach and how the male norm is maintained.

\section{References}

Kane, M. (2016). A socio-cultural examination of a lack of women coaches in sport leadership positions. In N. M. LaVoi (Ed.), Women in Sports Coaching (pp. 35-48). Routledge.

LaVoi, N. M. (2016). A framework to understand experiences of women coaches around the globe. In N. M. LaVoi (Ed.), Women in Sports Coaching (pp. 13-34). Routledge.

\section{Presenter Biography}

Inger Eliasson is an associate professor in pedagogy at Umeå University, Department of Education in Sweden. Eliasson has been a coach in football and floorball, two of the most popular sports in Sweden. For 20 years, Eliasson has been a lecturer and researcher at the university level. The main research interest is gender and generational perspectives of coaching, coaching in children's sports, socialisation among coaches, children, and parents in relation to children's rights.

\section{Youth Sport Participation Rates Across Europe}

Emmonds, Stacey; Weaving, D; Lara-Bercial, S; Till, K

Leeds Beckett University

The health and wellbeing benefits of taking part in organised sport for children and adolescents have been widely reported (Holt et al., 2017) yet participation levels have declined steadily and globally over the last decade (Eime, et al. 2019). However, most of this research has been conducted outside of Europe and although it is safe to assume certain similarities, there is a need for research to explore youth sport participation trends specifically within Europe to inform youth sport participation initiatives. Therefore, the aim of this study, part of Erasmus' co-funded project ICOACHKIDS+, was to explore organised youth sport participation rates across Europe. Participation data was collected for 5,565,860 children aged $6-18$ years (males $=4,456,915$; females $=1,108,945)$ across 18 sports and 27 countries. Differences in the participation rates between genders and biannual age categories were investigated using a generalised linear mixed effects model. Overall, youth male sport participation rates $(\sim 80 \%)$ are significantly higher than females $(\sim 20 \%)$. Sports participation peaks for both males and females between 12-14 years. Participation decreases significantly for boys from 14-to-18 years of age in most sports. Girls' participation significantly decreases between 14-16 years but increases again between 16-18 years in some sports. Findings suggest that strategies to keep more youth engaged in sport, in particular girls, are needed. It is also recommended that sport policy focuses upon overall participation across sports using a longitudinal track approach, and that further research is needed to understand sport attrition from the perspective of the young person, and across a range of demographic variables.

\section{References}

Eime, R. M., Harvey, J. T., \& Charity, M. J. (2019). Sport drop-out during adolescence: is it real, or an artefact of sampling behaviour? International Journal of Sport Policy and Politics, 11(4), 715-726.

Holt, N. L., Neely, K. C., Slater, L. G., Camiré, M., Côté, J., FraserThomas, J., . . \& Tamminen, K. A. (2017). A grounded theory of positive youth development through sport based on results from a qualitative metastudy. International review of sport and exercise psychology, 10(1), 1-49.

\section{Presenter Biography}

Dr Stacey Emmonds is a Reader in Sports Performance at Leeds Beckett University. Her main research interests are paediatric physiology, youth athletic development, talent development, as well as the match and training demands of youth athletes. Stacey also currently holds a number of applied practice roles in youth sport, including leading the athletic development programme for Leeds United girls football academy.

\section{Resilient Pioneers: Research of Women Coaches' Experiences in Martial Arts}

Erdogan, Sanna \& Tuunainen, Sari

The Finnish Association of Coaches. The Project Women Taking Responsibility in Coaching. Helsinki, Finland

The research examined why there are very few women as coaches in martial arts. The subscriber of the thesis was the Finnish Association of Coaches and its development project: Women Taking Responsibility in Coaching in Martial Arts. The theoretical framework focused on the gender equality scheme and the various aspects of equality between men and women both in sports and in society. The material was collected by using five theme interviews of top-level women coaches of martial arts. As a result, the top-level coaches are professional and resilient with strong self-efficacy. Resilience is an ability to turn misfortune into a learning experience. Self-efficacy is to believe in your own abilities. The results show that gender does not define the competence of the coach. Nevertheless, the obsolete line of thought prevents or hinders women to take responsibility for coaching. The inequality seems to be the reason why there is a shortage of female coaches. In martial arts there is still a strong image of the stereotype of the coach. The results propose actions to the project: Women Taking Responsibility in Coaching in Martial Arts and will provide useful information for the associations of martial arts in Finland and other sports, too. Fostering equality is very current issue. Diversity is a topic concerning all society and even the whole world.

\section{Presenter Biography}

Sanna Erdogan has over ten years of experience as an instructor and expert in the field of coache education in Finland. Erdogan is a doctorate of University of Lapland. Erdogan's doctoral thesis is about power and gender in martial arts. She is a project worker in the Project Women Taking Responsibility in Coaching.

\section{G}

\section{How do Elite Coaches and Staff Members Explain Football Coaching Volatility in Brazil?}

Galdino, Matheus \& Wicker, Pamela

Bielefeld University, Germany 
Football coaches are praised upon winning and blamed for losing games. Despite extensive quantitative studies investigating coaching replacements, the sport literature may further benefit from mixed-method analyses, allowing coaches to articulate their rationale (Gilbert \& Côté, 2013). Hence, this research confronts experienced practitioners with scientific evidence, seeking explanations for coaching volatility in Brazilian football. Specifically, within-season spells have lasted on average 65 days, while econometrics revealed a lagged effect of seven games prior to improvements following turnovers (Galdino et al., 2021). Two research questions arise: how do practitioners explain the level of coaching volatility? And, how can the status quo of constant turnovers be challenged? Qualitative, semistructured interviews were held with 30 elite coaches and 30 staff members. First, participants were provided with the main statistics and asked to openly interpret them. Secondly, they were asked to share suggestions on how to improve conditions for long-term coaching spells. Through a deductiveinductive approach, explanations revolved around three categories: (1) mismanagement, (2) irrationality, and (3) impatience. Reflecting on alternatives to upgrade the coaching scenario, recurring insights exposed four themes: (1) regulation, (2) professionalism, (3) competitive scheduling, and (4) media coverage. Interviewees advocated the academic evidence, claiming it reflected their reality and emphasized the power ratio of club officials, as similarly documented by Nissen (2016). Results suggest that coaches and staff members urge for professional accountability within Brazilian football, appealing for a rearrangement of organizational priorities. This research highlights how collaborations with sport experts may enhance coaching recognition and management practices.

\section{References}

Galdino, M., Wicker, P., \& Soebbing, B. P. (2021). Gambling with leadership succession in Brazilian football: Head coach turnovers and team performance. Sport, Business and Management, 11(3), 245-264. https://doi.org/10.1108/SBM-06-2020-0059

Gilbert, W. \& Côté, J. (2013). Defining coaching effectiveness: A focus on coaches' knowledge. In P. Potrac, W. Gilbert, \& J. Denison (Eds.), Routledge Handbook of Sports Coaching (pp. 147-159). Routledge.

Nissen, R. (2016). Hired to be fired? Being a coach in Danish professional football. International Journal of Sports Science \& Coaching, 11(2), 137148. https://doi.org/10.1177/1747954116636706

\section{Presenter Biography}

Matheus Galdino is currently a Ph.D. candidate in Sport Science at Bielefeld University (Germany), holds a M.Sc. in Sport Management from the German Sport University in Cologne (Germany), and has accumulated practical experiences working for Red Bull, ESPN, as well as a strategic consultant supporting elite athletes and professional football players. His research interests revolve around football coaching, talent development, and performance management.

\section{H}

\section{A 'Coach Support Programme' Delivery Tool for Coach Developers}

Harrison, Hayley

Sport Ireland Coaching, Republic of Ireland

A Coach Developer's role is to develop, support, and challenge coaches as they learn. All too often this is simply equated to the delivery of coach education courses. Coach education courses have their place, but as 'coach support' programmes become ever more popular in the overall development of coaches, the Coach Developer is often left to decide what support they can offer, to whom and when, without any support or guidance provided to them. I introduced the concept of a 'Wall of Support' in Ireland as part of the Coach Developer Programme in 2016 and it has since been adapted and adopted for use in the ICCE 'Supporting Coaches in Practice' international programme. It provides a framework for Coach Developers to identify various forms of coach support, to evaluate the viability of those forms of support in their own context and it can assist them in the design of both large- and small-scale coach-centred support programmes. This presentation will show how 'The Wall' has been used to assist a range of organisations to fundamentally change their coach development programmes to ones where the Coach Developer is more efficient, yet more effective, and the programme is entirely 'coach-centred.'

\section{Presenter Biography}

Hayley Harrison is the Head of the Coach Developer Programme for Sport Ireland Coaching in the Republic of Ireland and a Master Trainer within the ICCE. She has designed and delivered over 40 Coach Developer Programmes to participants in single and multi-sport environments and works both nationally and internationally in this capacity. Hayley is also responsible for the High-Performance Coach Support Programme in Ireland and continues to coach athletes at World and Olympic level in her spare time.

\section{$\mathbf{K}$}

Coaching for Personal Development: Retrospective Stories from 14 Swedish High-Performance Athletes

Kjær, Jørgen Bjärsholm; Daniel Fahlström, PG; \& Linnér, Susanne

Linnaeus University, Växjö, Sweden

Athlete-centred coaching is a foundation of the ICCE framework (ICCE, 2012). Coaches should help improve sport-specific skills and knowledge of an athlete, but an effective coach will also improve their confidence, connection, and character. Côté and Gilbert (2009) suggest that character is "respect for the sport and others (morality), integrity, empathy and responsibility" (p. 314). Furthermore, connection refers to the ability to create positive bonds and relations, both inside and outside of sport. Through the retrospective stories of 14 Swedish national team athletes, the objective of this presentation is to provide concrete examples of how coaches can help athletes grow as well as introduce Nodding's concept of practice for coaches, coach educators, and researchers to consider. In line with Nodding's concept of practice, Swedish elite athletes value time spent outside the sporting domain with their coach (e.g., on training camps). When coaches spend time off the court with a young adult, they have the chance to work with the athlete's mentality, which can have a positive influence on an athlete's connection and character. Nodding's concept of practice offers opportunities and challenges that coaches, coach educators and researchers need to consider. It highlights the important role coaches can/should serve acting as in loco parentis and the need for the coach to act as an educator (e.g., Jones, 2006). Implications of this study is for coaches and sport organisations/institutions more broadly to discuss how to implement the concept of practice into their program.

\section{References}

Côté, J., \& Gilbert, W. (2009). An integrative definition of coaching effectiveness and expertise. International Journal of Sports Science \& Coaching, 4(3), 307-323.

International Council for Coaching Excellence \& Association of Summer Olympic International Federations. (2012). International sport coaching framework, version 1.1. Human Kinetics. https://www.icce.ws/_assets/ files/iscf-1.2-10-7-15.pdf 
Jones, R. L. (2006). The sports coach as educator: Re-conceptualising sports coaching. Routledge.

Noddings, N. (2013). Caring: A relational approach to ethics and moral education. University of California Press.

\section{Presenter Biography}

Jørgen Bagger Kjær earned his Ph.D. from George Mason University. He is currently a senior lecturer at Linnaeus University (LNU). He works with Swedish elite coaches through LNU's master program and professional development courses. He has taught at universities in Denmark and the USA and is the former Athletic Director and Boys Soccer Coach at Sidwell Friends School, Washington DC.

\section{$\mathbf{L}$}

Bringing Practice into Research: Making Research in Sport Coaching More Relevant

Lyle, John

Carnegie School of Sport, Leeds Beckett University, Leeds, United Kingdom

Empirical research in the sport sciences contributes to our knowledge of performance enhancement. However, there are concerns about a similar contribution to athlete performance from research on coach behaviour and coaching practice over transferability, relevance, and application to coach education (Lyle, 2018). This presentation reports the findings of a survey of research publications in sport coaching journals between 2015 and 2020. The findings demonstrate an emphasis on interview data and reported behaviour; an absence of embedded, in situ research; the absence of athlete performance as an outcome measure; and a lack of concern for the particularities of coaches' practice in the sample population. The presentation argues that contributory factors are challenging research designs, academic snobbery about pragmatism, and a valuing of process over substance. The conclusion is that the priorities within the research community contribute to the disconnect between academic research and coaching practice.

\section{References}

Lyle, J. (2018). The transferability of sport coaching research: A critical commentary. Quest, 70(4), 419-437. https://doi.org/10.1080/00336297. 2018.1453846

\section{Presenter Biography}

Dr. John Lyle is Professor of Sport Coaching in the Carnegie School of Sport, Leeds Beckett University. He is the author of several influential textbooks, with a focus on conceptual development in sport coaching. This is complemented by personal experience as a coach, involvement in sport coaching policy in the UK, and the delivery of high-performance coach development. He has coached and played volleyball at international level and was also a professional footballer.

\section{M}

Talent Development Environments Across Five European Nations: Athlete, Parent and Coach Perceptions

Sargent Megicks, Barnaby ${ }^{1}$; Till, Kevin; Rongen, Fieke; Gledhill, Adam; Cowburn, Ian; Mitchell, Thomas; Emmonds, Stacey; \& Lara-Bercial, Sergio

Leeds Beckett University, UK.
Given the importance of the environment in athlete development, recent years have seen an increase in research examining Talent Development Environments (TDEs). However, most research is limited to a single nation and the athletes' perspective with little consideration of the views of parents or coaches. This study addresses these limitations by examining adolescent (13-18 years) athletes' $(n=202)$, parents' $(n=178)$ and coaches' $(n=59)$ perceptions of TDEs from five European nations. Athletes completed the Talent Development Environment Questionnaire-5 (TDEQ-5) (Li et al., 2015), with parents and coaches completing an adapted TDEQ-5. Items and subscales were analysed across athlete, coach, and parent groups. Parents $(4.14 \pm 1.51)$ had less-positive perceptions of their associated TDE across all items, compared with athletes $(4.42 \pm 1.45 ; \mathrm{p}<0.05)$ and coaches $(4.60 \pm 1.28 ; \mathrm{p}<0.05)$. Across groups, Long-term Development $(4.79 \pm 0.90)$ was the most positively perceived TDEQ-5 subscale. Support Network (4.02 \pm 1.23 ) and Alignment of Expectations (4.05 \pm 1.11 ) were the least positively perceived TDEQ-5 subscales. Furthermore, Holistic Quality Preparation $(4.30 \pm 1.07)$ and Communication $(4.47 \pm 1.12)$ scores for athletes and coaches were significantly higher $(\mathrm{p}<0.001)$ than parents. As parental perspectives of TDEs are consistently less positive than those of athletes and coaches, future research should explore reasons behind these differences and how they can inform developments considering the broader aims of TDEs. Moreover, recognising the performance and health implications associated with Support Network, Communication and Holistic Quality Preparation, together with the varying perceptions of these across the groups, offers opportunities for further investigation to develop European TDEs.

\section{References}

Li, C., Wang, C. K. J., Pyun, D. Y., \& Martindale, R. (2015). Further development of the talent development environment questionnaire for sport. Journal of Sport Sciences, 33(17), 1831-1843. https://doi.org/10 $.1080 / 02640414.2015 .1014828$

\section{Presenter Biography}

Barnaby Sargent Megicks is a PhD student at Leeds Beckett University in the Carnegie School of Sport. His research interests centre around holistic whole-person learning and development in youth sport. In conjunction with the ICOACHKIDS+ Erasmus project, his $\mathrm{PhD}$ focuses on talent development environments, exploring how they can be optimised for healthy and holistic athlete development. Barnaby also works as a research assistant at ICOACHKIDS. He holds a BSc from the University of Birmingham and a PGCE from Loughborough University.

\section{To Report, or Not to Report? From Code of Silence Suppositions to} Public Secrecy Reality

Moriconi, Marcelo ${ }^{1} \&$ De Cima, César ${ }^{2}$

${ }^{1}$ Iscte - Instituto Universitario de Lisboa, Lisboa, Portugal; ${ }^{2}$ Iscte - Instituto Universitario de Lisboa, Lisboa, Portugal

One of the main obstacles to detect undesirable conducts such as manipulation of games and competitions, and to combat corrupt behaviour in the sports world is the existence of the so-called code of silence among the sport's actors. Therefore, integrity educational campaigns, codes of conduct, ethics, and disciplinary norms include the obligation to report any suspicion, approach, tentative or case of match-fixing. In some countries, such as Portugal, the obligation to denounce is incorporated into criminal law. Although several protected reporting channels have been implemented for sport institutions and federations to encourage whistle-blowing practices, the level of denouncement is still 
low. Through the analysis of official discourses, ethnography and interviews with key informants, this presentation demonstrates that despite the formal norms, reporting on corruption in sport, mainly match-fixing, is a dangerous practice that can have serious consequences for the athletes' career. More than a code of silence within sports, what exist is a series of public secrecies that deliberately recognize the existence of informal institutions that create and materialize those dangers. However, while integrity actors show awareness of the situation, the official narrative and formal norms avoid considering these problems and, moreover, throw this evidence out of the integrity narrative framework. The result is a delegitimate and non-realistic narrative that pushes sports actors to keep quiet more than promoting ethical behaviours and whistle-blowing.

\section{Presenter Biography}

Marcelo Moriconi is a researcher and professor at the Instituto Universitario de Lisboa. He has a multidisciplinary background with a degree in Journalism and Communication, post-graduate studies in Sociology, and a Ph.D. in Political Science. He has researched on illegal markets in sport, sport corruption, organized crime, and sport integrity and good governance. He has published two books and more than 30 articles in peer reviewed, top-tier journals. He has led six international projects funded by European Commission.

\section{Coaches and Performance Analysis: A Mechanism of Monitoring and Evaluation}

Mulvenna, Claire

\section{St. Mary's Unviersity, Twickenham, London, UK.}

The use of the tools which form Performance Analysis (PA) allow for the increased evaluation of player performance, with current players being subject to more analysis than ever before (Harvey et al., 2017). Although this increased analysis is frequently presented as being a positive development in soccer, recent research has begun to query the use of technology as an aid to player development (Jones \& Denison, 2018). Consequently, the aims of this study were to identify the way in which coaches engage with PA and utilise the findings of PA to aid player development. 12 coaches who worked in EPPP category one or two academies with access to PA, participated in semi structured interviews in the 2019/2020 soccer season. Thematic analysis generated two higher order themes and seven lower order themes. The higher order themes were external auditors and weaponisation of PA. The first higher order theme analysed the influences on how PA was used, and the personnel involved in the decision making on how PA was used. The second higher order theme scrutinised the way in which PA is used by coaches and their colleagues as a tool to reinforce their authority and dominance. The results show PA can be used as a mechanism of control by soccer coaches particularly with regards to decision making on player retention and recruitment. Consequently, coaches should consider the alignment of their use of PA to their coaching philosophy and recognise the pitfalls of using PA a tool of power and control.

\section{References}

Harvey, S., Cope, E., \& Jones, L. (2017) Coaching behaviour and performance analysis. In K. Dieffenbach \& M. Thompson (Eds.), Coach education essentials. Human Kinetics.

Jones, L., \& Denison, J. (2018) Perspective surrounding the application of global positioning system technology: Suggestions for the strength and conditioning coach. Strength and Conditioning Journal, 40(6).

\section{Presenter Biography}

Claire is a lecturer at St. Mary's University, Twickenham and she specialises in the area of sport coaching, and coaches use of performance analysis. Claire has a Master's in Sport Coaching from Loughborough University and is currently studying a Ph.D. at the University Chester. Claire's Ph.D. focuses on how coaches use performance analysis and how it can change coaching practice. Claire has previously worked as both a coach and development officer for organisations including The FA and Manchester United Foundation.

\section{$\mathbf{N}$}

Coaching and Orchestrating in High-Performance Rhythmic Gymnastics: Insights from a Brazilian Coach

Nunomura, Myrian ${ }^{1}$; Carrara, Paulo ${ }^{1}$; \& Antualpa, Kizzy ${ }^{2}$

${ }^{1}$ University of São Paulo; ${ }^{2}$ Federal University of Bahia, Brazil

Rhythmic Gymnastics (RG) is part of the Olympic Program and is considered a complex artistic and aesthetic sport, with a rigid athlete development and training process, usually starting at early ages and requiring high degree of commitment to achieve and maintain at the elite level. The involvement of children and adolescents implies many challenges for coaching this sport, and criticism is not rare. Recently, the worldwide media highlighted elite gymnasts reporting negative experiences and claiming for changes in the sport culture. We explored the experience of an Olympic Brazilian RG coach, a former and successful gymnast, who is coaching the highest level for two decades. Based upon the Coaching as Orchestration approach (Jones \& Wallace, 2006), we revealed how the coach deals with athletes and negotiates towards desired ends. A semi-structured interview produced a transcript of 126 minutes and was thematically analysed. The coach-athlete relationship is based upon steering: I talk about my experience as an elite athlete; awareness: seminar and professional support on health; communication: I'm always talking and listening, and I make them feel comfortable and not fear to talk; and self-pressure: fight for your place in the team, as it is not guaranteed. The coach considers gymnasts' strengths and frailties and cares for their health and wellbeing. Nonetheless, the coach reminds the gymnasts that elite RG is about sacrifices, rules, discipline, commitment, and hard work; meanwhile she attempts to induce a friendly environment and build a trustful coach-athlete relationship along this pathway.

\section{References}

Jones, R. L., \& Wallace, M. (2006). The coach as 'orchestrator': More realistically managing the complex coaching context. In R. Jones (Ed.). The sports coach as educator: Reconceptualising sports coaching (pp. 5164). Routledge.

\section{Presenter Biography}

Myrian Nunomura is a Professor at the University of São Paulo, Brazil. She has published on the sports of gymnastics and sport pedagogy, including coaching and coach education, and is currently interested in the culture of high-performance gymnastics. Most of her research is qualitative in nature, focusing on interviews, documents, and observational field studies. She also has published books for coaches and teachers involved in gymnastics teaching as Gymnastics Foundations, Understanding Artistic Gymnastics, and High-Performance Gymnastics. 


\section{$\mathbf{S}$}

\section{If We Lose Them There Will be No Sport: The Case of Volunteer Coaches in Norway}

Sigurjonsson, Thorsteinn; Medard, Magnhild; Nilsen, Dag André; Tor Solbakken; \& Chroni, Stiliani "Ani”

Inland Norway University of Applied Sciences

Most Norwegian sport coaches are recruited and work on a voluntary basis without formal training (prior to and/or upon hiring), while Norwegian sport is by large supported via volunteer work (Seippel, 2002). Chroni et al. (2018) profiled 5,977 coaches, 4,404 men and 1,559 women, from 15 to 83 years old with coaching experience up to 23 years, representing 78 sports/ disciplines and 43 federations from every county in Norway. In this presentation we share analysis and findings from data on 4,483 volunteer coaches. Considering the extensive presence ( $75 \%$ of surveyed coaches) and work of volunteer coaches with local, regional, and national sport clubs and teams, studying them can give key insights regarding elements to be considered for further improving the coaching experience and in turn sports in Norway. The surveyed coaches had an average age of 42 years, and most had entered coaching between 30 and 39 years mainly wanting to contribute to athlete learning and development. The typical volunteer coach has little sports-specific education and up to 5 years of coaching experience but still experiences insecurity in coaching, as well as loneliness in coaching that somewhat impact his/her wellbeing. Based upon extensive data analysis, we will discuss how an increase in the volunteer coach knowledge, width and depth of the coaching experience via education programs, communities of practice, mentoring and reflective practice can shorten the learning curve of coach development - skills need to first be developed and practiced, then supported and valued for coaches to continue beyond the learning stage.

\section{References}

Chroni, S., Medgard, M., Nilsen, D. A., Sigurjonsson, T. \& Solbakken, T. (2018). Profiling the coaches of Norway report. UNIT. https://brage .bibsys.no/xmlui/handle/11250/2569671

Seippel, ã. (2002). Volunteers and professionals in Norwegian sport organizations. International Journal of Voluntary and Nonprofit Organizations, 13(3).

\section{Presenter Biography}

Dr. Thorsteinn Sigurjonsson is an associate professor of Sport Science, Pedagogy, and Sports Coaching with the Department of Public Health and Sports Science of Inland Norway University of Applied Sciences. He has extensive experience from both academia ( 28 years) and coaching practice (40 years) and is currently physical trainer for the men's team in the Champions League club Elverum Handball and professional consultant of elite sports for Olympiatoppen Innlandet (An organization that is part of Norwegian Olympic and Paralympic Committee).

\section{Coach and Athlete Perceptions of Half-Times in High-Performance Rugby Union}

Smith, Barry \& Sherwin, Ian

University of Limerick, Limerick, Ireland

Half-time (HT) is a crucial in-competition period and an important component of a coach's performance strategy (Kennedy \& Knight 2017). This period represents a complex and pivotal time (Mouchet
\& Duffy 2020) when coaches interact with athletes and multiple staff members (Allain et al., 2018). A dearth of evaluations of HTs is apparent within the exigent research, in particular, qualitative investigations of HTs within elite rugby. The aim of this study was to explore and critically evaluate coach and, importantly, player experiences and perceptions of HTs in elite rugby union, and to identify effective HT strategies. This study utilised a qualitative descriptive approach, adopting an interpretivist paradigm. Sixteen participants $(8$ coaches, 8 players) engaged in a semi-structured interview which was subjected to thematic analysis. Player recovery and the provision of a succinct tactical and technical plan for the 2nd half were prioritised by all respondents. Players reported a strong preference for using technology. The creation of a calm environment, facilitated by an emotionally controlled coach, was highlighted by all as a prerequisite to effective HTs. Further effective HT strategies included the provision of clear, consistent messages and avoiding information overload. A novel finding was the collaborative nature of HT interactions, with all participants strongly advocating for coach facilitated, collaborative HT planning and decision making. In conclusion, most participants believed that when done well, HT offered a brief but important window in which to positively impact 2 nd half performance, ultimately contributing to the goal in elite sport winning.

\section{References}

Kennedy, M. D., \& Knight, C. J. (2017). Bench behaviour of ice hockey coaches: Psychophysiological and verbal responses to critical game incidents. International Journal of Sports Science and Coaching, 12(3), 303-311.

Mouchet, A. \& Duffy, P. (2020). Rugby coaches; perceptions of their incompetition role. Sports Coaching Review, 9(1), 24-47.

Allain, J., Bloom, G., \& Gilbert, W. D. (2018). Successful high-performance ice hockey coaches' intermission routines and situational factors that guide implementation. The Sports Psychologist, 32, 210-219.

\section{Presenter Biography}

Barry Smith is a Chartered Physiotherapist working in the area of Sports and Exercise Medicine. Barry has just completed a M.Sc. in Applied Sports Coaching and has worked as a physio and coach in a variety of sports including rugby, soccer, hockey, and boxing. Barry's special interest areas include youth athletic development, the neuroscience of learning and memory and coaching behaviours. Barry has represented Ireland at both touch and tag rugby.

\section{Coaching in Finnish football: A Scoping Review}

Szerovay, Mihaly ${ }^{1,2} \&$ Louste, Henri ${ }^{1}$

${ }^{1}$ Faculty of Sport and Health Sciences, University of Jyväskylä, Finland; ${ }^{2}$ Football Association of Finland

Finnish elite football and futsal have been noticed internationally in recent years: the men's team, the women's team, and the men's futsal team have been qualified for the UEFA EURO 2020, the EURO 2022, and the Futsal EURO 2022, respectively. Simultaneously, the Finnish football community and the Football Association of Finland (FAF) in particular - has taken an increasing interest in cooperation with the research community. As a result, a joint Professor of Practice position has been established by the University of Jyväskylä and the FAF in 2020. Parallel to these developments, expectations of academic research to benefit football has risen. In responding to this need, this scoping review maps research about coaching in Finnish football and 
futsal to provide an overview of this hitherto uncharted area. The following research question is addressed: In what ways have coaching in Finnish football and futsal been explored in academic literature? Scoping reviews are useful in identifying studies conducted, key concepts applied, and methods used in a particular field (Munn et al., 2018). The PRISMA for Scoping Reviews checklist (Tricco et al., 2018) was used to ensure the quality of the study. Four academic databases, namely SPORTDiscus, JYX, Melinda, and JYKDOK, were searched. Peer-reviewed articles, master's and doctoral dissertations, and research reports written in English and Finnish language between 2000-2021 were eligible for the review. Over 150 eligible items were found, more than the half of which are master's dissertations. The most salient topic areas are player development, technical and tactical analysis of the game, physical performance, and sports injuries.

\section{References}

Munn, Z., Peters, M. D. J., Stern, C., Tufanaru, C., McArthur, A., \& Aromataris, E. (2018). Systematic review or scoping review: Guidance for authors when choosing between a systematic or scoping review approach. BMC Medical Research Methodology, 18, 143. https://doi.org/10.1186/ s12874-018-0611-x

Tricco, A. C., Lillie, E., Zarin, W., O’Brien, K. K., Colquhoun, H., Levac, D., Moher, D., Peters, M. D., Horsley, T., Weeks, L., Hempel, S., Akl, E. A., Chang, C., McGowan, J., Stewart, L., Hartling, L., Aldcroft, A., Wilson, M. G., Garrity, C., ... Straus, S. E. (2018). PRISMA extension for scoping reviews (PRISMA-ScR): Checklist and explanation. Annals of Internal Medicine, 169(7), 467-473. https://doi.org/10.7326/M18-0850

\section{Presenter Biography}

Mihaly Szerovay (Ph.D., Sport Science; UEFA B licence) is a Professor of Practice in Research and Development of football at the University of Jyväskylä and the Football Association of Finland. His main research interests lie in the various aspects of globalisation and professionalisation of sports. Szerovay is a former professional goalkeeper.

\section{$\mathbf{T}$}

Student-Athlete, Coach and Teacher Perspectives of the Features and Impacts of a UK Sports-Friendly School

Thompson, Ffion ${ }^{1}$; Rongen, Fieke ${ }^{2}$; Cowburn, Ian $^{1}$; \& Till, Kevin ${ }^{4}$

${ }^{1}$ Carnegie School of Sport, Leeds Beckett University, Leeds, United Kingdom and Queen Ethelburga's College, York, United Kingdom;
${ }^{2}$ Carnegie School of Sport, Leeds Beckett University, Leeds, United Kingdom; ${ }^{4}$ Carnegie School of Sport, Leeds Beckett University, Leeds, United Kingdom and Leeds Rhinos Rugby League Club, Leeds, United Kingdom

To understand the features of sport schools and their impacts on holistic development of student-athletes, it is important to take into account the voice of multiple stakeholders central to the programmes (student-athletes, coaches, teachers). Therefore, using five focus groups, with 19 student-athletes, and six semi-structured interviews with coaches/teachers, this study explored the perceived impacts of a sport-friendly school on holistic athlete development and the characteristics/features that drive these impacts. After thematic analysis, findings indicated a multitude of positive and negative impacts associated with academic/vocational (e.g., GCSE and A-level qualification vs. drop in academic grades), athletic/physical (e.g., performance development vs. injuries), psychosocial (e.g., social skills vs. social scarifies) and psychological (e.g., stress-relief vs. family pressure) development of sport-friendly school student-athletes. Across all domains stakeholders reported more largely beneficial impacts, with the main detrimental impacts centering around high workload (e.g., lack of rest and recovery, physical and mental fatigue), while positive impacts mainly centred around: integrated environment for sport, education and boarding; high quality coaches; sport science support; academic support (e.g., flexible curriculum, extra tutoring) and a coherent support network (e.g., pastoral services, house-parents, and community/team ethos). Although, overall, the sport-friendly school is largely positive, there are negative impacts that stakeholders should be aware of when designing, implementing, and evaluating sport-friendly school programmes. We recommend that practitioners aim to design and implement monitoring and evaluation tools that assess the holistic development impacts of student-athletes within their sport-friendly schools to ensure they are promoting all-round and healthy youth athlete development.

\section{Presenter Biography}

Ffion is currently undergoing her Ph.D. at Leeds Beckett University, Carnegie School of Sport, where she is researching: The Impacts of Sport Schools on Holistic Athlete Development. This Ph.D. is in partnership with Queen Ethelburga's school, where Ffion is the lead S\&C coach. As part of this relationship, Ffion conducts research alongside $\mathrm{S} \& \mathrm{C}$ provision to provide high-quality programs, while contributing to the field of LongTerm Athletic Development. Furthermore, Ffion is the Women's National Lacrosse and Wasps Superleague Netball lead S\&C. 


\section{Symposia}

(in alphabetical order by first author's last name) 


\section{Symposium 1: On the Elite Athlete-To- Coach Transition: Mapping an Event, an Experience, and A Call-To-Action}

\author{
An Overview of the Athlete to Coach Educational and Developmental \\ Pathways: What We Know
}

Blackett, A. ${ }^{1}$; Rynne, Steven ${ }^{2}$; Chroni, Stilani “Ani”,3 Dieffenbach, K. ${ }^{4}$; \& Pettersen, Sigurd ${ }^{3}$

\begin{abstract}
${ }^{1}$ Staffordshire University, School of Life Sciences and Education, UK; ${ }^{2}$ The University of Queensland, School of Human Movement and Nutrition Sciences, Australia; ${ }^{3}$ Inland Norway University of Applied Sciences, Faculty of Social and Health Sciences', Norway; ${ }^{4}$ West Virginia University, College of Physical Activity and Sport Sciences, USA
\end{abstract}

Studies have frequently reported a competitive athletic career serves as a potentially important setting for becoming an elite level coach (Watts \& Cushion, 2019; Werthner \& Trudel, 2009). Indeed, the athlete to coach (Ato-C) transition has become somewhat culturally accepted and, in some instances, increasingly promoted by national governing bodies of sport and player unions without any scrutiny on the potential value or adverse effects this has on the individual coaches and the athletes they work with. The underpinning, and uncritically reproduced assumptions have led to an increase of former and current elite athletes being "fast-tracked" through formal coach education structures. With national governments and coaching unions attempting to further professionalize coaching, the number of individuals being "fast-tracked" through formal education qualifications seems contradictory in meeting this objective of professionalization. Therefore, research has begun to empirically analyze the A-to-C pathway and specifically the "fast-tracking" of elite athletes into coaching roles in attempts to identify good practice along with problematizing the practice (Blackett et al., 2018; 2020; McMahon et al., 2020). In this presentation, some of the contemporary findings in this area will be outlined, including some relevant critiques related to A-to-C transitions. In so doing, recommendations will be offered regarding appropriate support mechanisms in developing former elite athletes making the A-to-C transition.

\section{References}

Blackett, A. D., Evans, A. B., \& Piggott, D. (2020). Negotiating a coach identity: A theoretical critique of elite athletes' transitions into post-athletic high-performance coaching roles. Sport, Education and Society, 1-13.

Blackett, A. D., Evans, A. B., \& Piggott, D. (2018). "Active" and "passive" coach pathways: Elite athletes' entry routes into high- performance coaching roles. International Sport Coaching Journal, 5(3), 213-226.

McMahon, J., Zehntner, C., McGannon, K. R., \& Lang, M. (2020). The fast-tracking of one elite athlete swimmer into a swimming coaching role: A practice contributing to the perpetuation and recycling of abuse in sport. European Journal for Sport and Society, 17(3), 265-284.

Watts, D. W., \& Cushion, C. J. (2017). Coaching journeys: Longitudinal experiences from professional football in Great Britain. Sports Coaching Review, 6(1), 76-93.

Werthner, P., \& Trudel, P. (2009). Investigating the idiosyncratic paths of elite Canadian coaches. International Journal of Sports Science and Coaching, 4(3), 433-449.

\section{Presenter Biography}

Alex Blackett is a Senior Lecturer in Sports Coaching at Staffordshire University and course leader of the M.Sc. Sports Coaching (distance learning, part-time) and BA (Hons) Sports Coaching degrees. After having coached soccer in New Zealand and across the Midwest of the United States of America, Alex entered academia and completed his Ph.D. at the University of Lincoln, UK in 2017. Alex is now director of the Staffs Unified Sports Research Alliance (SUSRA).

\section{Moving Forward: An Athletic Career Does Not Equate and Translate to Coaching Efficacy}

Chroni, Stiliani “Ani”" ${ }^{1}$; Blackett, A. ${ }^{2}$; Dieffenbach, K. ${ }^{3}$; Rynne, S.B. ${ }^{4}$; \& Pettersen, S. ${ }^{1}$

${ }^{1}$ Inland Norway University of Applied Sciences, Faculty of Social and Health Sciences, Elverum, Norway; ${ }^{2}$ Staffordshire University, School of Life Sciences and Education, Stoke-on-Trent, UK; ${ }^{3}$ West Virginia University, College of Physical Activity and Sport Sciences, Morgantown, WV, USA; ${ }^{4}$ The University of Queensland, School of Human Movement and Nutrition Sciences, Brisbane, Australia

Assumptions continue to be made that an athletic career equates to and can translate to coaching efficacy. The need to challenge this assumption becomes more apparent considering research advances on the A-to-C transition, early career coaches' challenges and impacts on their work and wellbeing or the perpetuation of toxic behaviors based upon how one was coached (Baker et al., 2014; Blackett et al., 2018; 2020; Chroni et al., 2020). Furthermore, the growth of the fast-tracking coach pathway and the absence of clear-cut findings on the product and quality of such programs may signal that it is time to act and bring on changes that will better serve the elite athletes transiting to coaching, the athletes they coach upon transiting and the sport itself. With regard to research, there is a need to better understand the individuals transiting, persons and practices in the recruiting and hiring, and any support provide at the new role. More research employing alternative methodologies focusing on women, ethnic minorities and disability coaches who follow the A-to-C pathway is also required. With regard to practices, we need to consider how the processes employed to this day which appear to be informal and anecdotally informed are serving the person in transit and what particular needs these practices serve (Chroni \& Dieffenbach, in press). Educating the person is one thing to care for yet the transition requires more than a coaching toolbox. The presentation will share both research and practice gaps and invite attendees to take a step forward.

\section{References}

Barker, D., Barker-Ruchti, N., Rynne, S. B., \& Lee, J. (2014). Moving out of sports: A sociocultural examination of Olympic career transitions. International Journal of Sports Science and Coaching, 9(2), 255-270.

Blackett, A. D., Evans, A. B., \& Piggott, D. (2020). Negotiating a coach identity: A theoretical critique of elite athletes' transitions into post-athletic high-performance coaching roles. Sport, Education and Society, 1-13.

Blackett, A. D., Evans, A. B., \& Piggott, D. (2018). "Active" and "passive" coach pathways: Elite athletes' entry routes into high- performance coaching roles. International Sport Coaching Journal, 5(3), 213-226. 
Chroni, S. \& Dieffenbach, K. (in press). Facilitating and supporting the elite athlete-to-coach transition: Lessons learned from Norwegian coaches and federations. Journal of Sport Psychology in Action.

Chroni, S., Pettersen, S., \& Dieffenbach, K. (2020). Going from athlete-tocoach in Norwegian winter sports: Understanding the transition journey. Sport in Society, 23(4), 751-773.

\section{Presenter Biography}

Dr. Stiliani "Ani” Chroni is a professor of Sport Psychology, Pedagogy, and Sports Coaching with the Institute of Public Health and Sports Science at Inland Norway University of Applied Sciences. Ani, possesses extended, versatile, high-level international work experience in academia, sport psychology consultancy and advocacy for gender equality with sport and action-based organizations. Her research focuses on coach wellbeing, studying elite coaches' stress experiences and the culture supporting them as well as the highly demanding transition going from elite athlete-to-coach.

\section{Recruitment and Support Structures in the A-to-C Transition}

Dieffenbach, K. ${ }^{1}$; Chroni, Stiliani “Ani", ; Blackett, A. ${ }^{3}$; Rynne, S.B. ${ }^{4}$; \& Pettersen, S. ${ }^{2}$

${ }^{1}$ West Virginia University, College of Physical Activity and Sport Sciences; ${ }^{2}$ Inland Norway University of Applied Sciences, Faculty of Social and Health Sciences; ${ }^{3}$ Staffordshire University, School of Life Sciences and Education; ${ }^{4}$ The University of Queensland, School of Human Movement and Nutrition Sciences

The experiences of an elite athlete provide unique insight into the culture and demands of the sport environment. From an organizational perspective, recruiting a person with lived experience and supporting their development as a coach makes sense from both a financial and human resources perspective (Chroni \& Dieffenbach, 2020), yet does not guarantee efficiency nor longevity. Still, worldwide, elite athletes are recruited or choose to enter coaching upon retirement. For both, fasting tracking and traditional pathways are available for developing the requisite knowledge and skills for the coaching profession (Blackett et al., 2018). Effective coaching requires an expanded understanding of training theories, context, and pedagogical, inter- and intra- personal skills to support the role. A successful within sport transition requires the individual to move beyond their solo athlete identity and embrace a "We" approach (Blackett et al., 2020). It appears that some efforts are being made by organizations who recruit and hire retiring athletes as coaches to support them during the early career phase, yet the support provided is unstructured, informal and its effectiveness unevaluated. For instance, while on the job mentoring can prove valuable, its effectiveness is variable depending on the skills of both the mentor and mentee. Providing intentional support for both the exit and immersion of within sport transition in addition to providing the education and skill development resources are essential to support an effective shift from being and doing as an elite athlete to being and doing as a coach.

\section{References}

Blackett, A. D., Evans, A. B., \& Piggott, D. (2020). Negotiating a coach identity: A theoretical critique of elite athletes' transitions into post-athletic high-performance coaching roles. Sport, Education and Society, 1-13.

Blackett, A. D., Evans, A. B., \& Piggott, D. (2018). "Active" and "passive" coach pathways: Elite athletes' entry routes into high- performance coaching roles. International Sport Coaching Journal, 5(3), 213-226.
Chroni, S. A., \& Dieffenbach, K. (2020). Facilitating and supporting the elite athlete-to-coach transition: Lessons learned from Norwegian coaches and federations. Journal of Sport Psychology in Action, 1-13.

\section{Presenter Biography}

Kristen Dieffenbach is the director of the Center for Applied Coaching and Sport Sciences at West Virginia University and an associate professor of Athletic Coaching Education. She is the president of the United States Center for Coaching Excellence, is a Certified Mental Performance Consultant through the Association of Applied Sport Psychology and has been a professional coach for over 20 years. Her research interests focus on coach developer training, coaching and professionalism, ethics and moral decision making in coach development.

\section{Leveraging Elite Athlete Experience in Coaching}

Rynne, Steven" ; Pettersen, Sigurd ${ }^{2}$; Chroni, Stiliani "Ani"2; Blackett, Alexander $^{3} ; \&$ Dieffenbach, Kristen ${ }^{4}$

${ }^{1}$ The University of Queensland, School of Human Movement and Nutrition Sciences, Brisbane, Australia; ${ }^{2}$ Inland Norway University of Applied Sciences, Faculty of Social and Health Sciences, Elverum, Norway; ${ }^{3}$ Staffordshire University, School of Life Sciences and Education, Staffordshire, UK; ${ }^{4}$ West Virginia University, College of Physical Activity and Sport Sciences, Morgantown, USA

The transitions of elite athletes out of sport have been found to often be difficult, requiring significant effort on a variety of fronts (Barker et al., 2014). In contrast to such findings, popular accounts in the media and from the general public tend to characterise the transitions of former athletes into coaching as relatively smooth, reflective of a perceived natural fit. The view that it is a natural fit is also contextual and driven by particular sporting cultures, meaning that this assumption is more or less engrained globally. As such, experience as an elite athlete is generally assumed to bring a variety aspects that are advantageous to elite sport coaching contexts. However, this assumption has been showed to be flawed in several respects (Blackett et al., 2020; Chroni et al., 2020). In this presentation, consideration will be given to the skills, understandings, and ways of being that elite athletes develop over their playing careers. Aspects that may be advantageous to an elite coaching future will be identified, along with aspects that may be problematic for elite athletes transitioning into coaching work. Finally, consideration will be given to some ways in which elite athletes who want to embark on a coaching career might best prepare themselves.

\section{References}

Barker, D., Barker-Ruchti, N., Rynne, S. B., \& Lee, J. (2014). Moving out of sports: A sociocultural examination of Olympic career transitions. International Journal of Sports Science and Coaching, 9(2), 255-270. https://doi.org/10.1260/1747-9541.9.2.255

Blackett, A. D., Evans, A. B., \& Piggott, D. (2020). Negotiating a coach identity: A theoretical critique of elite athletes' transitions into post-athletic high-performance coaching roles. Sport, Education and Society, 1-13. https://doi.org/10.1080/13573322.2020.1787371

Chroni, S. A., Pettersen, S., \& Dieffenbach, K. (2020). Going from athleteto-coach in Norwegian winter sports: Understanding the transition journey. Sport in Society, 23(4), 751-773. https://doi.org/10.1080/17430437.2019 .1631572 


\section{Presenter Biography}

Dr. Steven Rynne is an Associate Professor and Program Convenor for Sports Coaching with the School of Human Movement and Nutrition Sciences at The University of Queensland, Australia. Steven has worked and conducted research with a variety of peak domestic and international sporting bodies in the areas of high-performance coach learning and Indigenous sport. Steven teaches undergraduate and graduate students, is a registered HPE teacher, and coaches track cyclists.

\section{Symposium 2: From Sage on The Stage to Guide on The Side: USA Hockey's Evolving Coach Development System}

\section{From Sage on the Stage to Guide on the Side: USA Hockey's Evolving} Coach Development System

Dieffenbach, Kristen ${ }^{1}$; Kiosoglous, Cameron ${ }^{2}$; \& Thompson, Melissa ${ }^{3}$

${ }^{1}$ United States Center for Coaching Excellence \& West Virginia University, Morgantown, WV, USA; ${ }^{2}$ United States Center for Coaching Excellence, Drexel University \& US Rowing, Philadelphia, PA, USA; ${ }^{3}$ United States Center for Coaching Excellence \& University of Southern Mississippi, Hattisburg, MS, USA

This symposium will explore the systematic evolution of the USA Hockey (USAH) coaching education program (CEP), supported by the United States Center for Coaching Excellence. This evolution includes the shift from a presentation to classroom facilitation model grounded in adult learning theories and facilitated by coach developers. It will explore the subsequent growth of the volunteer-based network of coach education facilitators and the development of an internal Mentor Coach Developer (MCD) system to support scalability and consistency as well as the training and development of coach developers and coaches throughout the USAH system. In its role as a US Olympic and Paralympic Committee recognized national governing body (NGB), USAH serves roughly 392,800 players under the age of 18 years across the United States, relying on a system of approximately 61,000 volunteer and paid coaches. Among NGBs, USAH is a leader in advocating a holistic long term athletic development strategy, launching their American Development Model in 2009 (ADM; Martel, 2015). USAH has supported ADM through a wide range of resources to help coaches and programs enhance quality youth sport experiences. The USAH CEP, responsible for providing programming for approximately 11,000 new coaches and continuing education for approximately 23,000 coaches annually, has also integrated key ADM concepts into workshops. In 2018 , the CEP began a programmatic shift from "what to" to "how to" coach design that informs both the content and the coaching education delivery structure within USAH, with the addition of their MCD program in 2021.

\section{Presenter Biography}

Kristen Dieffenbach is the director of the Center for Applied Coaching and Sport Sciences at West Virginia University and an associate professor of Athletic Coaching Education. She is the president of the United States Center for Coaching Excellence, is a Certified Mental Performance Consultant through the Association of Applied Sport Psychology and has been a professional coach for over 20 years. Her research interests focus on coach developer training, coaching and professionalism, ethics and moral decision making in coach development.

\section{Symposium 3: Advances in the Use of Social Learning Theory}

Leadership for the 21st Century: Lessons for Social Learning Leaders

Culver, Diane ${ }^{1}$; Duarte, Tiago ${ }^{1}$; Werthner, Penny ${ }^{2}$; Kraft, Erin ${ }^{1}$; Beverly Wenger-Trayner ${ }^{3} ; \&$ Etienne Wenger-Trayner ${ }^{3}$

${ }^{1}$ University of Ottawa, Ottawa, Canada; ${ }^{2}$ University of Calgary, Calgary, Canada; ${ }^{3}$ Wenger-Trayner and Wenger-Trayner consultants, Sesimbra, Portugal

Based upon two decades of collaborative research studying communities of practice and social learning theory, this presentation explores the practical lessons learned around leading such learning spaces, particularly in coach education. Wenger-Trayner \& Wenger-Trayner (2020) define social learning leaders (SLL) as individuals who create conditions that enhance social learning. Still a largely unexplored concept in the literature, we will provide insight into what SLLs do to enable social learning, what challenges exist, and what lessons can be learned. These lessons stem for our social learning initiatives with various sport NGBs (i.e., single sport), multisport groups, and groups with participants from across the sport landscape. We introduce the role of a systems convener; that is, a SLL who works across multiple social learning spaces. Ultimately, we aim to share what the work of a SLL looks like, with examples of what has worked and where we might have gone wrong. Extending previous presentations about the use of the value creation framework, we will focus on SLLs and how they can use of the framework to help those in social learning spaces shape expectations, create value, do something with that value, and assess the difference the learning might make. Practical tips include (a) a thorough mapping of the landscape is a critical first step, (b) reflective cards can guide the work of SLLs, and (c) the number of potential or invited participants at learning activities is not as important as the value created for those who do participate.

\section{References}

Wenger-Trayner, E., \& Wenger-Trayner, B. (2020). Learning to make a difference: Value creation in social learning spaces. Cambridge University Press.

\section{Presenter Biography}

Diane is an associate professor at the School of Human Kinetics at the University of Ottawa in sport pedagogy and psychology. She was a senior coaching consultant for the Coaching Association of Canada before entering academia in July 2007. Her research interests are coaching and coach development, social learning theory, and women in sport leadership. Her previous working experience includes coaching for the Canadian National, and New Zealand Olympic, Ski Teams.

Leading an Online Social Learning Space About Safe Sport in HighPerformance Contexts

Duarte, Tiago $^{1}$; Culver, Diane ${ }^{1}$; Priest, Frances ${ }^{2} ; \&$ Charest, Isabelle ${ }^{2}$

${ }^{1}$ University of Ottawa, Ottawa, Canada $;{ }^{2}$ Coaching Association of Canada, Ottawa, Canada

In April 2020, Sport Canada began funding only those sport organizations providing safe sport training for everyone under their immediate authority. As a first step, the Coaching Association of Canada created a safe sport online course, available to their partner organizations. Moreover, the Responsible Coaching Movement was promoted as a benchmark to guide organisations. A further strategy saw the Coaching Association of Canada 
and Own the Podium reach out to researchers from the University of Ottawa to host an online social learning space (SLS) for high performance key stakeholders. A SLS is a simpler version of a community of practice in which participants share a desire to make a difference. The SLS comprised three social learning facilitators and 15 participants from eight sports and four parasports including head coaches and NextGen coaches travelling to the Tokyo Olympics and Paralympics. This presentation will discuss several aspects of this SLS from the perspective of the social learning leaders. For instance, this was our first SLS in which participants only met online. The group met monthly over 4 months. Also, the proximity to the Tokyo Games made the timing and need to adapt to the new policies of safe sport a priority for some of these coaches. COVID-19 and selection processes for the Games surfaced as safe sport issues. Value creation stories from the participants will illustrate that despite the brevity of project, coaches were able to reframe their perspectives regarding safe sport and apply some of the strategies cocreated by the participants.

\section{References}

Wenger-Trayner, E., \& Wenger-Trayner, B. (2020). Learning to make a difference: Value creation in social learning spaces. Cambridge University Press.

\section{Presenter Biography}

Tiago Duarte, Ph.D., is currently a post-doctoral fellow at the University of Ottawa and has dedicated the last 15 years to working and researching sport psychology and coaching. He was honoured to receive funding from some of the most prestigious Canadian organizations to support his collaborative research with national sport organizations, coaches, and athletes. Much of his work includes the nurturing and assessment of communities of practice, sport for people with impairments, and coach development.

\section{Designing and Implementing an Integrated Model of Athlete Devel- opment in a Brazilian Multisport Club}

Milistetd, Michel

Federal University of Santa Catarina, Florianopolis, Brazil

System conveners (SC) are individuals who bring people together from different sectors for multiple meeting interactions around complex issues, enabling collaboration across social and institutional systems (WengerTrayner et al., 2015). The aim of this presentation is to situate the role played by a SC as a key actor in the negotiation of knowledge, resources, and activities among a diverse group of academics, sports administrators, and sports coaches to design and implement an Integrated Model of Athlete Development in a Brazilian Multisport Club. To situate the context, the Multisport Club is in São Paulo and includes 39 sports, 200 coaches, and 5,000 participants and athletes from recreational to a high-performance levels. The Multisport club hired the SC based upon his previous projects in sports clubs and sports federations. The design and implementation of the integrated model of athlete development were divided into 2 dimensions: (a) Technical-pedagogical - Creation and negotiation, with a group of academics, coordinators, and coaches, of the conceptual model of athlete development (e.g., coaching frameworks); (b) Political-structural - Negotiation of the conditions to implement the project (external and internal communications, alignment of language and coaching practices, data system, coaches' development. Over two years, the project involved five different stages (mapping the context, defining the guiding principles, structuring the methods, piloting, and assessing and evaluating the model). This project is an example of a complex landscape in which a SC had to immerse himself, build bridges, and facilitate partnerships to translate the club philosophy into the coaches' routines.

\section{References}

Wenger-Trayner, E., \& Wenger-Trayner, B. (2015). System conveners in complex landscapes. In E. Wenger-Trayner, M. Fenton-O'Creevy, S. Hutchinson, C. Kubiak, \& B. Wenger-Trayner (Eds.), Learning in landscapes of practice: Boundaries, identity, and knowledgeability in practicebased learning (pp. 99-118). Routledge.

\section{Presenter Biography}

Michel Milistetd is an assistant professor at Sports Centre in Federal University of Santa Catarina (UFSC). Head of the Sports Pedagogy Research Center at UFSC. His main research focus is Coach Development, Coaching, and Positive Youth Development. He is certified as Coach Developer from NCDA/ICCE and works as a consultant with sports federations and sports clubs.

\section{"I Felt I'd Lost Myself as a Coach and not really knowing who I was": Negotiating identity as a CD}

Vinson, Don; Simpson, Harley-Jean; \& Cale, Andrew

University of Worcester, Worcester, United Kingdom

Recently, how Coach Developers learn has come under increased scrutiny. The framework of Landscapes of Practice encourages us to consider how Coach Developer learning can be better understood through consideration of their negotiated identity as a process of engagement, imagination and alignment. This Participatory and Appreciative Action and Reflection investigation explores the journey of two cohorts of Coach Developers $(n=24)$ through a bespoke formal learning programme commissioned by a National Governing Body of sport in the UK. Over three years, data were captured through reflective materials, focus groups, individual interviews, field notes and professional discussions. Here we discuss three major categories namely, (a) (pre) dispositions to the course; (b) epistemological development, criticality and theoretical congruity; and (c) the learning community. Coach Developers' identities were highly individualised and were constituted by engagement, imagination and alignment in different ways and to different degrees. Consideration of their engagement, imagination and alignment with the course helped to better understand the (re)negotiation of their identities as they deepened their understanding. By specifically addressing the Coach Developers' (pre)dispositions to the course we were able to offer the learners a more relevant and relatable programme to which they could choose to align - or not. There was evidence of deeply meaningful identity work going on within each individual. Future research should explore the role and functions of the different forms of social learning leadership in longitudinal courses such as this and seek to better understand how these individuals shape the identities of the learners they support.

\section{Presenter Biography}

Don Vinson is a Principal Lecturer in Sports Coaching Science at the University of Worcester, UK. Don's recent research concerns coach and Coach Developer learning, with a particular emphasis on Value Creation within Landscapes of Practice. Don has published coaching research from a broad range of perspectives including within pedagogic, leadership, faith, and performance analysis disciplines. Don is currently a junior international field hockey coach within the England Hockey National Age Group Programmes. 


\section{Symposium 4: Parasport Coaching and Coach Development}

Examining Disability Inclusion in Canada's Coach Education System Konoval, Tim ${ }^{1}$; Allen, Veronica ${ }^{2}$; Davey, Jenny ${ }^{3}$; \& Charest, Marie-Pier ${ }^{4}$

${ }^{1}$ Deakin University, Geelong, Australia; ${ }^{2}$ York University, Toronto, Canada; ${ }^{3}$ Canadian Paralympic Committee, Ottawa, Canada; ${ }^{4}$ Coaching Association of Canada, Ottawa, Canada

High-quality coach education is critical in creating an inclusive coaching workforce (DePauw, 2005; Ohrberg, 2013), and research has shown that coaches are not being effectively educated on the intricacies of coaching athletes with a disability (Wareham et al., 2018). More specifically, coaching researchers have noted that coach education programs are often framed around outdated views of disability and built on the assumption that able-bodied coaching principles can be unproblematically applied in parasport contexts (Allan et al., 2020; Townsend et al., 2018). As a result, several researchers have called on coach educators to develop coach education programs that highlight the complexities of coaching in parasport through contemporary views of disability (Townsend et al., 2018). However, limited research has examined the inclusion of disability knowledge in coach education programs to date. This presentation will discuss key findings from a research collaboration with the Coaching Association of Canada and the Canadian Paralympic Committee. Specifically, we analysed the coach education content of 27 sports that operate in parasport contexts to examine how disability inclusion is visible (or not visible) in Canada's coach education system. In doing so, we show how mainstream and para-specific sports have structured their disability inclusive content (e.g., separate, integrated), as well as how much and what types of disability inclusive content were included. Based upon these findings, we will share practical recommendations on how national sport organizations might structure and develop coach education curriculum that can lead to a more inclusive coaching workforce.

\section{References}

Allan, V., Blair Evans, M., Latimer-Cheung, A. E., \& Côté, J. (2020). From the athletes' perspective: A social-relational understanding of how coaches shape the disability sport experience. Journal of Applied Sport Psychology, 32(6), 546-564.

DePauw, K. P., \& Gavron, S. J. (2005). Disability sport. Human Kinetics.

Ohrberg, N. J. (2013). Autism spectrum disorder and youth sports: The role of the sports manager and coach. Journal of Physical Education, Recreation \& Dance, 84(9), 52- 56.

Townsend, R. C., Cushion, C. J., \& Smith, B. (2018). A social relational analysis of an impairment-specific mode of disability coach education. Qualitative Research in Sport, Exercise and Health, 10(3), 346-361.

Wareham, Y., Burkett, B., Innes, P., \& Lovell, G. P. (2018). Sport coaches' education, training and professional development: The perceptions and preferences of coaches of elite athletes with disability in Australia. Sport in Society, 21(12), 2048-2067.

\section{Presenter Biography}

Dr. Tim Konoval is a Lecturer in Sport Coaching at Deakin University in Geelong, Australia. His research examines the socio-cultural influences on coaching practice and coach education. Specifically, he collaborates with sport and parasport organizations to provide more effective and appropriate education opportunities for coaches working in parasport contexts.
Through his research, he aims to support coaches to provide inclusive, safe, accessible, and ethical sport for all.

\section{A Scoping Review of Coach Development Opportunities in Parasport}

Culver, Diane $\mathrm{M}^{1}$; Shaikh, Majidullah ${ }^{1}$; Duarte, Tiago ${ }^{1}$; Konoval, Tim $^{2} ; \&$ Fournier, Karine ${ }^{1}$

${ }^{1}$ University of Ottawa, Canada; ${ }^{2}$ Deakin University, Australia

A scoping review was conducted to map: (a) empirical literature on coach development opportunities in parasport, and (b) empirical literature on coaches' experiences (barriers and facilitators) of accessing coach development opportunities in parasport. Eight sport sciences databases were searched generating an initial 1,406 records; a three-phase process of screening narrowed the selection to 32 records. Data were charted on study aims, theory, context, program information, methodology, and results. Descriptive frequencies were calculated across these categories, and an inductive qualitative approach was taken to categorize the results. The descriptive results showed that relevant literature spanned years 1990 $2021,50 \%$ of records were published in the last decade, $68 \%$ were from Canada and USA, $47 \%$ were in elite or Paralympic contexts, $25 \%$ used human learning theories to frame their studies, $81 \%$ used qualitative approaches, and $75 \%$ were interview studies. The inductive results indicated that: (a) coaches often began their careers with limited education in parasport coaching; (b) coaches' formal education of coaching practices are most predominantly drawn from able-bodied education opportunities; (c) coaches most often learned through social opportunities, such as mentoring from experts, and through interactions with athletes, peer coaches, family; (c) coaches preferred information about strategies for working with different impairments, and preferred learning through handson, practical opportunities. Findings reveal the value of: (a) offering tailored, parasport-specific learning opportunities to coaches already coaching in parasport; (b) providing broader parasport education to coaches entering the context, and (c) and incorporating parasport coach development opportunities within undergraduate curriculums.

\section{Presenter Biography}

Maji Shaikh is a doctoral candidate at the University of Ottawa. His research area is positive youth development through sport and recreation. Maji's expertise spans trauma-sensitive practices, coach learning, program evaluation, and knowledge mobilisation. He has led three nationally funded reviews in the sport sciences, partnering with the Coaches' Association of Canada, Canadian Paralympic Committee, and E-Alliance for Gender+ Equity in Sport. Maji has worked with several communitybased youth organisations to evaluate their programs, including BGC Canada and Start2Finish.

\section{Developing European Guidelines for Inclusive and Empowering Para Coaching Practice}

Huntley, Tabo ${ }^{1}$; Townsend, Robert ${ }^{2}$; \& Cushion, Christopher ${ }^{3}$

${ }^{1}$ School of Sport and Exercise Science, Liverpool John Moores University, Liverpool, United Kingdom; ${ }^{2}$ School of Health, University of Waikato, New Zealand; ${ }^{3}$ School of Sport, Exercise and Health Sciences, Loughborough University Loughborough, United Kingdom

In Parasport, the role of coaches and coaching is recognised at the highest level of international sport policy for the ability to help achieve sporting and social outcomes related to the inclusion of disabled people (European Union 2017, The Work Plan for Sport 2017-2020). However, Para coaching 
research continually highlights both the limitations of formal coach education (CE) on coaches learning and the lack of a specific focus on disability. A ParaCoach framework may provide a reference point to guide the development of a comprehensive CE curriculum. To develop a ParaCoach framework, a process of co-production was employed to create a third space whereby, academics using multiple processes and stakeholder forums could collaborate in the process of knowledge production (Bhabha \& Rutherford. 2006). The following process was adopted to generate draft one of the frameworks: 1) Literature review of Para coaching research 2) Two phase workforce audit (e.g., online survey and interviews) 3) Best practice case studies interviews with coaches, coach educators and athletes, 4) Stakeholder workshops three international workshops consisting of coaches, coach educators, athletes, and academics, 5) Draft review by experts in CE and disability coaching research. The framework identifies: the complexities associated with understanding disability and the need to provide inclusive and empowering practices; coach and athlete learning as social learning and the importance of reflexivity for coaches and coach developers; a Para sport specific athlete pathway which highlights the talent characteristics and developmental phases; and the subjects areas that maybe infused within CE.

\section{References}

Bhabha, H. K., \& Rutherford, J. (2006). Third Space. Multitudes, 3, 95-107.

European Union. (2017). European Union Work Plan for Sport 20172020. Education, Youth, Culture and Sport Council.

\section{Presenter Biography}

Dr. Rob Townsend is a Senior Lecturer in Sport Coaching and Pedagogy at the University of Waikato. His research is interdisciplinary, bridging qualitative research, social science, and disability studies, with a specific focus on disability sport and sport coaching. He is a member of the Virtus Academy Scientific Committee (VASCOM) and has provided consultancy to the European Paralympic Committee on disability coach education. Rob is also on the editorial board of the International Sport Coaching Journal.

\section{A Global Workforce Audit of Special Olympics Coaches}

Huntley, Tabo; Hardwick, Amy Elizabeth; \& Whitehead, Amy

\section{Liverpool John Moores University, Liverpool, United Kingdom}

Special Olympics (SO) is an international, non-profit organisation that provides sporting opportunities for children and adults across the globe with intellectual disabilities (ID). Indeed, research has shown that participation in sport positively impacts on participants' life skills, self-confidence, competence, social skills, and their inclusion in mainstream sport (Cybulski et al., 2016; Harada et al., 2011). However, despite the importance of sport participation for participants with ID, we know little about the knowledge, education, and development of the global coaching workforce. Therefore, coach education and development may insufficiently prepare coaches for the complexity of effectively coaching and meeting the needs of their participants. To undertake the workforce audit, a two-part methodology was utilised which included an online survey $(\mathrm{N}=275)$ and follow up semi-structured interviews $(\mathrm{N}=21)$. Both survey and interview questions were guided by the premise that coaching involves the coach, the athlete, and the context. The survey findings suggested that coaching in SO is a blended profession that lacked the support of a specific formal coach education curriculum, which may have contributed to coaches' gaps in knowledge. Analysis of interviews revealed an idiosyncratic and serendipitous pathway into and through coaching. Coaches had to rely on informal learning opportunities to support their coaching practice. The outcome of coaches learning meant that disability was an abstract concept which was infused with medical model understandings. In conclusion, the findings highlight the need for the infusing of disability within a more encompassing coach education curriculum.

\section{References}

Cybulski, S., Culver, D. M., Kraft, E., \& Forneris, T. (2016). Special Olympics coaches: Examining the strategies they use to encourage their athletes to develop life skills. International Journal of Coaching Science, 10(2), 3-23.

Harda, C., Siperstein, G., \& Lenox, D. (2011). Promoting social inclusion for people with intellectual disabilities through sport: Special Olympics International, global sport initiatives and strategies. Sport in Society, 14(9), $1131-1148$.

\section{Presenter Biography}

Dr. Tabo Huntley is a full-time senior lecturer in sport coaching within the School of Sport and Exercise Science and a researcher within Paralympic and disability sport. Tabo has spent over 20 years in high performance sport, with the latter half coaching and mentoring in the Paralympic sport context.

Competencies and Professional Qualifications of the Coaches in Olympic and Paralympic Sports

Marek Piotr

Institute of Sport -National Research Institute, Poland

The main objective of the study was to identify the professional competencies of the coaches of the Polish national team of able-bodied and disabled athletes in Olympic and Paralympic sports. In order to do this, sport coaches and managers were recruited as participants. The identification of the researched issues was based on self-assessment of the respondents who had received/undergone training courses to establish professional qualifications. The method of a standardized written interview with the use of the Internet (online questionnaire) was used to collect data from coaches and sport managers selected for the analysis of Olympic and Paralympic sports organizations and associations. The data was analysed with reference to their level of competency and qualifications held. This presentation will outline the coaches' competencies in order to gain a better understanding of the similarities and differences between Olympic and Paralympic coach qualifications and competencies.

\section{Presenter Biography}

Piotr Marek is the marketing manager and the Coaching Academy manager in Sport Institute, an organization responsible for conducting research in the field of sport and for life-long learning program for high performance Olympic and Paralympic sports coaches. He represented Poland in various international competitions and in the Paralympic Games (Nagano 1998, Salt Lake City 2002) as alpine skier.

\section{Symposium 5: Mental Health and High- Performance Coaching}

\section{Mental Health and High-Performance Coaching}

Olusoga, Peter ${ }^{1}$; Kenttä, Göran ${ }^{2}$; Benzen, Marte ${ }^{3}$; Dieffenbach, Kristen ${ }^{4}$; Thompson, Melissa ${ }^{5}$; Côté, Jean ${ }^{6} ; \&$ Mallett, Cliff ${ }^{7}$ 
${ }^{1}$ Sheffield Hallam University, UK; Inland Norway University of Applied Sciences, Norway; ${ }^{2}$ GIH The Swedish School of Sport and Health Sciences, Stockholm, Sweden; ${ }^{3}$ Norwegian School of Sport Science, Norway; ${ }^{4}$ Center for Applied Coaching and Sport Studies at West Virginia University, Morgantown, WV, USA; ${ }^{5}$ University of Southern Mississippi, MS, USA; ${ }^{6}$ School of Kinesiology and Health Studies, Queen's University, Kingston, Ontario, Canada; ${ }^{7}$ The University of Queensland, Australia

Coaching is a blended profession with the potential to cultivate a range of rewarding and meaningful experiences. However, the high-performance environment, characterized by high-pressure, job insecurity, work-home interference, and a high threshold for help seeking, means that coaching can also be demanding, stressful, and can lead to impaired mental health. Mental health covers a continuum from illbeing to well-being and has rapidly gained attention in sport science practice and research, as evidenced by 10 published position statements (Vella \& Swann, 2021). Unfortunately, these position statements have failed to acknowledge the need to also include highperformance coaches' (HPC) mental health. The purpose of this presentation is to provide a brief theoretical background and rationale for mental health research that focus on HPC, to outline several keyrecommendations to support mental health, and finally to discuss and reflect upon steps forward with a panel of HPC. The following recommendations will be emphasized, (1) It is essential to give attention to the full mental health continuum as a basis for all recommendations for HPC, (2) Reducing stigma regarding mental health struggles among HPC is crucial in order to combat the high threshold for help-seeking, (3) Provide clear signposting and confidential referral pathway/networks and ensure contextual understanding among health care providers, (4) Create self-screening mental health website/resource for HPC, (5) Personal mental health included as topic in all levels of coach education that promote self-care for coaches as a strategy to sustainability.

\section{References}

Bentzen, M., Kenttä, G., Richter, A., \& Lemyre, P. N. (2020). Impact of job insecurity on psychological well- and ill-being among high-performance coaches. International Journal of Environmental Research and Public Health, 17, 6939-6954.

Kenttä, G., Bentzen, M., Dieffenbach, K., \& Olusoga, P. (2020). Challenges experienced by women high-performance coaches: Sustainability in the profession. International Sport Coaching Journal, 7(2), 200-208.

Norris, L. A., Didymus, F. F., \& Kaiseler, M. (2017). Stressors, coping, and well-being among sports coaches: A systematic review. Psychology of Sport and Exercise, 33, 93-112.

Olusoga, P., Bentzen, M., \& Kenttä, G. (2019). Coach burnout: A scoping review. International Sport Coaching Journal, 6(1), 42-62.

Vella, S. A. \& Swann, C. (2021). Time for mental healthcare guidelines for recreational sports: A call to action. British Journal of Sports Medicine, 55, 184-185.

\section{Presenter Biography}

Dr. Olusoga is a Senior Lecturer in Psychology at Sheffield Hallam University and holds an Associate Professor II position at Inland Norway University of Applied Sciences. His current research focuses on stress, burnout, and wellbeing in sports, with a particular interest in high-performance environments and elite coaching. In addition to research, Dr. Olusoga is a Chartered Psychologist with the British Psychological Society (BPS) and an active sport psychology consultant.

\section{Symposium 6: Learning About Our Coaches: Lessons from Gaelic Games}

\section{Challenges and Opportunities: The Role of External Coaches in Irish Primary Schools}

Bowles, Richard ${ }^{1}$; Donnelly, Paul ${ }^{2}$; Culhane, Pat $^{3}$; Haughey, Tandy ${ }^{4}$; Horgan, Peter ${ }^{5}$; McGourty, Padraig ${ }^{6}$; Murtagh, Elaine ${ }^{7}$

${ }^{1}$ Mary Immaculate College, Limerick, Ireland; ${ }^{2}$ Ulster University, Jordanstown, Ireland; ${ }^{3}$ Munster Technological University, Cork, Ireland; ${ }^{4}$ Ulster University, Jordanstown, Ireland; ${ }^{5}$ Gaelic Athletic Association, Dublin, Ireland; ${ }^{6}$ Institute of Technology, Sligo, Ireland; ${ }^{7}$ University of Limerick, Limerick, Ireland

Generalist teachers are responsible for teaching physical education in primary schools on the Island of Ireland, but the involvement of external coaches delivering sport-specific content is also widespread (Mangione et al., 2020). It is estimated that coaches representing the Gaelic Athletic Association (GAA) provide coaching input in over $90 \%$ of schools. This research sought to provide a deeper understanding of the role teachers and coaches play in the delivery of (i) curricular PE, and (ii) extracurricular school sport, leading to the provision of guidance for policymakers on the development of effective practices in primary schools. The research team used two data sources: quantitative data collected through a national GAA coaching survey, and qualitative semi-structured focus groups. Interviews were conducted with teachers $(n=14)$, volunteer coaches $(n=8)$ and full-time GAA coaches $(n=10)$ who had responded to the original survey. The qualitative data was analysed using a six-step process to establish key themes (Braun \& Clarke, 2021). Our preliminary findings highlight how external coaches contribute to both curricular and extracurricular activity within the school environment via the development of movement skills and the creation of school-community links. Teachers also played a pivotal role in the promotion of Gaelic games within schools. We also identified clear inconsistencies in practice across the country, whereby the interpretation of national education and sport policies vary widely. These findings have implications for sports' governing bodies, and can have a significant influence in informing the development of government policy for the organisation of PE and school sport.

\section{References}

Braun, V., \& Clarke, V. (2021). Thematic Analysis. In E. Lyons \& A. Coyle (Eds.), Analysing qualitative data in psychology (Vol. 3rd, pp. 128147). Sage.

Mangione, J., Parker, M., O’Sullivan, M., \& Quayle, M. (2020). Mapping the landscape of physical education external provision in Irish primary schools. Irish Educational Studies, 39(4), 475-494. https://doi.org/10 $.1080 / 03323315.2020 .1730218$

\section{Presenter Biography}

Dr. Richard Bowles is a lecturer in physical education at Mary Immaculate College, Limerick. He teaches on undergrad and postgrad courses. His research interests include the use of self-study as a qualitative research methodology; collaborative approaches to coach learning; and the provision of meaningful experiences in physical education and youth sport.

What Role Can Female Coaches Have in the Development of Gaelic Games?

Donnelly, Paul ${ }^{1}$; Haughey, Tandy Jane ${ }^{2}$; Graffin, Arron ${ }^{3}$; McGrane, Bronagh $^{4}$; Lane, Aoife ${ }^{5}$ : McGourty, Padraig ${ }^{6}$; Stapleton, Nora ${ }^{7}$; Bunt, Angharad $^{8}$; Williams, Niall ${ }^{9}$; Harmon, William ${ }^{10} ; \&$ Horgan, Peter ${ }^{11}$ 
${ }^{1}$ University of Ulster, Belfast, UK; ${ }^{2}$ University of Ulster, Belfast, UK; ${ }^{3}$ University of Ulster, Belfast, UK; ${ }^{4}$ Dublin City University, Dublin, Ireland; ${ }^{5}$ Athlone Institute of Technology, Athlone, Ireland; ${ }^{6}$ Sligo Institute of Technology, Sligo, Ireland; ${ }^{7}$ Sport Ireland, Dublin, Ireland; ${ }^{8}$ Sport Northern Ireland, Belfast, UK; ${ }^{9}$ Camogie Association, Dublin, Ireland; ${ }^{10}$ Ladies Gaelic Football Association, Dublin, Ireland; ${ }^{11}$ Gaelic Athletic Association, Dublin, Ireland

Research consistently identifies that representation of women in coaching reduces as the level of the pathway increases. This is mirrored by higher levels of drop-off within coach education as qualifications progress. Previous research has provided some evidence of the occupational landscape and experiences of females in coaching but there is a need to examine the structural level and culture of this within the Gaelic Athletic Association (GAA). This study aimed to explore the experiences of female coaches who have been actively involved in the development and delivery of Gaelic games in Ireland. Two data sources: quantitative collected through a national GAA coaching survey, and qualitative, 8 semi-structured focus groups $(n=40)$. Qualitative data were analysed using a six-step process to establish key themes (Braun \& Clarke, 2021). Preliminary findings highlight several issues facing female coaches actively involved in Gaelic games; Perceived Lack of Respect/Value: from their voice not being valued as strongly as a man's voice when coaching, to not being included in team-specific and broader club coaching activity. Gatekeepers: Having children is a strong access point for women into coaching. Females would like to progress in coaching as their children progress. Having a familial attachment to the club also seemed to support female coaches, a dad or husband involved in the club was an access point to coaching and maybe ensured a more positive experience for female coaches. These findings provide the Association with information on their coaching workforce to inform the development of their cultural perspective and coaching policies.

\section{References}

Braun, V., \& Clarke, V. (2021). Thematic analysis. In E. Lyons \& A. Coyle (Eds.), Analysing qualitative data in psychology (Vol. 3rd, pp. 128147). Sage.

\section{Presenter Biography}

Dr. Paul Donnelly is a lecturer in Sport Development and Coaching at the University of Ulster. Previously he was the Director of GAA's Gaelfast project, and the Head of Policy, Planning and Research at Sport Northern Ireland. Paul has published widely in a range of academic journals and has led the development and implementation of sport policy in the Northern Ireland context. Paul's research interests are around sport participation, physical activity, health, and coaching.

\section{An Investigation into the Coaching Workforce in Gaelic Games}

Horgan, Peter ${ }^{1}$; Bowles, Richard ${ }^{2}$; Considine, John ${ }^{3}$; Donnelly, Paul ${ }^{4}$; Harmon, William ${ }^{5}$; Harrison, Hayley ${ }^{6}$ Kelly, Seamus ${ }^{7}$; MacNamara, Áine ${ }^{8}$; McCullick, Bryan ${ }^{9}$; McGourty, Padraig ${ }^{10} ; \&$ Williams, Niall ${ }^{11}$

${ }^{1}$ Gaelic Athletic Association, Dublin, Ireland; ${ }^{2}$ Mary Immaculate College of Education, Limerick, Ireland; ${ }^{3}$ University College Cork, Cork, Ireland; ${ }^{4}$ University of Ulster, Belfast, UK; ${ }^{5}$ Ladies Gaelic Football Association, Dublin, Ireland; ${ }^{6}$ Sport Ireland Coaching, Limerick, Ireland; ${ }^{7}$ University College Dublin, Dublin, Ireland; ${ }^{8}$ Dublin City University, Dublin, Ireland; ${ }^{9}$ University of Georgia, Athens, USA; ${ }^{10}$ Institute of Technology, Sligo, Sligo, Ireland; ${ }^{11}$ Camogie Association, Dublin, Ireland

While previous research explored coaching/coach education in Ireland (Chambers \& Gregg, 2016) and the Football Association of Ireland (O'Regan
\& Kelly, 2018), this presentation focuses on coaching and coach education amateur, volunteer-led sporting organisations. The Gaelic games coach study was created by the Gaelic Athletic Association (GAA), Camogie Association, and Ladies Gaelic Football Association (LGFA) to provide a detailed picture of their coaching workforce. A web-based questionnaire was issued to coaches from across the three Associations early in 2020. Questions related to coaches' experience and practice, and their coaching futures. 10,647 respondents had coached in the previous 12 months. Following analysis of the survey data, eight virtual focus groups were conducted with survey respondents $(n=38)$, with focus group questions adapted based on the initial survey findings. Findings indicated that Gaelic games coaches are a complex mix of individuals who have coaching experiences unique to their code, their location, and personal situation. Respondents were predominantly male (79\%), aged between 25 - $54(85.7 \%)$, well-educated $(72.4 \%$ 3rd Level qualified), and in full-time employment $(66.3 \%)$. Coaches primarily held voluntary roles (95.2\%) and engaged in coaching on multiple days each week $(78.3 \%) .63 \%$ of coaches intend continuing coaching for more than two years, while just $2.5 \%$ of coaches do not intend to continue coaching. Of those coaches who intend to continue, Balancing Coaching with Other Demands (73.8\%) was their primary concern. These findings provide the GAA, LGFA, and Camogie Association with detailed information to inform the development of coaching policy.

\section{References}

Chambers, F., \& Gregg, R. (2016). Coaching and coach education in Ireland. International Sport Coaching Journal, 3(1), 65-74.

O'Regan, N., \& Kelly, S. (2018). Coaching and coach education in the Football Association of Ireland. International Sport Coaching Journal, 5(2), 183-191.

\section{Presenter Biography}

Peter Horgan is the Education Officer for the Gaelic Athletic Association. Part of his role involves managing a programme of high-quality research and policy analysis relevant to current and anticipated organisational planning, policy, and decision-making needs. He led the development and implementation of the Gaelic Games Coach Study which is the largest coaching study in Gaelic games. His research interests revolve around coach education and the development of coach educators.

\section{The Coach Education Experiences and Desires of Gaelic Games Coaches}

Horgan, Peter ${ }^{1}$; Bowles, Richard ${ }^{2}$; Considine, John ${ }^{3}$; Donnelly, Paul ${ }^{4}$; Harmon, William ${ }^{5}$; Harrison, Hayley ${ }^{6}$; Kelly, Seamus ${ }^{7}$; MacNamara, Áine $^{8}$; McCullick, Bryan ${ }^{9}$; McGourty, Padraig ${ }^{10} ; \&$ Williams, Niall ${ }^{11}$

${ }^{1}$ Gaelic Athletic Association, Dublin, Ireland; ${ }^{2}$ Mary Immaculate College of Education, Limerick, Ireland; ${ }^{3}$ University College Cork, Cork, Ireland; ${ }^{4}$ University of Ulster, Belfast, UK; ${ }^{5}$ Ladies Gaelic Football Association, Dublin, Ireland; ${ }^{6}$ Sport Ireland Coaching, Limerick, Ireland; ${ }^{7}$ University College Dublin, Dublin, Ireland; ${ }^{8}$ Dublin City University, Dublin, Ireland; ${ }^{9}$ University of Georgia, Athens, USA; ${ }^{10}$ Institute of Technology, Sligo, Sligo, Ireland; ${ }^{11}$ Camogie Association, Dublin, Ireland

It has been argued that there is a necessity to explore the realities of coach education to understand what appears to be a dynamic and ambiguous environment (Jones \& Wallace, 2005). The Gaelic Games Coach Study investigated the coach education experiences of coaches in the Gaelic Athletic Association (GAA), Camogie Association, and the Ladies Gaelic Football Association (LGFA). 10,647 active coaches responded to an online questionnaire during Spring, 2020. Findings indicated that $91.3 \%$ of respondents were accredited through the GAA, LGFA, or Camogie 
Association coach development programmes. Almost two thirds of respondents $(61.4 \%)$ have gained their most recent qualification in the last three years. Lack of time (55.9\%) and Work/life balance challenges $(45.3 \%)$ were identified as reasons for not having engaged in coach education more recently. Respondents also identified taking part in a variety of learning opportunities over the previous 12 months, including courses $(48.3 \%)$, workshops (52.7\%), and webinars (52.2\%). Over three quarters of respondents have observed other coaches' sessions (78.3\%), while almost two thirds have received feedback from their players (63.3\%) on their coaching practice. An overwhelming majority of the respondents consider future learning to be important to their coaching (94.6\%). Respondents sought content focused on player development $(59.8 \%)$, sport specific techniques $(56.3 \%)$, and the skills of coaching $(48.3 \%)$. This study provides the first empirical evidence on the coach education experiences and desires of coaches of Gaelic games. These findings have implications for sport governing bodies, informing the development and content of future coach learning opportunities.

\section{References}

Jones, R. L., \& Wallace, M. (2005). Another bad day at the training ground: Coping with ambiguity in the coaching context. Sport, Education and Society, 10(1), 119-134.

\section{Presenter Biography}

Dr. Peter Horgan is the Education Officer for the Gaelic Athletic Association. Part of his role is to manage a programme of high-quality research and policy analysis relevant to current and anticipated organisational planning, policy, and decision-making needs. In 2020 he led the development and rollout of the Gaelic games Coach Study, which was the largest study of its kind conducted by the GAA. His research interests are around coach education and the development of coach educators.

\section{Symposium 7: Sports Coaches Dropping Out of Coaching}

\section{Why Coaches Quit Coaching in Finland?}

Blomqvist, Minna ${ }^{1}$; Mononen, Kaisu ${ }^{1}$; \& Hämäläinen, Kirsi ${ }^{2}$

${ }^{1}$ Research Institute for Olympic Sports, Jyväskylä, Finland; ${ }^{2}$ Finnish Olympic Committee, Helsinki, Finland

The development and learning of coaches have received increased research attention in recent years. However less research has focused on coach drop out even though it could offer valuable insights into how to retain coaches within sports. In Finland three large coaching surveys have been conducted during the past ten years. The first survey with Finnish coaches was launched in 2009 to provide an overall picture of coaches and to track coaches' experiences and perceptions of their learning and development. The main goal of the second survey in 2013 was to follow up the respondents' coaching careers over a period of four years and the last 2019 survey to provide an update of Finnish coaches after 10 years. The follow up survey in 2013 showed that $35 \%(n=252)$ of the coaches had stopped coaching during the previous four years. Dropping out of coaching was more common among: coaches under 30years and over 50-years age bands; women coaches; less educated and less experienced coaches; and coaches working on a voluntary basis. The main reasons for giving up coaching were mainly related to personal issues such as family, health, or lack of time (60\%). In addition, $20 \%$ of the coaches were dissatisfied with the payment or suffered from lack of support from the sporting club or parents. The 2019 survey $(n=153)$ revealed the main reasons provided for taking a break or giving up coaching were again lack of time (68\%), personal reasons $(54 \%)$ and lack of support $(47 \%)$.

\section{Presenter Biography}

Minna Blomqvist, $\mathrm{Ph} . \mathrm{D}$. is a leading researcher in sports pedagogy in the Research Institute for Olympic Sports, Finland. Dr. Blomqvist has a long experience in applied scientific research and the main emphasis of her research has been on the motor and cognitive aspects of sport performance and athlete development. More recently, also coach learning and development and assessment in coach education have been her research areas.

\section{Some Coaches Retire Old and Others Dropout Young: The Case of Norway}

Chroni, Stiliani “Ani”; Medard, Magnhild; Nilsen, Dag André Sigurjonsson, Thorsteinn; \& Solbakken, Tor

\section{Inland Norway University of Applied Sciences, Elverum, Norway}

The professionalization of sport coaching has attracted the attention of researchers and sport stakeholders (Taylor \& Garratt, 2013). Majority of works focus on the development of effective coaches, the identification of standardized knowledge and skills for the profession (ICCE, 2013), the evolvement of a volunteer activity to a paid job. While knowledge on coaches and coaching has increased, many appear to exit coaching prematurely before reaching retirement age (Chroni et al., 2018). Learning from those who dropout of coaching prematurely can give us great insight into previously undiscussed barriers that may impact both coaches' wellbeing and career longevity. A large number of sports coaches across Norway was surveyed with the aim to profile the men and women who coach the developing, elite and recreational athletes of Norway (Chroni et al., 2018). The PROCON survey collected responses from 5,977 coaches, of whom 930 had stopped coaching. The focus here is on what we can learn from the inactive coaches, bearing in mind that fewer of them $(8 \%)$ were of retirement age and more (92\%) exited coaching at earlier ages. Most often reported reason for exiting was the challenging work-life situations, followed by skills not being needed anymore, their child having stopped sport, and lastly experiencing burnout/lacking motivation. Our analyses also take into consideration gender, age, and coaching status (volunteer/employed). The findings will be discussed with reference to future research and policy work considering that a rather high number of employed coaches dropout of coaching before the age of 29 years.

\section{References}

Chroni, S., Medgard, M., Nilsen, D. A., Sigurjonsson, T. \& Solbakken, T. (2018). Profiling the coaches of Norway report. UNIT. https://brage .bibsys.no/xmlui/handle/11250/2569671

International Council for Coaching Excellence, Association of Summer Olympic International Federations, \& Leeds Beckett University. (2013). International sport coaching framework. Human Kinetics. https://www .icce.ws/_assets/files/iscf-1.2-10-7-15.pdf

Taylor, W. G. \& Garratt, D. (2013). Coaching and professionalization. In P. Potrac, W. Gilbert, \& J. Denison (Eds.), Routledge handbook of sports coaching (pp. 27-39). Routledge. 


\section{Presenter Biography}

Dr. Stiliani "Ani” Chroni is a professor of Sport Psychology, Pedagogy, and Sports Coaching with the Institute of Public Health and Sports Science of Inland Norway University of Applied Sciences. Ani, possess extended, versatile, high-level international work experience in academia, sport psychology consultancy and advocacy for gender equality with sport and action-based organizations. Her research focuses on coach wellbeing, studying elite coaches' stress experiences and the culture supporting them as well as the highly demanding transition going from elite athlete-to-coach.

Using Realist Evaluation as a Research Philosophy and Approach to Understanding Coach Drop-Out

McCarthy, Liam

University of Central Lancashire

Sports coaches play a significant role in society, and this is increasingly being recognised within sports policy (e.g., Sport England, 2016). Indeed, the sports coaching workforce is said to be responsible for a vast remit; this includes encouraging healthy and active lifestyles, improving the performance of individual athletes and teams, while supporting the personal well-being of participants (Ponnet et al., 2020). As a result, concern has grown over the number of coaches who leave the coaching workforce each year (Thompson \& Mcilroy, 2017). Specifically, in Flanders (Belgium), Norway and Finland, recent studies reveal high levels of coach dropout and provide new insights in relationships between coach dropout on the one hand and gender, age, status, and qualification level on the other. While the literature can (at times) paint a pessimistic view of the situation, within this presentation we call for policy makers and other related professionals to move beyond the statistical data and get inside the black box of coach dropout. To do this, we propose a research philosophy and approach to inquiry which enables us to go beyond descriptions of how many coaches drop out. Instead, it becomes possible to identify in what circumstances coach dropout is likely to occur, for whom and why. Drawing largely on the work of Pawson and Tiley (1997) and North (2017), we argue that there is much to be gained by exploring the causal mechanisms which bring about this specific outcome.

\section{References}

North, J. (2017). Sport coaching research and practice: Ontology, interdisciplinarity and critical realism. Taylor \& Francis.

Pawson, R., \& Tilley, N. (1997). Realistic Evaluation. Sage.

Ponnet, H., Vangrunderbeek, H., \& McCarthy, L. (2020). The Flemish interactive coaching monitoring systems (FICOMS), International Sport Coaching Journal, 1-10.

Sport England. (2016). Coaching in an active nation. The coaching plan for England 2017-21. Sport England. https://sportengland-productionfiles.s3.eu-west-2.amazonaws.com/s3fs-public/coaching-in-an-activenation_the-coaching-plan-for-england.pdf

Thompson, B., \& Mcilroy, J. (2017, October). Coaching in the UK: The coaching workforce statistical report. UK Coaching.

\section{Presenter Biography}

Liam McCarthy has a track record of high-quality teaching, research, and international knowledge exchange activity in the field of coach education. Liam currently works at the University of Central Lancashire, as a lecturer in sports coaching and development, and at the Premier League where he contributes to the design and delivery of coach development programmes. Further, Liam is currently project manager for an International Council for
Coaching Excellence (ICCE) working group, exploring assessment as a feature of coach education.

\section{Dropout of Coaches in Organised Sports in Flanders (Belgium)}

Vangrunderbeek, Hans ${ }^{1}$ \& Ponnet, Hans ${ }^{2}$

${ }^{1}$ Flemish School for Coach Education, Brussels, Belgium; ${ }^{2}$ Flemish School for Coach Education, Brussels, Belgium

Alongside the learning and development of coaches, coach retention is an important issue for sport delivery systems and coaching policy. So far, few studies have drawn attention specifically to coach dropout; which is in stark contrast to the significantly larger volume of athlete dropout literature. To understand why coaches drop out, it is essential to first identify the characteristics of your coaching workforce. In Flanders (Belgium), the Flemish Interactive Coaching Monitoring System (FICOMS) was set up in 2019 and provides a profile of active and inactive coaches from 2014-2019 (Ponnet et al., 2021; Vangrunderbeek \& Ponnet, 2020). The majority of coaches in Flanders are volunteers. Analysis of the data from FICOMS revealed there has been a steady increase in the number of active coaches over the past 5 years. However, $21 \%(\mathrm{~N}=14,277)$ of coaches $(\mathrm{N}=67,878$ in 2018 ) in 50 organised sports dropped out and did not coach in 2019. Specifically, between 2014-2019 the dropout rate of non-qualified coaches is significantly higher than qualified coaches (2019: $26.3 \%$ vs. $13.9 \%$ ). Results also revealed significant differences in dropout rate between coaches of different sports (e.g. Karate: $5 \%$ vs. Football: $34.1 \%$ in 2019), the size of the sports club, age, and gender of the coaches. Findings from this study demonstrate the magnitude and complexity of the problem sports federations face in retaining their coaches. This is a first step in providing evidence that may encourage further research that can inform policy.

\section{References}

Ponnet, H., Vangrunderbeek, H., \& McCarthy, L. (2021). The Flemish interactive coaching monitoring systems. International Sport Coaching Journal, 8(2), 253-262. https://doi.org/10.1123/iscj.2020-0093

Vangrunderbeek, H., \& Ponnet, H. (2020). The history of coach education in Flanders. International Sport Coaching Journal, 7(3), 380-389. https:// doi.org/10.1123/iscj.2020-0049

\section{Presenter Biography}

Dr. Hans Vangrunderbeek is coach education manager at the Flemish School for Coach Education. In his Ph.D., he focussed on the scientific development of physical education/sports in Belgium. In 2011, he obtained a grant for a research stay at Harvard University in Cambridge. He published more than 40 papers within the fields of sports (history, sociology, pedagogy, ethics, management, coach education) and gave lectures at several international congresses. In 2019-2020, he successfully completed the NSSU-ICCE Coach Developer program in Tokyo.

\section{Symposium 8: Positive Youth Development Through Sport in Portugal}

\section{Positive Youth Development Through Sport: Looking Back and Looking Forward}

Camiré, Martin

\section{School of Human Kinetics, University of Ottawa, Canada}

Positive youth development represents an asset-based approach to development in which life skills are recognized as desired outcomes. In many 
countries around the world, there is increased attention paid to the teaching of life skills through sport. However, researchers have raised awareness about contemporary challenges in relation what positive youth development and life skills are and how they should be fostered. In this presentation, several challenges and strategies will be discussed.

\section{Presenter Biography}

Martin Camiré is an Associate Professor at the University of Ottawa in Canada. Through his research, he is interested in examining how positive youth development can be facilitated in the context of sport. Further, he studies the role played by coaches in facilitating the development and transfer of life skills in youth sport participants. His teaching interests lie in the areas of intervention, health promotion, and research methods.

\section{Portuguese National Sport Organizations' Managerial Strategies: What Counts as Effective Practice in Youth Sport?}

MacDonald, Dany J.

Department of Applied Human Sciences, University of Prince Edward Island, Canada

In Portugal, national sport organizations receive funding from the government to achieve three key objectives: organize competitions; train key stakeholders; and foster human development. To better understand if and how the third key objective of fostering human development is positioned in the Portuguese sport system, more specifically as it relates to the psychosocial development of youth, the purpose of the present study was to examine national sport organizations' practices through a document analysis of their annual reports and plans of activities. Such analysis may help understand how sport policy and funding influence sport organizations' practices. Findings showed how changes may need to occur within the Portuguese sport system if the psychosocial development of youth is to become more of a priority on the ground. Moving forward, there is the need to devise concrete strategies to better situate psychosocial development within the Portuguese context in ways that are relevant for youth in the $21^{\text {st }}$ century. To achieve this objective, several recommendations are provided.

\section{Presenter Biography}

Dr. Dany MacDonald is an Associate Professor in the Department of Applied Human Sciences at the University of Prince Edward Island. His research interests are in positive youth development through sport and revolve around athlete and coach development. He is also interested in instrument development capable of assessing the experiences of sport participants.

\section{Continuous Coach Education Courses in Portugal: Implications for Youth Development}

Rathwell, Scott

Department of Kinesiology \& Physical Education, University of Lethbridge, Canada

Continuous coach education has been considered a crucial vehicle in enabling coaches to learn how to maximize the potential of sport to foster the development of youth. The purpose of this article was to understand the distribution of coach education courses in Portugal and derive implications for youth development. Based upon the findings, implications are offered in relation to further promoting themes surrounding youth development in coach education that help youth attain meaningful outcomes.

\section{Presenter Biography}

Scott Rathwell is an assistant professor in the Department of Kinesiology \& Physical Education at the University of Lethbridge. Scott's research focuses on the psychosocial factors related to lifelong sport and the mechanisms through which Masters athletes maintain their elite performance. He also researches how university sport can be used to promote varsity athletes' personal and psychosocial growth. Finally, he is currently studying the influence of psychological factors during athletes' return to play following a diagnosed concussion.

\section{Integrating an Assets-Based Approach to Development in the Portu- guese Sport System}

Santos, Fernando

Escola Superior de Educação, Instituto Politécnico do Porto e Viana do Castelo, Portugal; inED, Center for Research and Innovation in Education, Portugal.

The purpose of this presentation is to propose the integration of an assets-based approach to development in the Portuguese sport system. This reflection aims to instigate changes on policy-level initiatives to better the state of sport in Portugal. We argue that to positively influence the current Portuguese sport culture, changes from an assets-based approach, are needed in both policy and practice. It appears that Portuguese sport policy may be misaligned with Portuguese sport culture as sport is expected to have great power for social development, but performance and winning are still prioritized over other developmental outcomes that could be deemed equally important. Specifically, an assets-based approach could prompt a move towards deliverables aimed at promoting social development rather than a unidimensional focus on winning and performance. Reflections for rethinking the culture and policies of the Portuguese sport system are offered.

\section{Presenter Biography}

Fernando Santos is a lecturer at both the Polytechnic Institute of Porto, Higher School of Education and the Polytechnic Institute of Viana do Castelo in Portugal. He is also a researcher at the Centre for Research and Innovation in Education (inED). His main areas of research include positive youth development within different coaching contexts. He is interested in understanding how coaches can provide their athletes with a high quality sporting experience, as well as in the role played by coach education.

\section{Examining Sport Stakeholders' Needs to Foster Youth Development Through Sport: How Can Sustainable Change Occur?}

Strachan, Leisha

Department of Kinesiology \& Recreation Management, University of Manitoba, Canada

Sport is a setting worthy of promoting youth development. However, considering that sport stakeholders may or may not embrace the implementation of a youth development mandate, it may be necessary to assess sport stakeholders' needs to shed light on the intricacies behind fostering positive developmental outcomes. Therefore, the purpose of this presentation is to analyse sport stakeholders' perceptions concerning their needs to foster youth development within the Portuguese sport system. Implications for research and practice are discussed. 


\section{Presenter Biography}

Dr. Strachan is a Professor and currently serving as Associate Dean Research and Graduate Studies in the Faculty of Kinesiology and Recreation Management at the University of Manitoba. Her research is focused on positive youth development through sport, and she is interested in exploring positive coaching behaviors and parent involvement. She is currently working on a SSHRC/Sport Canada research project evaluating Project SCORE. Further, Dr. Strachan is interested in cultural relevancy within the field of positive youth development and has recently completed a SSHRCfunded grant that explored the Cs through the voices of Indigenous youth. In addition, she is part of a research team exploring anti-racism policies and practices in Winnipeg and the sport experiences of newcomers in the community.

\section{Symposium 9: The Think Aloud Method and Its Utility Within Coach, Athlete, and Sport Psychology Practitioner Development}

\section{Applied Sport Psychologists' Use of Think Aloud When Working} With Athletes and Coaches

Jackman, Trish ${ }^{1}$; McEwan, Hayley ${ }^{2}$; Whitehead, Amy $^{3}$; \& Birch, Phil ${ }^{4}$

${ }^{1}$ University of Lincoln; ${ }^{2}$ University of the West of Scotland; ${ }^{3}$ Liverpool John Moores University; ${ }^{4}$ University of Chichester

A primary objective of sport psychology consulting is to assist athletes and coaches in identifying the thoughts, feelings, and behaviours associated with effective performance. A potential method that has been adopted within research is the think aloud (TA) method, which has been used to explore athlete cognition in a variety of different sports. TA involves asking a participant to verbalise their thoughts concurrently throughout the duration of a task (Ericsson \& Simon, 1993). Previous studies have used TA to generate information about athletes' and coach's thoughts to understand how they think during performances, cope with pressure, and focus their attention. With the growth in interest in TA as a method to generate insights into athletes" "in-event" cognitions, it is timely to examine the utility of this method in applied sport psychology practice. Therefore, this study aims to investigate the use of TA within sport psychology practice. To achieve this, we delivered an educational workshop on TA to 25 trainee or HCPC sport psychologists and conducted follow-up interviews with 10 trainees and 4 HCPC practitioners at 6 and 12 weeks' post-workshop to identify if and how the participants used TA within their practice as applied sport psychologists. Preliminary findings reveal the practicalities of applying TA with a range of athletes (e.g., golfers, rugby kickers) and coaches. Applied implications demonstrate how TA can be used at different phases of applied sport psychology support (e.g., needs analysis, monitoring phases). Finally, conclusions are drawn on the perceived benefits and limitations of TA in applied sport psychology practice.

\section{Reference}

Ericsson, K. A., \& Simon, H. A. (1993). Verbal reports as data. MIT Press.

\section{Presenter Biography}

Dr. Patricia C. Jackman is a Lecturer in Sport and Exercise Psychology at the University of Lincoln, UK. Her research interests include: optimal psychological states (flow and clutch states) in sport and exercise; selfregulation of optimal experiences; cognition in sport; and goal setting in physical activity. She has published quantitative, qualitative, and mixed method studies, as well as systematic reviews in these areas.
Dr. Phil Birch is a Senior Lecturer in Sport and Exercise Psychology at University of Chichester, England. Phil's research focuses on performance psychology, with a particular focus on the psychological determinants of performance in both traditional sports and esports. Phil's research in traditional sports has examined the use of think aloud protocols to capture in-event cognitions in athletes. Phil's research in esports primarily focuses on stress, coping and mental health.

Developing 'The Triad of Knowledge' in Coaching: Coach Perceptions of Think Aloud as a Reflective Tool Within a Category 1 Football Academy

Swettenham, Laura

International Federation of Esports Coaches \& University of Portsmouth

The current study aims to explore the perceptions of football academy coaches on their use of a novel reflective tool (Think Aloud) and to understand if the tool can support the development of knowledge within these coaches. Eight male coaches $(\mathrm{M}$ age $=36$ years) employed full time at a category 1 football academy within the UK took part. All coaches attended a 2-hour workshop on the use of Think Aloud (TA) as a reflective tool, with the opportunity to practice TA on the pitch whilst coaching. Participants were then interviewed on their perceptions of TA as a reflective tool using a semi-structured interview guide. Interviews were analysed using thematic analysis. Data were analysed inductively initially before formulating deductively using 'The Triad of Knowledge' (professional, interpersonal, and intrapersonal knowledge), which has been adopted within coaching and identified as component for developing coaching expertise (Côté \& Gillbert, 2009). Results from the current study suggest all three types of knowledge can be developed through the use of TA, with secondary themes identified within each type of knowledge: Professional knowledge (player development, session design), interpersonal knowledge (communication, relationships), intrapersonal knowledge (biases, self-awareness, reflection). This research offers a novel perspective on coach development through the implementation of TA, with the potential to support the development of coaching knowledge and expertise.

\section{Reference}

Côté, J., \& Gilbert, W. (2009). An integrative definition of coaching effectiveness and expertise. International Journal of Sports Science \& Coaching, 4(3), 307-323. https://doi.org/10.1260/174795409789623892

\section{Presenter Biography}

Dr. Laura Swettenham is a Sport and Exercise Psychologist and is currently appointed at Blackburn Rovers Football Club where she delivers sport psychology support within their Academy. Laura is also lead of sport psychology and coach development at the International Federation of Esports Coaches and an associate lecturer at the University of Portsmouth. Laura's recent publications have focused on the use of Think Aloud to develop coaches and understand stress and coping in athletes.

Me, My Bike and My Thoughts: A Cyclist's Subjective Experience of Using Think Aloud and Its Application to Coaching

Vaughan, Steven

\section{Liverpool John Moores University}

At present understanding cognitions of endurance athletes has mainly relied on retrospective data collected after performance, which may limit a coach's understanding of their athletes in event thoughts. Recently, Think 
Aloud (TA) has been used to capture athlete thoughts during competition over 1 or 2 sessions, however, no TA study has collected data during realworld routine training sessions longitudinally. Therefore, this mixed methods study used TA, a diary and reflective interview to record the subjective experience of using TA to collect verbal reports from a single self-as-participant cyclist, during their training over 11-weeks. These three data sources combined to provide an integrated analysis over this period. Qualitative data were inductively coded, identifying three phases each typified by a predominant theme; an initial phase (w1-3) centred on the process of using TA whilst cycling was followed by a period (w4-7) where areas of cognitive focus were recognised by the cyclist. Evidence of reactivity was identified, which led to a final phase (w8-11) of enhanced cognitive awareness and engagement. Deductive coding of transcribed TA data enabled mapping onto existing metacognitive attentional dimensions, for analysis in line with identified phases. Verbalised cognitions changed over time, thoughts with an internal focus (on self-monitoring and selfregulation) significantly increased from $55 \%$ to $64 \%$ between phases 1 and 3 . Thus suggesting that metacognitive development appeared to mirror the stages of Fitts and Posner's (1967) Skills Acquisition Model. For coaches, these findings suggest that TA could be used to understand athlete cognitions during training and develop athlete self-awareness.

\section{Reference}

Fitts, P. \& Posner, M. I. (1967). Human Performance. Brooks/Cole Publishing.

\section{Presenter Biography}

Steven is a Professional Doctorate student and Trainee Sport \& Exercise Psychologist. He has a specific interest in enhancing the athlete's cognitive knowledge whilst participating in endurance sports. His current research will contribute to the development of a framework and training package based upon reflection from in-action verbalised cognitions using Think Aloud for endurance athletes, coaches and applied Sport Psychologists. In his applied practice, Steven works with a range of athletes including elite cyclists and triathletes.

\section{Think Aloud as a Coach Developer Tool}

Whitehead, Amy ${ }^{1} \&$ McEwan, Hayley ${ }^{2}$

${ }^{1}$ Liverpool John Moores University; ${ }^{2}$ University of the West of Scotland

During 2020, remote coach development became a priority for coach developers. The aim of this project was to pilot the use of Think Aloud (TA) as a remote coach development tool with coaches working on a UK coach development programme. TA was introduced as an in-situ reflection tool to 30 coaches and 3 coach developers. TA involves coaches wearing a clip-mic and recording device and verbalising their thoughts aloud (where possible) whilst in the act of coaching and reflecting on these thoughts as they occur. Coaches are then encouraged to listen to their recordings and reflect on what, so what and now what (Driscoll, 2007). Coaches were supported by their individual coach developer to explore perceptions of TA and how reflection could be further developed. Four coaches and all three coach developers were interviewed at 4-, 10- and 16-week time points. Interviews were conducted to understand perceptions of TA as a tool to develop coach reflection, to support the coach development process and to develop coaching practice. Initial analysis from the first two data collection points (weeks 4 and 10) demonstrates that TA was viewed by the coach developer as a useful tool to develop rapport and a vehicle for conversation with their coach on areas for development. Coaches perceived TA to be beneficial for analysing and challenging their own thought processes during coaching practice. Final analysis will allow applied implications for the use of TA as a coach developer tool.

\section{Reference}

Driscoll, J. (2007) Practicing clinical supervision: A reflective approach for healthcare professionals. Elsevier.

\section{Presenter Biography}

Dr. Amy Whitehead is a Reader in Sport Psychology and Coaching at Liverpool John Moores University. Her research focuses on the use of Think Aloud to understand athlete and coach cognition and how Think Aloud can used as a reflective practice tool for coaches. Dr. Whitehead is also a BPS accredited Sport and Exercise Psychologist working as a consultant with a variety of athletes.

Dr. Hayley McEwan is a Senior Lecturer in Sport Psychology and Coaching at University of the West of Scotland. Her research focuses on development of practitioners in support of athletes (e.g., coaches, psychologists). Hayley is training and education lead for the British Association of Sport \& Exercise Sciences (BASES) sport psychology accreditation route.

\section{Symposium 10: Bridging the Gap Between Research and Coaching Practice: How Do Athletes Visually Perceive and Act in Team Sports?}

Esteves, Pedro

\section{Polytechnic Institute of Guarda, Portugal}

Despite of the multidimensionality nature of perceptual information, it is argued that visual information represents 85 to $90 \%$ of the overall sensory stream of information perceived by sport athletes (Khanal, 2015). Visual information is considered as a key element to successfully perform in team sports such as futsal, soccer, and volleyball. Typically, in these performance contexts, athletes engage on an active search for relevant visual information within the environment that allow them to: i) regulate their ongoing actions and anticipate upcoming situations (Williams et al., 2004) and ii) adapt their movements to dynamically changing environments of team sports (Davids et al., 2012). This exploration process is importantly shaped by the interaction between a different range of constraints related to the individual (e.g., emotions, fatigue), the task (e.g., number of players, space of play) and to the environment (e.g., luminosity, audience interference) (Renshaw \& Shaw, 2019). Portable eye-tracking systems have opened a prominent window of opportunity for a greater comprehension on the visual constraints that underpin goal-directed performance during real situations in team sports (Appelbaum \& Erickson, 2018). Much of coaching intervention at the level of visual perception and action is based on experiential knowledge. Given this situation, there is an opportunity to bridge the gap between research and practice to increase the level of information sharing and empower coaches to further design learning environments that may facilitate the ability for players to successfully perceive and act in team sports (Passos \& Davids, 2015).

This symposium tackles this goal by outlining four experimental studies with a high applied potential in the sports of futsal, soccer, and volleyball: In the first study conceived by Gaspar and collaborators, Analyzing the visual fixation patterns of futsal players in 1xl game sub-phase, it will be shown how information picked-up from the body orientation of defender appears to regulate the successful actions of the attacker in a $1 \times 1+$ Goalkeeper situation. In the second study elaborated by Casanova, The 
gaze behaviour and defensive tactical performance of soccer players during small-sided games: An in situ approach, it will be reported how the time of play impacts on tactical behaviour but also how visual search behaviours emerge as an adaptation to the increasingly level of fatigue.In the third study conceived by Luis del Campo and collaborators, Influence of kickers ' ball speed on goalkeepers' performance in a penalty shooting task in soccer, it will be exposed how the manipulation of ball shooting speed may constrain the goalkeeper's motor behaviour and performance during a penalty in soccer. Finally, in the fourth study formulated by Esteves and collaborators, "Eyes on the ball": Top-level setters marginally fixate the attackers and the opponents in volleyball, it will be showed that gaze behavior of top level setters are not preferentially directed to the attacker and their opponents after a serve, which suggests the important use of peripheral vision.

\section{References}

Appelbaum, L. G. \& Erickson, G. (2018). Sports vision training: A review of the state-of- the-art in digital training techniques. International Review of Sport and Exercise Psychology, 11(1), 160-189.

Davids, K., Araojo, D., Hristovski, R., Passos, P., \& Chow, J. Y. (2012). Ecological dynamics and motor learning design in sport. In A. M.,
Williams \& N. Hodges (Eds.). Skill acquisition in sport: Research, theory \& practice (2nd ed.) (pp. 112-130). Routledge.

Khanal, S. (2015). Impact of visual skills training om sports performance: Current and future perspectives. Advances in Opthalmology \& Visual System, 2(1), 26-28.

Passos, P., \& Davids, K. (2015). Learning design to facilitate interactive behaviours in team sports. Revista Internacional de Ciencias del Deporte, $39,18-32$.

Renshaw, I. \&, Chow, Y. (2019) A constraint-led approach to sport and physical education pedagogy. Physical Education and Sport Pedagogy, 24(2), 103-116.

Williams, A. M., Jannelle, C. M., \& Davids, K. (2004). Constraints on the search for visual information in sport. International Journal of Sport and Exercise Psychology 2, 301-318.

\section{Presenter Biography}

Pedro Tiago Esteves is an adjunct professor at the Polytechnic Institute of Guarda, Portugal; a researcher at CIDESD; and a sports consultant and coach. 


\section{Posters}

(in alphabetical order by first author's last name) 


\section{A}

\section{An Overview of Interscholastic Coaching Requirements in the United States}

Atkinson, Obidiah; Goodway, Jacqueline; \& Sutherland, Sue

\section{The Ohio State University, Columbus, $\mathrm{OH}$, United States}

The National Federation of State High School Associations recently reported that approximately eight million boys and girls participate in interscholastic athletics. Yet, $33(65 \%)$ states have reported decreased participation rates. A critical component towards youth participating in sport, is the coach. Since the last National Coaching Report in 2008, much has changed regarding policy for coaching education for school coaches. Most states (96\%) require a coaching licensure but there are exemptions for certified teachers $(\mathrm{n}=20 ; 39 \%)$, certified physical educators $(n=4,8 \%)$, and college credit $(n=2,4 \%)$ with $18(35 \%)$ states having no exceptions in place. The certification process has mainly been using online courses in full or some capacity $(n=43$; $84 \%)$. In the majority of states, both assistant $(\mathrm{n}=43 ; 84 \%)$ and volunteer $(\mathrm{n}=35 ; 68 \%)$ coaches have the same requirements as their head coaches. A total of $32(63 \%)$ states requires coaches to complete all components prior to start date with nine (18\%) providing a year or less time frame. Despite the required training for high school coaches, 31 states $(61 \%)$ have no policies for middle school coaches. A large number of states $(\mathrm{n}=39 ; 76 \%)$ require a recertification process for health-related components (e.g., concussion training), but surprisingly only nine states $(17 \%)$ require coaches to recertify coaching pedagogy training. While most states require coaches have licensure, this process varies with many states requiring multiple health-related components and coach pedagogy training becoming a one-time stop.

\section{References}

Bodey, K. J., Brylinsky, J., Flannery, T., Kuhlman, J. S., \& Bolger, C. (2008). National coaching report. National Association for Sport and Physical Education.

Gilbert, W. D., \& Trudel, P. (2004). Role of the coach: How model youth team sport coaches frame their roles. The Sport Psychologist, 18(1), 21-43. https://doi.org/10.1123/tsp.18.1.21

National Federation of State High Schools Associations [NFHS]. (2019). 2018-19 High school athletics participation survey. National Federation of State High School Associations. https://www.nfhs.org/media/1020412/ 2018-19_participation_survey.pdf

\section{Presenter Biography}

Obidiah (Obi) Atkinson is a 2nd year doctoral student at The Ohio State University. Originally from Ontario, Canada, Obi is obtaining his degree in kinesiology - physical education and has a cognate in sport pedagogy in youth sport. His advisors are Dr. Jacqueline Goodway and Dr. Sue Sutherland.

\section{B}

\section{Profile of Full-Time Coaches in Finland}

Blomqvist, Minna ${ }^{1}$; Mononen, Kaisu ${ }^{1}$; \& Hämäläinen, Kirsi ${ }^{2}$
${ }^{1}$ Research Institute for Olympic Sports, Jyväskylä, Finland; ${ }^{2}$ Finnish Olympic Committee, Helsinki, Finland

Objective information of coaches and understanding coaches needs and experiences are essential factors in developing an excellent coaching system. In 2019 a large survey was conducted for Finnish coaches to form an overall picture of coaches and to track their experiences in terms of their current coaching position, coach development, and wellbeing. A total of 2,612 coaches answered to the web-based questionnaire from which 19 $\%(\mathrm{n}=490)$ worked as full-time coaches. The majority $(69 \%)$ of full-time coaches were male, over half (54\%) were 30-49 years of age and had an average of 16 years of coaching experience. Almost all coaches (98\%) had completed formal coach education and appreciated also further education (92\%). Coaches spent on average 29 hours/week on coaching and 16 hours/week on other coaching related tasks. Most often the current coaching role of full-time coaches was in sports clubs $(76 \%)$ coaching older adolescent or adult athletes $(59 \%)$ at national $(47 \%)$ or international (31\%) level. Future goals of full-time coaches were most often related to developing coaching practices and processes $(71 \%)$ and to develop further as a coach $(68 \%)$. The most cited reasons to continue coaching were related to enjoyment derived from seeing athletes to develop (82\%) and being in interaction with athletes $(72 \%)$. Competence and experience as a coach $(92 \%)$, athletes performance level $(79 \%)$, and relationships within the sporting community (77\%) affected most often positively on coaches' wellbeing whereas, balancing between work and personal life (33\%), other coaching related tasks (30\%) and coaching workload (29\%) affected negatively.

\section{Presenter Biography}

Minna Blomqvist, $\mathrm{Ph} . \mathrm{D}$. is a leading researcher in sports pedagogy in the Research Institute for Olympic Sports, Finland. Dr. Blomqvist has a long experience in applied scientific research and the main emphasis of her research has been on the motor and cognitive aspects of sport performance and athlete development. More recently, also coach learning and development and assessment in coach education have been her research areas.

\section{Coaches' Cultural Intelligence: What Are the Cultural Training Needs of Football Coaches?}

Borges, Mario ${ }^{1}$; de Oliveira, Rita ${ }^{1}$; Rosado, Antonio ${ }^{2}$; Lobinger, Babett ${ }^{3}$; \& Freitas, Francisco ${ }^{4}$

${ }^{1}$ School of Applied Sciences, London South Bank University, London, UK.; ${ }^{2}$ Faculty of Human Kinetics, University of Lisbon, Lisbon, Portugal; ${ }^{3}$ Institute of Psychology, German Sport University Cologne, Cologne, Germany; ${ }^{4}$ Faculty of Economy, University of Coimbra, Portugal.

The rise of globalisation over the past decades has impacted nearly every aspect of modern sport across the world. In European football, for example, this phenomenon has changed the dynamics in the way coaches move between countries and has also increased their need to rapidly adapt to new realities. Coaches and players are interacting with people from different cultures and backgrounds more than ever before, and whilst this cultural diversity can inspire creativity and drive innovation, it also poses some additional challenges (Borges et al., 2015). The ability to function effectively in different cultural contexts, called Cultural Intelligence (Earley \& Ang, 2003), has never been more relevant for coaches Participants were 209 football coaches (38.8-10.4 years) either with international experience $(n=88)$ or without $(n=121)$, and different levels 
of education and coaching certification. The independent variables were migration experience, education level and certification level. The dependent variables were cultural intelligence and cross-cultural training needs assessed through the survey. We used a One-Way ANOVA for comparisons across independent variables and deductive thematic analysis for open-ended questions. Coaches with international experience rated themselves with higher cultural intelligence than coaches with no international experience on its cognitive, motivational, and metacognitive aspects. Coaches with no international experience or with lower coaching qualifications also rated themselves with more training needs. Most coaches reported they had no training on cultural training. They showed divergent views on the need for it, either seeing as an opportunity for professional development or as unnecessary given the universal language of sport. The present research represents the first attempt, to our knowledge, to examine the football coaches' needs for cultural intelligence. In this research, we found that there is a general need to further enhance the cross-cultural education of coaches to better prepare them for the cultural nuances of the modern world.

\section{References}

Borges, M., Rosado, A., de Oliveira R., \& Freitas, F. (2015). Coaches' migration: A qualitative analysis of recruitment, motivations and experiences. Leisure Studies, 34(5), 588-602.

Earley, P. \& Ang, S. (2003). Cultural Intelligence: Individual Interactions across Cultures. Stanford University Press.

\section{Presenter Biography}

Mario Borges is a Senior Lecturer in Sports Coaching and Analysis. Rita de Oliveira is an Associate Professor in Sport and Exercise Science. Antonio Rosado is a Professor of Sport Pedagogy. Babett Lobinger is a Senior Researcher in Sport Psychology Francisco Freitas is a Researcher and Data Analyst.

\section{Coaching and Competition: An Exploratory Study of Coaches' Emotions}

Brandão, Regina; Oliveira, Rosemeire; Mastrocola, Ana Paula; Correa, Mariana; Hernandes, Vania; \& Villas Boas Junior, Marcelo

University of São Judas, São Paulo, Brazil

This study aimed to investigate coaches' emotions in three different moments: before, during, and after competitions. Thirty-six coaches from different sports modalities, and from The Brazilian Academy of Coaches of The Brazilian Olympic Committee (mean of age 42,68-11,70 years old) participated in a semi-structured interview to explore and understand the participants' emotions. NVivo qualitative data analysis software was used to analyze the data. Findings suggested that: competitive emotions like anxiety, insomnia and apprehension are elicited even before the competitions; the sportive competition is a pressure moment that includes psychological and physical stressors, concerns about the athlete's performance, and feelings of nervousness; and the result of the competition impact the experienced emotions post-competition. Some coaches reported health problems, such as gastritis because of the stress they experienced. Others reported seeking medical help after an important competition because they thought they will have or had heart problems. The practical significance of the study was to highlight the emotions the coaches feel, and the repercussion they have in their life affecting the thinking processes, resilience, and social connections. There has been a significant body of literature focused on the emotions and competitions on athletes, and ways of training how to deal with them, the study of coaches' emotions are quite rare but necessary to learn how to best respond to emotions.

\section{Presenter Biography}

Regina Brandão, graduate in psychology, in physical education from the State University of Campinas, and post-doctorate from the Faculty of Human Motricity, Lisbon, Portugal. A sports psychologist, she works on the psychological preparation of Olympic and Paralympic athletes. She is now a professor of the Master's and Ph.D. Program in Physical Education and the Psychology course of The University of São Judas Tadeu, Brazil. She is vice-president of the Ibero-American Society of Psychological Affairs del Deporte, SIPD and researcher at the Anima SOCIESC Institute of Innovation.

\section{Coaching Orchestration of a Brazilian Men Artistic Gymnastics Expert Coach}

Carrara, Paulo \& Nunomura, Myrian

University of São Paulo, São Paulo, Brazil

The coaching process of high-level sports involves professionals of diverse areas, but is coordinated by the coach, who is responsible for managing and combining these collaborations in an efficient strategy to improve performance (Lyle, 2005). Therefore, coaching is a dynamic social activity, where coaches, athletes and other people engaged interact continuously. Thus, coaches' actions, attitudes, behaviour, and decision making are affected by internal and external factors. Beyond performing many functions and daily tasks, these negotiations with persons and institutions imply managing ambiguities. Jones \& Wallace $(2005,2006)$ developed metaphors coaching as orchestration to support coaches, because coaching is influenced by vision of coaching functions, expectation, and interactions among the involved. In Brazil, there are still challenges about management of the coach-athlete relationship in Men's artistic Gymnastics (MAG). Most participants in MAG are children and youth, which could imply power imbalance and culminate in excessive authoritarianism. The aim of this study was to explore a practice coaching of a Brazilian Olympic medallist MAG coach, using a coaching as orchestration approach. Interview and training session observations were performed and thematically analysed. One theme emerging was goalmatching and actions coordinated. Coach and athletes' coinciding in goals were a compromise, where they both wanted to accomplish results and success. The development of mutual wisdom about how and when to act in many situations and career phases allowed objectives to be established and fostered conditions that were favourable to the health of the coach-athlete relationship.

\section{References}

Jones, R. L., \& Wallace, M. (2005). Another bad day at the training ground: Coping with ambiguity in the coaching context. Sport, Education and Society, 10(1), 119-134.

Jones, R. L., \& Wallace, M. (2006). The coach as orchestrator. In R. L. Jones (Ed.), The sports coach as educator: Re-conceptualising sports coaching (pp. 51-64). Routledge. 
Lyle, J. (2005). Sports coaching concepts: A framework for coaches' behaviour. Routledge.

\section{Presenter Biography}

Paulo Carrara is Ph.D. in Sport Sciences and Brevet judge at Fédération Internationale de Gymnastique (FIG). Myrian Nunomura is professor and gymnastics researcher within Brazilian Olympic Committee.

\section{G}

\section{High-Performance Sport in the Philippines from the Coaches' Perspective}

Garzon, Mauricio ${ }^{1}$; Abarra, Airnel ${ }^{2}$; Dagenais, Marc $^{1}$; \& Ayo Noly ${ }^{2}$

${ }^{1}$ Adrenaline Solutions, Montreal, Canada; ${ }^{2}$ Adrenaline Solutions, Davao City, Philippines

The combination of the ingredients to perform at international sporting events depends on social, cultural, and political factors (De Bosscher et al., 2010; Garzon, 2019; Henry et al., 2020; Winand, 2009). This study aims to explore the high-performance environment in the Philippines to focus on the key element of coaching provision and development. Philippine national team sports coaches (NSC) and national sports administrators (NSA) were asked to answer two questionnaires to identify the current conditions of the coaches' context favorable for achieving the best of their abilities, and how significant they were in achieving results with their athletes at the highest competitive level. Descriptive and ANOVA analyses of the pilot sample was used for the data analysis. Responses indicated that overall and by group, less than $50 \%(<10 / 20$ questions) of the items found in the context of developed countries are present in the context of the Philippines. Although the perception of the factors that have influenced the results in high-performance sport was not significantly different between NSC and NSA, it is important to note that the average of the responses was less than 5 on a Ten-point Likert scale. The item with the best perception (> 5 points) was the International Competition at the best level in the open category. This pilot study invites further analysis of the context of coach development in the Philippines to guide the management of high-performance sport in making future strategic decisions.

\section{References}

De Bosscher, V., Shibli, S., Van Bottenburg, M., De Knop, P., \& Truyens, J. (2010). Developing a method for comparing the elite sport systems and policies of nations: A mixed research methods approach. Journal of Sport Management, 24(5), 567-600. https://doi.org/10.1123/jsm.24.5.567

Garzon M., \& E., M. (2019). Pilotage de la performance de haut niveau des fédérations sportives en Colombie: Le développement des entraôneurs. MEMOS - Solidarité Olympique.

Henry, I., Dowling, M., Ko, L.-M., \& Brown, P. (2020). Challenging the new orthodoxy: A critique of SPLISS and variable-oriented approaches to comparing sporting nations. European Sport Management Quarterly, 20(4), 520-536. https://doi.org/10.1080/16184742.2020.1719428

Winand, M. (2009). Déterminants de la performance organisationnelle des fédérations sportives: une analyse comparée des ligues sportives de la Communauté franñaise de Belgique [Unpublished doctoral dissertation]. Université Catholique de Louvain.

\section{Presenter Biography}

Mauricio Garzon has a Ph.D. in Physical Activity Sciences at Montreal University and Executive Master's in Sports Organisation Management -
MEMOS at Olympic Solidarity - International Olympic Committee. He has more than 20 years of experience fulfilling different roles from coach, general manager, researcher, and high-performance consultant. He is the Director of Sports Science \& Performance at Adrenaline Solutions, an adjunct university professor in Canada and Colombia, instructor of the National Coach Certification Program at SportsQuébec, as well as member of the Emerging Countries Working Group of ICCE.

\section{COVID-19 and the Sports Coach: Education, Development and Skills}

Gonzaga, Luós ${ }^{1} \&$ Sequeira, Pedro ${ }^{2}$

${ }^{1}$ Sport Sciences School of Rio Maior - Polytechnic Institute of Santarém, Santarém, Portugal; ${ }^{1}$ Research Center in Life Quality (CIEQV), Leiria/ Santarém, Portugal; ${ }^{2}$ Coaching Portugal, Lisboa, Portugal

The global pandemic of COVID-19, declared by the WHO on March 11, 2020, had resulted in social and economic disturbance on the entire society. All over the world, almost all training and competitions stopped as well. Because of this, coaches, athletes, referees, and officers could not work in their normal conditions. Portugal obviously was also affected. One and a half years later, youth sport has returned to a possible normality with the occasional ailments left by the prolonged pandemic vacuum that we want to try to identify and quantify. The purpose of this study was to understand the impact of COVID-19 on the education, development, and skills of the coach. Semi-structured interviews were conducted with four coaching experts in youth training of different sports, ranging in age from 34 to 63 years $(M=50.5)$. We defined expertise in coaches with more than 10 years of coaching young athletes. The development of the interview protocol was based upon expertise validation. Interviews were conducted inside the Zoom platform by a skilled interviewer with in-depth understanding of community sport and sport coach training, transcribed verbatim and used content analysis. Coaches considered that their experience as a coach and/or in another professional activity was essential to adapt their role throughout the pandemic effects. However, contents in public health (thinking the specificity of the younger generations' characteristics), and social and emotional skills (recognized as important tools preventing and build up resilience, positive affectivity, and meaningful living) were referred as essential for the future coach education programs.

\section{Presenter Biography}

Luós Gonzaga was born in Pombal, Portugal. Degree in Psychology (University of Coimbra, Portugal), Master's in Educational Psychology (ISPA - Lisbon, Portugal) and Diploma in Advanced Studies (DEA) in Methodological Foundations of Research in Physical Activity and Sport, by the National Institute of Physical Education of Catalonia (INEFC Universitat de Lleida, Spain). Adjunct Professor at the Sport Sciences School of Rio Maior, Polytechnic Institute of Santarém. Specialist in Sport Psychology and in Educational Psychology by the Portuguese Psychologists Association.

\section{H}

\section{Associations Between Finnish Top Tier Players' Leadership Role and Coach Leadership Behavior}

Holopainen, Sakari ${ }^{1}$; Szerovay, Mihaly ${ }^{1,2}$; Konttinen, Niilo ${ }^{3}$; \& Kokkonen, Marja ${ }^{4}$

${ }^{1}$ Faculty of Sport and Health Sciences, University of Jyväskylä, Finland; ${ }^{2}$ Football Association of Finland; ${ }^{3}$ Research Institute for Olympic Sports, 
Finland; ${ }^{4}$ Faculty of Sport and Health Sciences, University of Jyväskylä, Finland

Leadership behavior as a whole is an important part of elite sports performance (Cotterill \& Fransen, 2016). In team sports, the effect of athlete leadership becomes also crucial (Fransen et al., 2015). The aim of our study was to investigate the associations between Finnish top tier players' self-assessed leadership role and player-assessed coach leadership behavior in a sample of 146 footballers: males ( $n=53$, mean age 26.2 years, $\mathrm{SD}=5.5$ ), females $(\mathrm{n}=91$, mean age 22.5 years, $\mathrm{SD}=3.8)$. One player did not identify as man or woman, and one chose not to answer to the question. The data was collected anonymously by an online survey where coaches' leadership behavior was measured with Williams et al. (2003) coaching behavior questionnaire. Players' self-assessed leadership role was determined with a modified questionnaire by Fransen et al. (2014). The reliability of sum scores was measured with Cronbach's alphas and data was analyzed by Spearman's correlational coefficients and independent samples t-tests. The results showed that 1) males scored higher in task and external leadership than females; 2) older players estimated themselves to be stronger leaders than younger players; and 3) players' self-assessed leadership roles were positively correlated with their evaluation of their coach's leadership roles and the coach's positive leadership behavior during practices.

\section{References}

Cotterill, S. T., \& Fransen, K. (2016). Athlete leadership in sport teams: Current understanding and future directions. International Review of Sport and Exercise Psychology, 9(1), 116-133.

Fransen, K., Van Puyenbroeck, S., Loughead, T. M., Vanbeselaere, N., De Cuyper, B., Broek, G. V., \& Boen, F. (2015). Who takes the lead? Social network analysis as a pioneering tool to investigate shared leadership within sports teams. Social networks, 43, 28-38.

Williams, J. M., Kenow, L. J., Jerome, G. J., Rogers, T., Sartain, T. A. \& Darland, G. (2003). Factor structure of the coaching behavior questionnaire and its relationship to athlete variables. The Sport Psychologist, 17(1), 16-34.

\section{Presenter Biography}

Sakari Holopainen (M.Sc., Sport Sciences) is a Ph.D. student at the Faculty of Sport and Health Sciences at the University of Jyväskylä, Finland. He is also a UEFA B licensed football coach and a player at the top tier in the Finnish futsal league system. His research interests include athletic careers and leadership behaviour of coaches and players.

\section{I}

Action Research: Assessing a Graduate-Level Program's Student Learning in Strength and Conditioning

Ishisaki, Kyler; Kuklick, Clayton; \& Gearity, Brian

University of Denver, Denver, USA

The National Strength and Conditioning Association (NSCA) is a leading strength and conditioning (S\&C) organization that has developed professional standards, competencies, and a highly regarded certification (i.e., CSCS) for S\&C professionals. Research has shown S\&C professionals develop competencies through experience, collaboration, and formal education (Dorgo, 2009). The importance of formal education in S\&C professionals' knowledge development creates a need to understand how to prepare students for these competencies and the CSCS. Scholars have explored how exercise science and health curriculums prepare students with exercise prescription and training knowledge; however, this literature is limited to undergraduate curriculums and omits consideration of the CSCS exam (Ekkekakis et al., 2016; Ives \& Knudson, 2007; Malek et al., 2002). The purpose of this study was to explore to what extent one graduate level sport coaching curriculum prepares $S \& C$ coaches for the NSCA's professional standards and CSCS exam. We used Aldridge and Benefield's (1998) two feedback system to assess the influence of the curriculum and coach developers? instructional strategies on student achievement of learning objectives for the S\&C profession and CSCS. We found that students exceeded in demonstrating the NSCA's competencies because of the inclusion of sociology in the curriculum, which helped students develop the knowledge and skills to critique bio-physical science knowledge, leading to greater understanding of training approaches. Using this programmatic assessment, coach developers can monitor and meet the needs of its constituents by adapting the courses, curriculum, and program to develop competent, certified, and knowledgeable coaches.

\section{References}

Aldridge, M. D., \& Benefield, L. D. (1998). Assessing a specific program, In F. Hubbard (Ed.), How do you measure success? (pp. 27-34). ASEE Professional Books.

Dorgo, S. (2009). Unfolding the practical knowledge of an expert strength and conditioning coach. International Journal of Sports Science \& Coaching, 4(1), 17-30. https://doi.org/10.1260/1747-9541.4.1.17

Ekkekakis, P., Albee, M. J., \& Zenko, Z. (2016). Knowledge of exercise prescription guidelines across one 4-year kinesiology curriculum. Research Quarterly for Exercise and Sport, 87(1), 124-130.

Ives, J. C., \& Knudson, D. (2007). Professional practice in exercise science: The need for greater disciplinary balance. Sports Medicine, $37(2), 103-115$.

Malek, M. H., Nalbone, D. P., Berger, D. E., \& Coburn J. W. (2002). Importance of health science education for personal fitness trainers. The Journal of Strength and Conditioning Research, 16(1), 19-24.

\section{Presenter Biography}

Kyler Ishisaki is a current student in the Master of Arts in Sport Coaching program at the University of Denver. He has been a certified strength and conditioning specialist since 2012. Since then, he has coached populations of all ages and abilities throughout his career in both the private sector and with high school strength and conditioning. He currently resides and coaches in the San Francisco Bay area.

\section{M}

\section{Coaches' Cross-Cultural Training Needs}

Mario Borges ${ }^{1}$; Antonio Rosado ${ }^{2}$; Babett Lobinger ${ }^{3}$; Francisco Freitas ${ }^{4} ; \&$ Rita F. de Oliveira ${ }^{1}$

${ }^{1}$ School of Applied Sciences, London South Bank University, London, UK.; ${ }^{2}$ Faculty of Human Kinetics, University of Lisbon, Lisbon, Portugal; ${ }^{3}$ Institute of Psychology, German Sport University Cologne, Cologne, Germany; ${ }^{4}$ Faculty of Economy, University of Coimbra, Portugal.

The ability to interact and communicate effectively in different cultural contexts has never been more relevant for football coaches because cultural diversity in football has increased in the past decades. Yet no cultural training is currently offered within UEFA's coach education, and it is 
unknown whether coaches feel the need for such training. This study aimed to explore the cross-cultural training needs of 115 football coaches $(\mathrm{M}=13.4$ years; $\mathrm{SD}=8.53)$ with national and/or international experience. To maximise recruitment reach, an online survey with open-ended questions was used followed by qualitative thematic analysis. There were four master themes: Cross-cultural training needs in the global football market; Cross-cultural awareness is important in football; Football-specific cultural training; Training by migrant coaches, no matter how. Most coaches perceived a benefit from cultural training in preparation for international appointments, but some felt that coaches already had cultural awareness because they manage individuals and that coaches adjust easily to different cultures. Cross-cultural training would be best delivered by migrant coaches and with a football-specific focus. This is the first study to explore the perceptions of football coaches about cross-cultural awareness and training needs and provides insights to providers of coach education.

\section{Presenter Biography}

Mario Borges: Senior Lecturer in Sports Coaching and Analysis at London South Bank University. Antonio Rosado: Professor of Sport Pedagogics at the University of Lisbon. Babett Lobinger: Senior Researcher at the German Sport University Cologne Francisco Freitas: Researcher and Data Analyst at the Centre of Social Studies of the University of Coimbra. Rita de Oliveira: Associate Professor in Sport and Exercise Science at London South Bank University

\section{The Relationship Between Emotional Intelligence and Coaching Suc- cess: Not What We Thought}

Magrum, Eric D ${ }^{1} \&$ Schempp, Paul G. ${ }^{2}$

Stockton University ${ }^{1}$; University of Georgia ${ }^{2}$

Successful individuals tend to display higher levels of emotional intelligence (EI) (Bradberry \& Greaves, 2009). Thus, many believe that coaches with higher EI are more successful. To test these commonly held beliefs, this study investigated the relationship between coaches' EI and their career winning percentage. Both current and former collegiate coaches were recruited in person and via email to participate in the study. A total of 277 of the 486 recruited coaches met the inclusion criteria, completed the background questionnaire, and the Assessing Emotions Scale (Schutte et al., 1998; 2009). Multiple linear regression analyses were computed. Coaches' career winning percentage served as the primary dependent variable, while age, gender, coaching experience, education level, and playing experience were independent variables. Data analyses revealed that EI did not uniformly impact coaches' success, as previously thought. Specifically, statistical analysis revealed that EI did not significantly predict winning percentage for volleyball coaches. However, EI was a significant predictor of basketball coach's success. More precisely, a model including EI subfactors utilizing emotions and managing others' emotions significantly impacted coaches' career winning percentage. Utilizing emotions accounted for $12.39 \%$ of the variance in coaching success, while managing others' emotions accounted for $3.84 \%$ of the variance. Another interesting finding was that coaches' belief in their ability to manage others' emotions negatively influenced their coaching success.

\section{References}

Bradberry, T. \& Greaves, J. (2009). Emotional Intelligence 2.0. TalentSmart Publishing.

Schutte, N. S., Malouff, J. M., Hall, L. E., Haggerty, D. J., Cooper, J. T., Golden, C. J., \& Dornhiem, L. (1998). Development and validation of a measure of emotional intelligence. Personality and Individual Differences, $25,167-177$
Schutte, N.S., Malouff, J. M., \& Bhullar, N. (2009). The assessing emotions Scale. In C. Stough, D. Saklofske, \& J. Parker (Eds.), The assessment of emotional intelligence (pp. 119-135). Springer Publishing.

\section{Presenter Biography}

Dr. Eric Magrum is an Assistant Professor of Exercise Science at Stockton where he teaches Strength and Conditioning, Motor Learning and Biomechanics, and Nutrition. Eric's primary area of expertise is the impact of emotional intelligence on coaching.

\section{Female Soccer Coaches in Brazil and the Career Context}

Mastrocola, Ana Paula \& Brandão, Regina

University of São Judas, São Paulo, Brazil

The aim of this study was to understand the process of relationship between the personal attributes of female soccer coaches in Brazil and the context throughout their career, from the perspective of the Bioecological Model of Human Development. The model postulates that the development of the person is the result of interaction and modifications generated reciprocally between person and the environment to which they are inserted. Eight Brazilian female soccer coaches, older than 18 years and with a minimum of two years of experience in different categories of soccer, participated in a semi-structured interview. The results showed that the coaches are inserted in a context that is still culturally male, which shows resistance from men towards women, whether athlete or coach, an environment in which coaches are constantly evaluated and distrust of their competence in coaching teams appears frequently. Relations with directors and the technical committee were presented in a negative way; however, interpersonal relationships with family, friends and athletes were positive, attracting a generative disposition for engagement and permanence in the career. It was also observed that these coaches have a feeling of passion for football and for the career, in addition to personal attributes (disposition, resources and demands) that proved so strong that they made them overcome barriers, difficulties and perform their tasks with competence.

\section{Presenter Biography}

Ana Paula Mastrocola is a master's student in physical education, specializing in sports training and sports management. She is a former athlete and soccer coach. She is a researcher in the field of soccer and soccer coaches in Brazil.

\section{The First Step of a Multisport Club to Transform Itself into a Learning Organization}

Milistetd, Michel ${ }^{1}$; Trudel, Pierre $^{2}$; Tozetto, Alexandre ${ }^{3} ; \&$ Cortela, Caio ${ }^{4}$

${ }^{1}$ Federal University of Santa Catarina, Brazil; ${ }^{2}$ University of Ottawa, Canada; ${ }^{3}$ Federal University of Santa Catarina, Brazil; ${ }^{4}$ Brazilian Confederation of Tennis, Brazil

In an increasingly complex and globalized society, the continuous development of new skills and knowledge is essential (Hess, 2014). Thus, being no exception, sports organizations (clubs, associations, federations) must gradually transform into learning organizations (Sessa \& London, 2015). In this communication, we will (a) present the main components of a one-year coach development initiative - a collaborative inquiry - implemented in a multisport club in Brazil, and (b) present the participants' perspectives regarding what they have learned. A total of 45 coaches from 8 different sports responded to 
an open questionnaire, and interviews were conducted with 3 managers and 8 head coaches. The Value Creation Framework (Wenger-Trayner \& WengerTrayner, 2020) was used to analyze the data. The findings revealed that the participants, to some extent, created value within each of the eight cycles: Immediate value, potential value, applied value, realized value, strategic value, enabling value, transformative value, and orienting value. It also emerges from this study that the process of becoming a learning organization is gradual and must be supported by someone with a good understanding of social learning theory (Duarte et al., 2020).

\section{References}

Duarte, T., Culver, D., \& Paquette, K. (2020). Framing a social learning space for wheelchair curling. International Sport Coaching Journal, 7(2), $117-126$

Hess, E. D. (2014). Learn or die: Using science to build a leading-edge learning organization. Columbia University Press.

Sessa, V. I., \& London, M. (2015). Continuous learning in organizations: Individual, group, and organizational perspectives. Psychology Press.

\section{Presenter Biography}

Michel Milistetd is an assistant professor at the Sports Centre at the Federal University of Santa Catarina. Ph.D. in Physical Education, Michel's main research focus is Coach Development and Positive Youth Development. $\mathrm{He}$ is certified as a Coach Developer from NCDA/ICCE and works as a consultant in sports federations and sports clubs.

\section{Becoming a Professional Surf Coach-A Social Participation Journey}

Milistetd, Michel ${ }^{1}$; Brasil, Vinicius Zeilmann ${ }^{2}$; Ramos, Valmor ${ }^{3}$; Culver, Diane $^{4} ; \&$ Nascimento, Juarez Vieira do ${ }^{5}$

${ }^{1}$ Federal University of Santa Catarina, Florianopolis, Brazil; ${ }^{2}$ Santa Catarina State University, Florianopolis, Brazil; ${ }^{3}$ Santa Catarina State University, Florianopolis, Brazil; ${ }^{4}$ University of Ottawa, Ottawa, Canada; ${ }^{5}$ Federal University of Santa Catarina, Florianopolis, Brazil

Becoming an adventure sports coach is an underexplored phenomenon in the coaching research agenda. There is a need to better understand how the social issues of these sports drive coaches' learning in terms of identity formation and perspectives on coaching. Based upon the Social Learning Theory (Wenger, 1998) this investigation examined the social participation trajectory of a Brazilian surf coach (pseudonym Lisa). Semi-structured interviews and Rappaport Time Line were used. Thematic analysis was adopted featuring two main themes: pre-coaching trajectory - becoming a surfer and surf coaching trajectory. Lisa's experiences over her pre-coaching trajectory involved an unconscious learning process based upon participation in her family's leisure time playing on the beach and in the sea, school sports, and surfing practice. Lisa's social interactions and mutual engagement in those practices allowed her to negotiate the meanings of her experiences, develop regimes of competences, and construct a surfer identity. Within Lisa's coaching trajectory, she was a full participant in the surfing culture, which involved an intentional learning process. Competing as an athlete, taking courses, and coaching surfing were the foundations for Lisa to (re)negotiate the meanings of her engagement in the social practices linked to surfing; and to align her coaching perspectives and identity as a coach with the broader surfing and coaching world. The process of becoming a surfing coach was based upon Lisa's engagement in numerous social structures and social practices. The surfing lifestyle developed since her childhood shaped her interests, aspirations, enterprises, and perspectives as a surfing coach.

\section{References}

Wenger, E. (1998). Communities of practice: Learning, meaning, and identity. Cambridge University Press.

\section{Presenter Biography}

Michel Milistetd is an assistant professor at Sports Centre in Federal University of Santa Catarina (UFSC). Head of the Sports Pedagogy Research Center at UFSC. His main research focus is Coach Development, Coaching, and Positive Youth Development. He is certified as Coach Developer from NCDA/ICCE and works as consultant in sports federations and sports clubs.

\section{Psychometric Properties of the Multidimensional Sport Leadership} Scale: Comparison to Multifactorial

Morais, Catarina ${ }^{1}$; Gomes, Rui ${ }^{2}$; Simães, C. ${ }^{3} ; \&$ Resende, Rui. ${ }^{4}$

${ }^{1}$ Research Centre for Human Development, Faculty of Education and Psychology, Universidade Catolica Portuguesa. Portugal; ${ }^{2}$ Psychology Research Centre. School of Psychology. University of Minho. Portugal; ${ }^{3}$ Health Sciences Research Unit: Nursing (UICISA: E). School of Nursing, University of Minho. Portugal; ${ }^{4}$ Life Quality Research Centre. University Institute of Maia. Portugal.

Clarifying the actions of leaders and reducing construct redundancy in evaluation leadership is vital to improve knowledge about leadership. This study compares the psychometric properties of Multidimensional Sport Leadership Scale (MSLS; Gomes \& Resende, 2014) and Multifactor Leadership Questionnaire (MLQ-5X; Bass \& Avolio, 2000). Data collection included 379 athletes competing at national level of collective sports. Athletes fulfilled the MSL, MLQ-5X, and the Athlete Satisfaction Questionnaire (ASQ; Riener \& Chelladurai, 1998). Data analysis included construct validity, scale reliability, convergent validity, and discriminant validity. Construct validity revealed original structures of MSLS and MLQ-5X, although MLQ-5X presented higher problems of internal consistency (Cronbach's alpha) and convergent validity than MSLS. Transformational constructs of both instruments revealed convergent validity with satisfaction with leadership of ASQ instrument but MLQ$5 \mathrm{X}$ transactional constructs assumed stronger correlation with ASQ than the MSLS transactional constructs. In conclusion, MSLS revealed better psychometric properties than MLQ-5X, representing an alternative to evaluate leadership.

\section{References}

Bass, B. M., \& Avolio, B. J. (2000). MLQ multifactor leadership questionnaire. Mind Garden.

Gomes, A. R., \& Resende, R. (2014). Assessing leadership styles of coaches and testing the augmentation effect in sport. In C. Mohiyeddini (Ed.), Contemporary topics and trends in the psychology of sports (pp. 115-137). Nova Science Publishers.

Riemer, H. A., \& Chelladurai, P. (1998). Development of the athlete satisfaction questionnaire (ASQ). Journal of Sport \& Exercise Psychology, 20(2), 127-156.

\section{Presenter Biography}

Catarina Morais teaches at Faculty of Education and Psychology, Universidade Catolica Portuguesa, since 2019 and is a member of the Centre for Studies in Human Development. Her Ph.D. in Social Psychology was awarded by the University of Kent (United Kingdom), where she 
developed her research on the impact of ethical and unethical leadership on group dynamics. Currently, Catarina's research interests focus on leadership in sports context, as well as the development of psychological skills to promote sport performance.

\section{Creating a Learning Community of Practice in Soccer}

Moreira, Carlos ${ }^{1} \&$ Mañãs, Victor ${ }^{2}$

${ }^{1}$ Universidade de Trás-os-Montes e Alto Douro, Departamento de Desporto; Instituto Superior de Ciências Educativas do Douro, Penafiel; ${ }^{2}$ Universidade de Trás-os-Montes e Alto Douro, Departamento de Desporto

Learning communities of practice $(\mathrm{CoP})$ provide an opportunity to exchange experiences through social interaction between peers, which, according to Stoszkonski and Collins (2012), offers the opportunity and great potential for the development of coaches' knowledge. Further Stoszkonski and colleagues (2015) stated that coaches benefit from observation, interaction, and communication among peers, in what can be considered an effective learning community and can be facilitated with technology linked to web 2.0. Thus, we propose the creation and dissemination of a CoP, with meaning and identity, where coaches, but also all those who enjoy the training process, namely the construction of exercises, can present, consult and use the proposals of this entire community. In this way, our CoP is based upon the web, more specifically the use of blogs and social media. Using a problem-based instructional method, the project builds soccer training exercises after a presentation of a certain problems posed by the platform manager. The challenge presented at the beginning of each week may be a game principle, a game moment, or a real game situation (image, video, or theoretical description). The work will be posted on the project's support blog so that the CoP people can analyze, comment on and learn from the knowledge shared.

\section{References}

Stoszkowski, J., \& Collins, D. (2012). Communities of practice, social learning and networks: Exploiting the social side of coach development. Sport, Education and Society, 19, 773-788. https://doi.org/10.1080/ 13573322.2012.692671

Stoszkowski, J., Collins, D., \& Olsson, C. (2015). Using shared online blogs to structure and support informal coach learning. Part 2: the participants' view and implications for coach education. Sport, Education and Society, 22, 407-425. https://doi.org/10.1080/13573322.2015 .1030382

\section{Presenter Biography}

Carlos Moreira was a professional soccer player and is a level III soccer coach. He has a degree in Physical Education and Sport and Specialist Teacher in the field of Sport (soccer) by the Institute of Educational Sciences of Douro. Ph.D. student in the Sports Science course at the University of Trás-os-Montes and Alto Douro

\section{$\mathbf{N}$}

\section{Workplace Learning of Futsal Coaches}

Nascimento, Saulo Augusto Rocha ${ }^{1}$; Lima, Claudio Olóvio Vilela ${ }^{1}$; Souza, Vanessa Guilherme ${ }^{1} ; \&$ Milistetd, Michel $^{2}$

${ }^{1}$ Minas Tenis Clube, Belo Horizonte, Minas Gerais, Brazil.; ${ }^{2}$ Universidade Federal de Santa Catarina, Florianopolis Santa Catarina, Brazil.
The coach who engages in different learning situations becomes an active agent on the construction of his own knowledge, sharing experiences with colleagues, discussing real problems and experimenting new ways (Milistetd et al, 2017). The Communities of Practice (CoP) are defined as a group of people who share and learn from each other, with the purpose of solving common problems, always looking for the best practices (McDermott, 2000). The aim of this study was to verify what the coaches put together while participating in a CoP. 110 coaches, from a nationally recognized sports club, participated in a continuous professional development initiative. Five participants were futsal coaches and built an action plan to solve the detected problems. The strategies were created based upon the competence of building relationships (ICCE, 2013). As an example, we present 3 strategies: conduct biannual meetings with athlete and family to discuss technical evolution, based upon performed evaluations, effective participation of the parents on practices and matches, so that the parents can create empathy about the challenges and experiences that their children go through during the learning process of the modality; at the matches the parents should enter the futsal court holding hands with the opposing athletes encouraging exemplary actions and behaviors of the players. We conclude that the aim of the $\mathrm{CoP}$ was achieved. Through discussions among peers, extremely important strategies for the coaches' professional practice were created seeking the integral development of the athletes.

\section{References}

International Council for Coaching Excellence. (2013). International Sport Coaching Framework: Version 1.2. Human Kinetics.

McDermott, R. (2000). Critical success factors in building communities of practice. Knowledge Management Review, 3(2), 5.

Milistetd, M., Galatti, L., Collet, C., Tozetto, A., \& Nascimento, J. V. (2017). Formañão de treinadores esportivos: Orientañies para a organizañão das praticas pedagogicas Nos cursos de bacharelado em educação física. Revista da Educação física/UEM, 28, 2849-2850.

\section{Presenter Biography}

Saulo Augusto Rocha Nascimento is a postgraduate in Football and Futsal: sport sciences and training methodology by the Universidade Gama Filho. Graduated in Physical Education at Centro University Center of Belo Horizonte. He worked for about 10 years as a futsal and football teacher. $\mathrm{He}$ is currently Coordinator of Sports Training for the Futsal and Soçaite Football Courses at Minas Tenis Clube.

\section{Development and Implementation of a Program for Surf Coach Education in Italy}

Nicolo Di Tullio ${ }^{1}$ \& Claudio Mantovani ${ }^{2}$

${ }^{1} \mathrm{G}$ d'Annunzio University/Italian Waterski and Wakeboard Federation (Chieti, Italy); ${ }^{2}$ Scuola dello Sport (Rome, Italy)

The International Olympic Committee, together with the International Surfing Association (ISA), included surfing in Tokyo 2020 Olympic Games. Nowadays, the Italian surfing movement is mainly composed by surfing enthusiasts and secondly by athletes. A new section of the Italian Wakeboard and Waterski Federation is officially embracing surfing activities since 2018. The aim of the present study is to define surfing and its characteristics, in terms of cultural movement and to propose a formal training structure for sport professionals. Data has been collected using two methods: interviews and questionnaires submitted to national and international experts, foreign federations and surf clubs, questioning about their background and the necessities of surf sports coaches' education. Data 
were analyzed by a panel of experts, in collaboration with the Nippon Sport Science University's Coach Developer Academy. A formal program for surf coaches is currently in phase of implementation in Italy, pursuant to the Italian System for Sport Qualifications which is following the ICCE guidelines. Congruences and dissimilarities between the Italian circumstance and international leading countries are pointed out in terms of cultural heritage and perspectives. Currently, courses for coaches, judges, managers, and S\&Cs are delivered nationwide. The surfing movement shows an increase in numbers of participants and in media attention (Eigenschenk et al., 2019), despite the challenges raised by the SARSCoV-2 pandemic. Still a lot is to be done in the surfing sport qualification education.

\section{References}

Eigenschenk, B., Thomann, A., McClure, M., Davies, L., Gregory, M., Dettweiler, U., \& Inglés, E. (2019). Benefits of outdoor sports for society. A systematic literature review and reflections on evidence. International Journal of Environmental Research and Public Health, 16(6), 937.

\section{Presenter Biography}

Nicolo Di Tullio, MS, master coach (4th level), Biologist, is an international presenter of the International Surfing Association and the International Lifesaving federation. He received his MS degrees (Marine Sciences and Biology) in Genoa. He is teaching in the nautical institute San Giorgio. Di Tullio is collaborating with the Italian Olympic Committee as well as with the University of Chieti-Pescara and the University of Genova. Nicolo recognizes the sport as central contributor to personal and social development.

\section{0}

\section{Career Development Journey of a Brazilian: Two-Times Olympic} Champion Coach

Oliveira, Daniel Campos da Cunha; Oliveira, Rosemeire; Oliveira, Alessandra Santos; Mastrocola, Ana Paula; Queiroz, Diego Faria; Moura, Larissa de Paula; \& Brandão, Maria Regina Ferreira

University of São Judas, São Paulo, Brazil

The objective of this study was to analyze the career development journey of a two-time Olympic champion coach. To do so, an individual, semistructured interview was conducted with an experienced, aged, multichampion, acting coach and former athlete of the long jump discipline of athletics, with wide recognition in the national and international scene in his sport. The career analysis was conducted in light of the model entitled Development of sports coaches: a lifelong learning journey, proposed by Milistetd et al. (2018). The participant has 40 years of experience as a sports coach, 30 years as a high-performance coach, a bachelor's degree in physical education, a master's degree in physical education, and national and international certifications in his sport. Primary socialization, understood as within the family, played an important role in the interviewee's formation of key values. The secondary socialization, understood as school and sporting experiences, had an influence on the formation and performance as a coach. The transition from athlete to coach took place in a planned manner, going through coaching programs and specific certifications. The interviewee worked as a coach for 10 years until he reached high performance, and 18 years until his first call to the main national team. Although the model proposed by Milistetd et al. (2018) is based on international studies, it was considered an efficient tool to analyze the career development journey of this Brazilian coach.

\section{References}

Milistetd, M., Peniza, L., Trudel, P., \& Paquette, K. (2018). Nurturing High-Performance Sport Coaches' Learning and Development Using a Narrative-Collaborative Coaching Approach. LASE Journal of Sport Science, 9(1), 6-38.

\section{Presenter Biography}

Graduated in Physical Education from Centro University Center Sant'Anna (2011). He is currently a Physical Activity Educator at Sesc SPSocial Service for Commerce and Technical Director at D2W Assessoria Esportiva. Master's student in Physical Education at Universidade São Judas Tadeu (Beginning in 2019).

\section{Retrospective Analysis of the Coach's Motivational Climate from the Perspective of an Olympic Athlete}

Oliveira, Rosemeire ${ }^{1,2}$; Oliveira, Alessandra ${ }^{1}$; Oliveira, Daniel ${ }^{1}$; Brandão, Regina $^{1}$

${ }^{1}$ University of São Judas, São Paulo, Brazil; ${ }^{2}$ University of Santo Amaro, São

The motivational climate created by the coach plays an important role in the athlete's performance. Thus, the aim of this study was to analyze how the Coach's Motivational Climate impacted on the performance of a world and Olympic basketball champion athlete, with 35 years of experience in highperformance sports in national and European clubs and several international titles and individual awards through a Retrospective Analysis on 19 former coaches. For the analysis of the perceived motivational climate, the athlete used for each coach the Empowering Disempowering Motivational Climate Questionnaire (EDMCQ-C). The results indicated that the best performances of his career were associated with motivational climates of the coaches characterized as Empowering, especially social support. On the other hand, motivational disempowering climates were associated with a greater dissatisfaction of the athlete with the coaches and consequently the worst performances in the seasons played. The results observed in the Social Support aspect (Empowering) are interesting because the athlete is an expatriate in environmental and cultural contexts different from that of her origin, but that facilitated her intercultural adjustment and, consequently, her performance. It can be concluded that greater social support, expressed by the coaches, is related to the emotional and social support perceived by the athlete to face, and overcome the challenges of the sport. These results can serve as a support for a better understanding of the choices of strategies to be used by coaches and thus reduce the main difficulties related to sports performance and consequently the success of the

\section{Presenter Biography}

Graduated in Physical Education, Master's degree in Pedagogy of the Human Movement from the School of Physical Education and Sport of the University of São Paulo (EEFEUSP) and student of the strictu sensu program in Physical Education, PhD level of the São Judas University. Coordinator of the undergraduate course in Physical Education of the University of Santo Amaro (UNISA).

\section{S}

Experiencing Explicit Strategies for Develop Life Skills Through Sport

Souza, Vanessa Guilherme ${ }^{1}$; Lima, Claudio Olóvio Vilela ${ }^{1}$; Collet, Carine $^{2} ; \&$ Milistetd, Michelx ${ }^{2}$ 
${ }^{1}$ Minas Tenis Clube, Belo Horizonte, Minas Gerais, Brazil; ${ }^{2}$ Universidade do Estado de Santa Catarina, Florianopolis Santa Catarina, Brazil

Sports programs using explicit strategies for develop life skills are closer to providing positive results in youth athletes (Bean \& Forneris, 2016). Our objective was to describe the actions used in a continuing professional education (CPD) of sports coaches to create explicit strategies for develop life skills through sport. 75 coaches participated from a recognized Brazilian multisport club, who used the principles of Communities of Practice (CoP) (Wenger, 1999) in weekly meetings took place for seven months in order to share experiences of explicit strategies during training sessions. Data were collected during the meetings and the evaluation of sports plan and practices according to discuss and practice life skills, as well as discuss and practice the transfer of life skills (Bean et al., 2018). During the CoP, coaches discussed the possibilities to plan and use sports activities by explicit strategies for develop life skills. They shared information about the implementation of a few minutes in the beginning of the sessions to discuss and practice a specific life skill (e.g., respect), given explicit feedbacks during the sport activities, as well as a few minutes in the end of the sessions to discuss and practice the transfer to outside sports environment. We perceived an evolution of coaches' knowledge on how to develop life skills by explicit strategies and the positive results that it provides. In addition, offering opportunities for sharing and learning, through $\mathrm{CoP}$ in the same club, favors coaches to share experiences and develop more effective coaching practices.

\section{References}

Bean, C., \& Forneris, T. (2016). Examining the importance of intentionally structuring the youth sport context to facilitate positive youth development. Journal of Applied Sport Psychology, 28(4), 410-425.

Bean, C., Kramers, S., Forneris, T., \& Camiré, M. (2018). The implicit/ explicit continuum of life skills development and transfer. Quest, 70(4), $1-15$.

Wenger, E. (1999). Communities of practice: Learning, meaning and identity. Cambridge University Press.

\section{Presenter Biography}

Vanessa Guilherme Souza is a doctoral student in Education from the SEK University of Chile, has a Master's in Education from the PUC University of Minas Gerais, is a specialist in School Physical Education from the PUC University of Minas Gerais, and Psychopedagogy from the UNIBH. Graduation in Psychology and Physical Education from the Federal University of Minas Gerais. She is an educational specialist at Minas Tenis Clube

\section{W}

Learner-Centered Coach Development: Re-Envisioning the Coaching Practice Through a Humanistic Lens

Welch, Brianna ${ }^{1}$; Kiosoglous, Cameron ${ }^{2}$; Langdon, Jody $^{3}$; \& McQuade, Sarah $^{4}$

${ }^{1}$ Welch Coaching and Consulting LLC, Burlington Vermont; ${ }^{2}$ Drexel University, Philadelphia, Pennsylvania; ${ }^{3}$ Georgia Southern University, Statesboro, Georgia; ${ }^{4}$ e.t.c coaching consultants, Amherst, Massachusetts

Sports culture has placed high value on a coach-centered, instructional approach and strongly emphasizes the outcome over process. This environment stresses technical expertise, over interpersonal and intrapersonal knowledge, contributing to a focus on the athlete separate from the human being. These principles still dominate current coaching practices. Yet, many coaches do not recognize the impact it has on their own approach and subsequently, positive athlete development. Our understanding of coaching effectiveness began to shift with the application of humanistic learning theory to sports in the 1980's, recognizing individuals' inherent holism and untapped potential. An evolving view of what it means to be a quality coach has prompted coach developers to 1) Reconsider the coaching characteristics needed to best support the whole athlete (the what) and 2) Re-conceptualize coach education through a learner centered lens to more effectively engage and support coaches in their development (the how). Our poster provides a look at both the "what" and "how" of coach education and how they intertwine in our program. We describe our implementation of an eight-week virtual course that empowers coaches through a process of knowledge acquisition, reflection, and practical application. We provide examples of coaches' ability to translate a whole athlete approach into action and discuss our unique facilitation approach modeled on humanistic learning and informed by a constructivist perspective. Finally, we describe how, in the virtual setting, we fostered an environment of collaborative knowledge creation, coach autonomy and personalization that allowed coaches to connect back to their existing experiences.

\section{Presenter Biography}

Brianna Welch is an independent coach and consultant supporting leaders in athletics in their professional growth to positively transform athletic climates in which they work. Through a collaborative learning process, she equips coaches with the tools to empower their student-athletes to thrive on and off the field. Brianna holds a B.A. in Public Policy from Duke University and an M.Ed. in Educational Leadership from the University of Vermont. She wears many hats as a current athlete, coach, and coach developer.

\section{Z}

\section{The Intersection Between Leadership and Relationship Dimensions in Sport Coaching}

Zhao, Chen \& Jowett, Sophia

\section{Loughborough University, United Kingdom.}

The link between the concepts of coach transformational leadership and coach-athlete relationship (CAR) was explored using canonical correlation analyses. A total of 213 athletes (122 Male; 91 Female) from various performance levels and sports completed a multi-section questionnaire. Statistical analyses of the obtained data indicated that coach transformational leadership and CAR were highly interconnected (67\% of the shared variance for all athletes) but not interchangeable. The findings further highlighted that the least overlap between these concepts was recorded for male athletes (59\%) and the most for female athletes (79\%) suggesting that the intersection between coach leadership and CAR differs by gender. A close inspection revealed patterns of correlations emerging between and within the dimensions of leadership and CAR. For example, the dimensions between Providing an Appropriate Model (PAM) and Direct Closeness were strongly and positively correlated suggesting that athletes' perceptions of their coach as a good role model intersect with their trust, respect, and appreciation for that coach. It was also found that perceived Individualised Support was negatively associated with Direct Commitment to the coach for both genders suggesting that perhaps too much support may be detrimental to athletes' long-term orientation to the relationship and commitment to the coach. This study showed that understanding the role of gender in the intersection of coach transformational leadership and CAR 
can facilitate better coaching practices that are both effective and impactful.

\section{Presenter Biography}

Chen Zhao is a third-year Sports Psychology Ph.D. student studying at the School of Sport, Exercise and Health Sciences of Loughborough
University. He received a bachelor's degree in Sports Exercise Training from Beijing Normal University in China and a master's degree in Management Science from Southeast Missouri State University in the United States. Chen's current interest is in the coach-athlete relationship and leadership behaviours in the sports context. 